\title{
Unravelling Territoriality in the European Union: Reconfiguring Territorial Affairs by Reconsidering the Guardian and Commercial Systems of Survival
}

\author{
Bastiaan Matthijs Hissink Muller \\ University of Amsterdam, Urban and Regional Planning, Amsterdam, The Netherlands \\ Email: b.m.hissinkmuller@uva.nl
}

How to cite this paper: Hissink Muller, B. M. (2021). Unravelling Territoriality in the European Union: Reconfiguring Territorial Affairs by Reconsidering the Guardian and Commercial Systems of Survival. Open Journal of Social Sciences, 9, 201-278. https://doi.org/10.4236/jss.2021.95015

Received: March 15, 2021

Accepted: May 15, 2021

Published: May 18, 2021

Copyright $\odot 2021$ by author(s) and Scientific Research Publishing Inc. This work is licensed under the Creative Commons Attribution International License (CC BY 4.0).

http://creativecommons.org/licenses/by/4.0/ (c) (i) Open Access

\begin{abstract}
Even when seen in its simplest forms, the basics of the territorial affairs of the European Union are complicated. For that reason, the purpose of this research is to make them easier to understand this by using the guardian and commercial systems of survival as heuristic tool. Through conceptual reflection five related developments then come to the fore: 1) the commercial syndrome emerges in the essentially guardian territorial affairs, 2) commercial rule challenges guardian encircling rule via networking, 3 ) the market of territories formed with commercial territoriality makes the territorial affairs in the European Union chaotic and ambivalent, 4) parasitic traders engender corruption in guardian corpora and generate systemic corruption in those territorial affairs, and 5) technical elites puzzle two contradictory territorial logics together by complexifying and loosening cognitive dissonance away. In short, what helps to more thoroughly understand the puzzling territorial affairs in the European Union is to recognise their fundaments in two interrelated puzzles, the guardian and commercial ones, instead of just seeing a single one. The reconsideration of the guardian and commercial syndromes this involves then indicates essential reconfigurations of territorial affairs and that, paradoxically, this symbiosis between the two systems of survival stays on course as long as the territorial puzzles are not solved. And to easier understand territorial affairs thus, also opens up a wide field of inquiry uncovering the interlinked underlying manners of territorialisation, which are exemplarily shown in the European Union by territorial cohesion policy.
\end{abstract}

\section{Keywords}

Territoriality, European Union, Systems of Survival, Territorial Cohesion 


\section{Introduction}

We do not have to wait for Brexit follow-ups, more immigration problems, or another pandemic to see that also today borders play a very important role in Europe. A raison de être of the European Union, however, is to open up territories for the market, which implies overcoming borders. Territorial issues then lie at the margin of the ways of doing and thinking of this institutional complex; the territorial has respectively to do with leaving, what is outside of, or national crisis situations within it instead of with its own modus operandi for instance. No wonder that political geographical debates about territoriality within the European Union can appear to be puzzling, this with de- and re-territorializations, various related scales, fuzziness, and change (e.g. Berezin \& Schain, 2004; Ansell \& Di Palma, 2004). A more thorough reflection on the reconfigurations of these affairs seems thus in order. For that reason, we will in this essay reflect upon the question of how the understanding of such territorial affairs can be made easier when the two systems of survival characterized by Jacobs (1992) function as our heuristic tool.

The conceptual reflection then revolves around the ways in which encircling behaviour, as territoriality is defined in its simplest form below, is in the European Union formed by precepts for dealing with territories and/or those for, paradoxically, dealing with markets too, that is, the guardian and commercial systems of survival respectively (Jacobs, 1992). The European Union's notoriously vague territorial cohesion policy (e.g. Campbell, 2005; Faludi, 2005a; ESPON, 2006; Janssen-Jansen \& Waterhout, 2006), as it might for instance aim for balanced development, territorial capital, services of general interest, and/or policy coordination (Hissink Muller, 2016), hereby exemplarily shows what this guardian and commercial encircling means for our territorial affairs in general.

We will then take four steps, as if it were a four-course meal, to answer the question posed above (Papéritif) to reflect upon. First we will try to grasp the territorial basics of territory, scale, and territoriality and look at how these return for the European Union in the most elementary outlines conceivable ( $\$ 2$, P amuse). Thereafter we introduce (Jacobs, 1992; Taylor, 2007) systems of survival to familiarize ourselves with the guardian and commercial syndromes $(\$ 3$, Pentrée) before we especially relate the latter to the territorial "puzzles" in the European Union ( $\$ 4$, le plat principal). And at the end, we will with discussions on the European Union's territorial cohesion policy (e.g. Husson, 2002; Polverari \& Bachtler, 2005; Faludi, 2013a, 2014), exemplify the use of Jacobs' (1992) systems of survival for an easier understanding of the complicated territoriality involved $(\$ 5$, le dessert $)$, to afterwards draw our conclusions $(\$ 6$, le digestif $)$.

\section{Basically Visualising Territorial Essentials}

\subsection{Towards Seeing Territorial Basics}

We start with visualising the territorial essentials of the European Union before we show how the guardian and commercial ways of thinking $(\$ 3)$ return in the 
territorial fundaments involved $(\$ 4)$. The need to reflect upon these territorial affairs more thoroughly first namely becomes clear by realising that these territorial essentials are for the European Union difficult, if not impossible, to pin down. A realisation that comes forward most strongly when we grasp them with territorial basics. Below, we therefore visualise the three analytically separable basics of territory ( $\$ 2.2)$, scale ( $\$ 2.3)$, and territoriality ( $\$ 2.4)$ in their simplest forms, which also show their strong but not inevitable linkages. After this we will try to envision the territorial affairs of the European Union of today with them $(\$ 2.5)$.

\subsection{Seeing Territory}

Now, as you all know, a territory is a demarcated portion of geographical space (Gottman, 1975: 29; Neocleous, 2003: 411), making territories and borders coterminous (Berezin, 2004: 4). In its simplest form, such an encircled space can be thought of as, indeed, a circle (Figure 1(a)).

Yet, it is always "someone's" territory'; leading Deleuze \& Guatarri (1980/ 1987: $372,433,505,509)$ to paradoxically say that territory entails the first de-territorialisation. Territory is then marked, thus never neutral. Not merely because "it is connected to the exercise of social and political power" (Berezin, 2004: 4, 8), but also because the institution of its boundaries goes hand in hand with the establishment of authority (Perkmann 2007: 257; Vaughan-Williams, 2011: 185; Faludi, 2013b: 1305). This makes that an outlined portion of geographical space coincides "with the spatial extent of a government's jurisdiction" (Gottman, 1975: 29; Neocleous, 2003: 411). Yet, no matter whether this concretizes the power relations coming with a king or democratic sovereignty and with a more or less developed political body (Weber, 1978; Berezin, 2004: 8), the circle as the simplest form of a territory should thus always be envisioned with a point above it, that is to say, a territory as circle always entails a cone (Figure $1(b))$.

This cone, this portion of space of "someone", involves posing a claim of course. Territory therefore "suggests a behavioural strategy of boundary making" (Berezin, 2004: 5). Space and politics are then linked through the making of

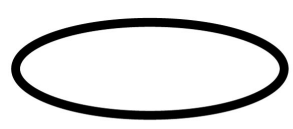

(a)

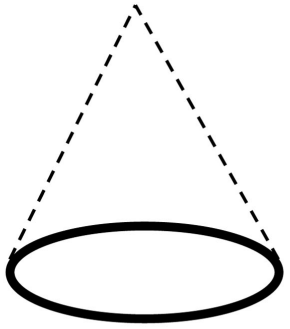

(b)

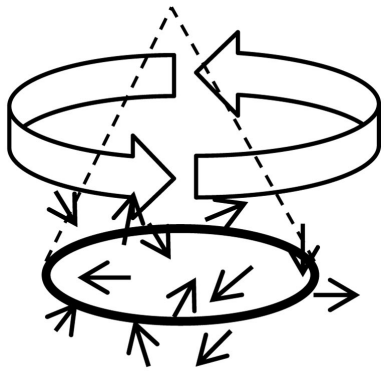

(c)

Figure 1. "Territory" in simplest forms: circle (a), cone (b), encirclement (c).

${ }^{1}$ We return to the question who this "someone" is today a bit in $\$ 2.4, \$ 3.3$, and especially in $\$ 4$. For now it does not matter yet who this is, however constructed he might be. 
a physical container (Gottman, 1975: 29; Neocleous, 2003: 411), for its population, for example, as another "core of any territorial unit" (Berezin, 2004: 26). No matter whether this containing then delimits the area where violence is legitimate (Weber, 1978; Berezin, 2004: 8), controls access (Elden, 2010: 802; Faludi, 2013b: 1308), and/or controls "the movement of people, services, and goods" (Vaughan-Williams, 2011: 185; Faludi, 2013b: 1305), it is a behaviour to influence the manoeuvring behaviour of others by indicating a (farthest) limit. In its simplest form this behaviour can be imagined as an encirclement of arrows (e.g. stay within the circle), and thus in short, literally as encirclement (Figure 1(c)).

Seeing territory in this simplified way helps us to come to terms with its multiple and overlapping forms in reality (Faludi, 2014: 182), especially when these would fundamentally change these days. Although according to Faludi (2014: 180) territory is in the European Union "seen as a container with fixed walls within which the state exercises its territoriality" (see \$2.4), Agnew (1994) namely shows that the conventional thought of states as "containers" of societies are no longer helpful (Faludi, 2012: 204) and Jones \& Paasi (2013: 2) that also " $[t]$ raditional views of regions as bounded, homogenous units have been mostly rejected" (Faludi, 2013c: 8). Taylor's (2007) example can then point us in a direction to understand what is happening; more from Taylor (2007) below (\$3). While "the subordination of cities to territorial states [would be] the most important geographical attribute of modernity", cities would now be "able to position themselves in the global society" (Knight \& Gabbert, 1989: 19; Taylor, 2007: 134, 135). Meaning, even though states still have cities inside their borders, they do not control them anymore, what opens up room between two meanings of the word "contain". As control was the objective for borders as means, that "having inside" does not automatically mean "having control over" anymore, is essential to understand the territorial "puzzles" in the European Union of today, as we will see below.

This opened double of containment can be clarified by using such forms as above, because they underline some fundamental differences at play due to their simplification. It for instance becomes easy to analytically dissect the development of the above "state-cities contest" in a circle (i.e. the same borders with the same inside), cone (i.e. the same "someone" of this filled circle), and encirclement (i.e. that someone has less control over that encircled inside). With simplest forms, we then do not leave the complex socio-spatial relations behind that exist in reality "from territories of control and surveillance to domains of organisation and administration" (Richardson \& Jensen, 2003: 10). The logic used namely is that these complex relations create "institutional environments within which symbolised spaces are produced and attributed meanings" (Richardson \& Jensen, 2003: 10), different relations institutionalise different symbols, making the cleaner ideational an indication of the messy real, and different ways of thinking can thus signal fundaments of ways of doing. Hence, to visualise the territorial essentials of the European Union with territorial basics, we can for the territories involved now draw on the simplest forms of circle, cone, and encir- 
clement.

\subsection{Seeing Scale}

When we see territory in simplest forms (i.e. circle, cone, encirclement), the next question becomes how scale then looks. Difference in geographical scale namely already comes forward when we recognize that in, for example, the "state-cities contest" mentioned above (Taylor, 2007), cities have territories as well. Within the single and world-encompassing social-spatial reality, scale then says how much of this world, from the global to the body, one considers in the territorial unit (Lefebvre, 1976: 67-69; Collinge, 1999; Brenner, 1998; Brenner, 2001: 597). The circles thus vary in size, that is to say, each territory thus has a certain scale. Yet, when these circles in varying sizes would not cross, there would be no need to visualise scale as one of the territorial basics, as the circle, cone, and encirclement would be enough for that and scale merely a variation in empirical reality. Then again, what is intrinsic to territorial affairs is that the many smaller and increasingly less many larger circles thereby relate in nests (Lefebvre, 1976: 67-69; Brenner, 1998; Allen et al., 1998). Commonly, we then talk about a vertical ordering of social relations in levels, leading to a spatial hierarchy (e.g. Lefebvre, 1976: 67-69; Collinge, 1999; Brenner, 1998; Brenner, 2001: 597), even that "social agents [would use] more or less fixed notions of [it] to navigate reality" (Richardson \& Jensen, 2003: 13). Yet, in first instance, these territories are solely nested. In its simplest form, you can see scale thus as a larger circle including several smaller circles (Figure 2(a)).

The vertical ordering of these nested circles in levels comes with the "someones" of the territories, with the cones that is. According to Brenner (2001: 599-600, 604), "politics of scale" in the singular means that each scale functions as a boundary that separates self-enclosed geographical units in which specific activities take place. Although scales do not always entail someones as territories do, territorial scales, our concern, do come with nested cones. This of course leads to the question of who rules what, as more than one someone then rules the same portion of space. Notwithstanding the verticality involved, also in the

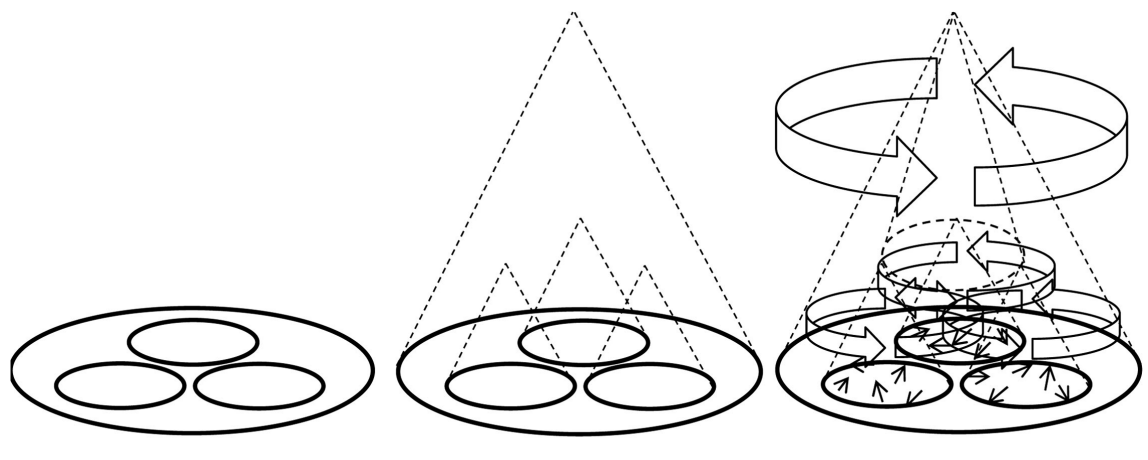

(a)

(b)

(c)

Figure 2. "Scale" in simplest forms: nested circles (a), cone-incorporation (b), intertwined encirclement swirls (c). 
second instance scale in itself does not address this issue though; what is similar to the difference between the cone mark and encirclement for territory above (see \$2.2). Nested circles as the simplest form of scale in territorial affairs should however always be considered with a larger cone incorporating smaller cones (Figure 2(b)).

Such a hierarchy of integration nevertheless often leads to and/or is taken as a hierarchy of domination. This however depends on how the scales of territories are structured, what entails that these scales are constructed for and/or by rule instead of being given and fixed; what Brenner (2001: 599-600, 604) calls "politics of scale" in a general sense. With our simplest forms we would then ask the question of how nested circles and their incorporating/-ed cones set up, that is, how these encirclements are set up in levels. Meaning, "someone" on a higher level does not only more or less incorporate the encirclements for control of the someones of the lower level territories, but simultaneously more or less controls these someones by indicating a limit as well.

Moreover, in practice, there are more than two scales of course, what complicates these encirclements (e.g. have those "someones" encircled on several scales, skip scales). More essential though, "in the social as much as geographical contest to establish boundaries between different places" (Smith, 1993), both each scale is historically formed, provisionally stabilized, and possibly transformed and scales mutually constitute each other (LeFebvre, 1976: 67, 69; Brenner, 1998). We thus have to deal with periodic and a/synchronous reorderings among intertwined scales; a "politics of scale" in the plural which Brenner (2001: 599-600, 604) terms "politics of scaling". The encirclements on various levels thus have intertwined swirls with circles formed with someones and rearranged controls more above and/or below in the incorporating/-ed cones. This controlling behaviour that always comes with scale can in its simplest form therefore be imagined as intertwined encirclement swirls (Figure $2(c)^{2}$ ).

Yet, where do these intertwined encirclements swirls come from? Smith (1993: 101) holds that we can see scales as both the materialization and active progenitors of contesting social forces (Brenner, 1998). In this paradox you can see " $t$ ] he scale of struggle and the struggle over scale [as] two sides of the same coin" (Smith, 1993: 101; Brenner, 2001: 608). We should therefore keep in mind that encirclement is merely one way of behaving, and that setting up encirclements is affected by and has effects on other ways, both those within one size of circle and cone and those about which (size of) circle and cone to choose. Still, while for instance Jensen \& Richardson (2003) say that socio-spatial practices and the construction of symbolic meanings take place at particular politically defined scales, in the re-/framing of territorial policies for example, Gualini (2001) ${ }^{3}$

${ }^{2}$ Note that in this figure the arrows, which stand for active people, do not appear outside of the territory at the lowest scale anymore, as in Figure 1(c), while even in this simplified abstraction they should also be there to represent scale with territories. Yet, with simplest forms as circles for territories all borders, from the territories at both levels, cannot align anymore. I choose simplified above representative representation to let the fundaments remain as clear as possible.

${ }^{3}$ I thank Dr E. Gualini for giving me a draft version of his paper. 
even thinks that scales cannot be used to describe such processes, but are part of what should be described. And although encirclements with intertwined swirls an various levels complex territorial affairs immensely in practice, the simplest forms of scale basically show their fundaments for that. To visualise the territorial essentials of the European Union with territorial basics, we can for the scales involved thus draw on nests, cone incorporation, and intertwined encirclement swirls besides the circle, cone, and encirclement for territories.

\subsection{Seeing Territoriality}

In the simplest forms, we encounter the same world with territoriality as with territory and scale, but from another angle. Territoriality is namely the strategic behaviour that forms boundaries to affect, influence, and/or control social content, such as people and resources, in space (Sack, 1986; Taylor, 1994: 151; Taylor, 2007: 141; Mamadouh, 2001: 421; Faludi, 2012: 205; Faludi, 2014: 180). This behaviour does not take a territory as given, as encirclement does by indicating limits (see \$2.2), but can make one too, as “someone" uses territoriality, and in itself thus does not imply a fixed territory. Hence, territoriality can in its simplest form be understood as, again literally, an encircling behaviour that through a cone marks a circle (Figure 3(a)).

As such, "[t]erritoriality involves the physical organisation of political space", and thus a political organization whose "legal reach of public authority is coterminous with certain spatial boundaries" (Caporaso \& Jupille, 2004: 72). Political organizations often have various scales, and although "territoriality represents only one possible dimension of [the] rich sociospatiality [of scale]" (Cox, 1998; Low, 1997; Whatmore \& Thorne, 1997; Brenner, 2001: 606), territoriality is an "indispensable means to power at all levels" (Sack, 1986: 1; Mamadouh, 2001: 421; Berezin, 2004: 7). The effects of territories as constructed forms of spatial relations thereby "depend upon who is controlling whom and for what purposes” (Sack, 1986: 216; Berezin, 2004: 7). This reminds us of scale and the encirclements on various levels with intertwined swirls up- and down-wards, which

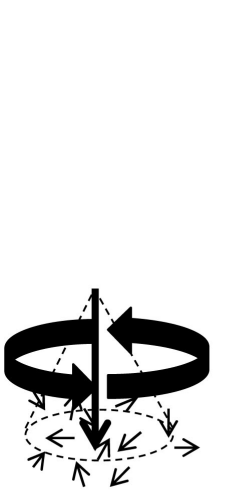

(a)

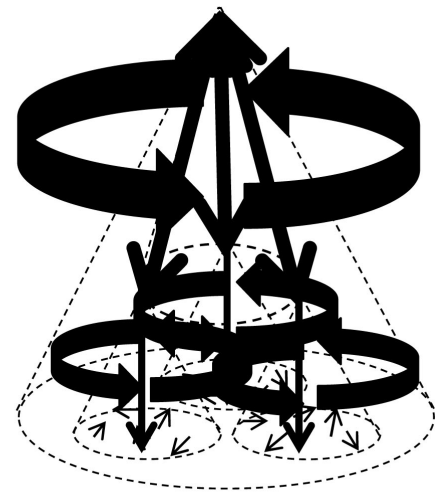

(b)

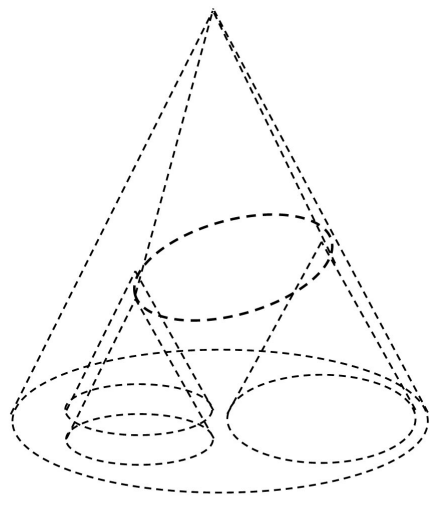

(c)

Figure 3. "Territoriality" in simplest forms: encircling (a), swirling up and/or down (b), differing and/or overlapping circles and cones (c). 
affect and are affected by other behaviour, and now underline the rearrangements of "someone's" control over others (e.g. a population) and/or other someones (e.g. rulers). Encircling behaviour that through a cone marks a circle as the simplest form of territoriality should with several levels thus also always be thought of as both swirling down towards some or all circles and/or up towards the point of the cone (Figure $3(\mathrm{~b})$ ).

State territoriality is often taken as the exemplar of territoriality (Harvey, 1985: 326; Faludi, 2014: 180), while it is a very characteristic one, especially in its comprehensiveness in the modern state system (Taylor, 1994; Storey, 2001; Mamadouh, 2001: 421). Territoriality is "a common strategy to many individuals and groups" though (Sack, 1986: 1; Mamadouh, 2001: 421), and therefore does not inevitably come with the supreme rule, exclusive dominion, multipurpose administrations, and fixed borders as shown by states. In simplest forms state territoriality namely entails that the encircling solely swirls downwards from the top "someone" to others and/or someones of lower levels and leads to kept circles and levels that contain completely (i.e. centralising sovereignty). Yet, functional areas (e.g. for water management) are for instance also "territorial", but imply "pluropolic" governance (i.e. with multiple providing someones) and a shared territoriality (Faludi, 2013b: 1309). In its simplest form territoriality can then not only be imagined as an encircling behaviour swirling up- and downwards, but also that this can lead to overlapping circles on the same level, instead of circles with totally different areas, moreover, that cones, and thus their circles, can differ in size too, instead of necessarily having same-size cones on each "level" (Figure 3(c)). When we see territoriality as such a wide strategy, we are not stuck to territories (as through cones constructed circles) anymore, but are enabled to focus on the (swirling) encircling itself. And this will help to visualise the territorial essentials of the European Union immensely, as we will see below (see $\$ 2.5$ ), because the simplest forms for the territorial basics of territory (i.e. circle, cone, encirclement) and scale (i.e. nests, cone incorporation, intertwined encirclement swirls) seem hard to find.

\subsection{The Territorial Affairs of the European Union in Sight}

When we see the territorial basics of territory, scale, and territoriality in both, in brief, circles, cones, as well as encircling, the question becomes how to use these simplest forms to have the territorial essentials of the European Union in sight. On the outset, according to Schön (2005: 399n6), the European Union namely has no territory, not in the strict sense at least, as is not a nation-state. The plurality of distinct nation-states in Europe, however, has, following Fabbrini (2004: 164), moved towards this continental-sized integrated polity. The integration of the European Union thereby aimed for a "Europe without borders", what challenges state territoriality (Faludi, 2013b: 1308) in two ways. It did not only add a supranational level to the traditional model of the Westphalian state, to which ${ }^{4}$ Do note that this "someone" can of course be constituted by lower levels, but this is done by another behavior than encircling. 
these then lower levels lost sovereignty, but also added another territorial logic to the Westphalian political order (Murphy, 2008: 7; Faludi, 2012: 204), by promoting "a polity in which the relations between authority and territory are no longer clearly settled" (Fabbrini, 2004: 164) instead of straightforwardly having territoriality and peoplehood as basic principles (Borneman \& Fowler, 1997; Olsen, 2002: 925). In simplest forms this addition of a higher level and other logic can be seen as a cone on top of smaller ones, with a swirling encircling to control them, but without an incorporation of the smaller cones and the circles marked with them (Figure 4(a)).

Imaging the territorial affairs of the European Union thus relates to the ways it is politically organised of course. As Olsen (2002: 924) holds, its increasing union grows this political entity stronger, and also relates to territorial space and centre-building. However, as Mamadouh (2001: 433) says, territories have not been transferred to a supranational entity, selected powers have. The European Union therefore is not directly controlling a territory in the absolute way a modern nation-state would, but depends on the member states for that (e.g. interest representation, policy implementation, law enforcement) (Mamadouh, 2001: 433). With this higher level there thus neither appear an own circle, so no nests either, nor encirclement, so neither their intertwined swirls. Already then we can ask the question to what this logic leads to in territorial affairs.

Furthermore, one could characterise the European Union's polity as a Kafkaesque $S c h l o \beta$ (i.e. castle/lock) due to its multiple layers, in-built development, polycentrism covering governmental and non-governmental centres, networks of countless connections, fuzzy limits between in- and outside, and bureaucratic make-up (Hissink Muller, 2016). Centre-building then entails building several centres for instance. No wonder that Faludi (2012: 204) poses that this organisation changes territorial affairs. These can "no longer be understood in terms of the sovereignty norms of the modern state system because governmental competencies are no longer concentrated in discrete political spaces organized at a

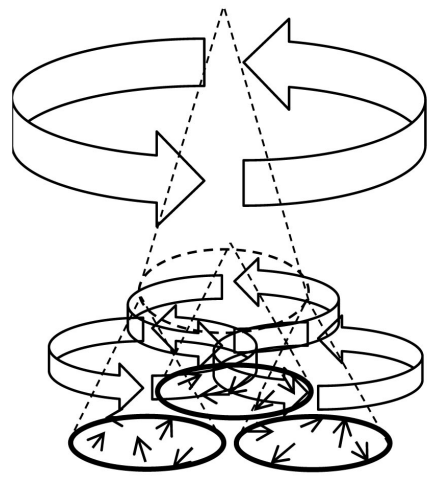

(a)

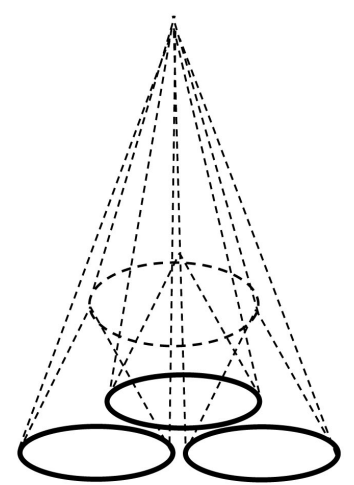

(b)

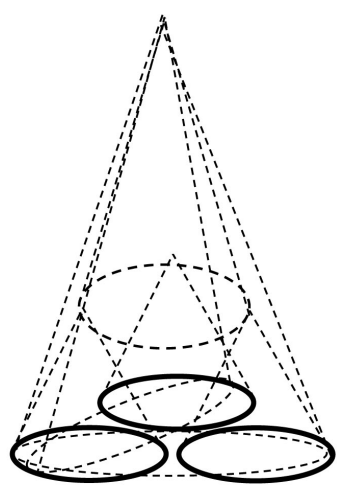

(c)

Figure 4. Territorial affairs in the European Union in simplest forms: swirling encircling without cone-incorporation (a), encircling through cones without own circles (b), encircling with temporary, partial, and overlapping ovals (c). 
single scale or level" (Murphy, 2008: 7), but control is "dispersed over a field featuring competing but interlocking institutions" (Faludi, 2012: 205). What begs the question of what this territorial logic means for the European Union in the sense of our simplest forms.

As the addition of a political level came without changes in territory (i.e. no transfer), we can start with its territoriality, its encircling behaviour that is. The changing relationship between territory and governance can then be understood as an "unbundling" of territoriality (Ruggie, 1993) and a "re-bundling" of territoriality (Ansell, 2004: 5). To start with the latter, insofar the European Union "has 'offices' that speak for the EU as a whole" with authoritative and integrative law, it at least "operates much more like a new territorial ontology-a corporate personality-on a higher sale" (Ansell, 2004: 15n11); do note that this "someone" thereby at least consists of multiple centres, if it is not more Kafkaesque. However, insofar the European Union "is simply as set of discrete functional authorities" it represents an unbundling of territoriality (Ansell, 2004: 15n11); again with its peculiar "someone". Both this re-bundling and unbundling can be pictured in our simplest forms.

The European Union re-bundles territorialities by clearly challenging the unity of the national territorial frameworks of its member states with its own territorial considerations and components to frame functional policy choices (Bartolini, 2004: 34). The largest category of legal acts of the European Union, directives and regulations, namely, "pertain to a territory under jurisdiction of the EU", due to which territoriality remains its main control mechanism (Mamadouh, 2001: 424; Ansell, 2004: 228). Paradoxically, policies are then territorially framed, but the political decisions for them are not grounded in any (own) territory. Instead, this territoriality is "primarily derivative of the territoriality of the member states in that they implement and administer these directives" (Ansell, 2004: 228). Perhaps one could say this involves an administrative instead of political territoriality. Anyways, in the simplest forms, you can then see this mediated territoriality of the European Union (Mamadouh, 2001: 433) as cones from the top of the cone on the smaller ones, "through" the "circle" on the lower cones marked by the upper cone, to the circles of the lower cones, also with an encircling to control the lower cones through their own circles (Figure $4(\mathrm{~b})^{5}$ ).

The European Union also unbundles territoriality by challenging the monopoly of state territoriality, making territoriality fluid and dynamic (Burgess \& Vollaard, 2006: 1, 7-8; Faludi, 2013b: 1308-1309). Besides the nation-state's hierarchy and fixed spatial frame, which "takes no account of the multiplicity of arenas, identities, interests and power relations criss-crossing territorial boundaries" (Faludi, 2013a; Faludi, 2014: 180), voluntarism is added, which does account for that multiplicity, but then without requiring the "uniform participa-

${ }^{5}$ Note that in Figure 4(b) the small straight and larger round arrows that respectively signify the maneuvering others that are encircled and the encircling of territoriality are left out, but this is done merely for the clarity of the figure; meaning, the maneuvering others and encircling are still there, and thus the arrows should be envisioned in this figure too. 
tion of all territorial subunits" (Ansell, 2004: 227). Following Mamadouh (2001: 422,433 ), we then have a multiple territoriality with territorial systems of rule that depend on the task at hand (i.e. variable geometry), are not "necessarily territorially fixed and certainly not mutually exclusive" (e.g. a triple territoriality, with different scales for military, economic and cultural tasks). In simplest forms you can see this multiple territoriality of the European Union in a similar fashion as its mediated territoriality, but then with ovals that are not kept, but overlap each other and cover several but not each of the kept circles on that level (Figure 4(c)).

You might have noticed that seeing the territorial essentials of the European Union, the added supranational level and territorial logic that is, is not so trouble-free in our simplest forms anymore. And do note that both this re-bundling and unbundling of territoriality by the European Union does not only reconfigure its supranational territorial affairs, but those on lower levels too (e.g. its member states). Moreover, that this reconfiguration works through these territorial affairs in the European Union is an essential part of it. To figure out the territorial logic involved you should on top of that even picture the not so trouble-free three simplest forms together to show the mediated and multiple territoriality of territorially framed policies and legal acts and of functional "territories" as they play out simultaneously. This is even exceptionally complex when we leave differences between the used territorial frameworks as defined by member states to the side (i.e. as the cones that differ in size on each "level" in Figure 3(c)), such as subnational regions (e.g. Länder, Provincies). Hence, with our simplest forms the complex territorial affairs of the European Union are in sight, but the puzzling ways territoriality works there withholds us from seeing their fundaments. We should therefore try an alternative way besides our visualisation of territorial basics to get to the underlying essentials of the territorial logic of the European Union.

\section{Preparing the Systems of Survival for Their Usage as Heuristic Tool}

\subsection{Towards the Territorial Affairs of the Systems of Survival}

For those who are accustomed to the territorial logic of the nation-state, figuring out the territorial logic of the European Union takes some mind-bending activity. Yet, we do understand the territorial logics that were in place before the nation-state. We for example know how European nation-state building implied the disintegration of "previously existing and integrated territories, economies, and societies" (Bartolini, 2004: 20). So, our understanding is not caught in the territorial logic of the nation-state, and, what is more, the continuity in these different territorial logics could enlighten our attempts to grasp the one of the European Union, especially if the older ways partly remain to function today as well. Jacobs (1992) helps us in this matter, as she discerns "the basic social practices" in a transhistorical manner (Taylor, 2007: 135). Territorial affairs share 
centre stage in this (\$3.2), something on which we will focus in the abstract (\$3.3), while heavily leaning on Taylor (2007), and through European history (\$3.4), what offers us an alternative because more thorough way to look at the territorial affairs of the European Union (\$3.5).

\subsection{Introducing the Guardian and Commercial Syndromes}

Jacobs (1992: 19-20) argues "that morality and practical matters" are "one and the same" and challenges "orthodox thinking [on] the content of ethics in moral philosophy" (Taylor, 2007: 135). She namely takes "an unusually inductive approach" to systematically deal with the "'perplexing contradictions' [in] what is deemed moral behaviour" (Jacobs, 1992: 19-20, 27; Taylor, 2007: 135). There for instance "appear to be circumstances when loyalty is more important than honesty and vice versa" (Jacobs, 1992: 27; Taylor, 2007: 135). She however did find "patterns in lists of 'precepts' though, that is, what people should (not) do, and through clustering resolved the moral contradictions 'into two systems, each with its own integrity"' (Jacobs, 1992: 27; Taylor, 2007: 135).

The "two groups define the circumstances when one precept overrides another": a guardian context, in which "loyalty is all-important (necessary to power)", and a commercial context, in which "honesty is paramount (necessary for trust)" (Taylor, 2007: 135). That is to say, through millennia of experience humans added making and trading to hunting and gathering, leading to what is still "the essential division of labour" today: either you take or make (Jacobs, 1992: xii; Taylor, 2007: 136). It is with these two systems of survival, the guardian ${ }^{6}$ and commercial syndrome, that our interest in understanding the basics of territorial affairs returns.

Far from being arbitrary constructs ${ }^{7}$, these syndromes namely derive from our traditions in on the one hand "organizing and managing territories" and "trading and producing" on the other hand (Jacobs, 1992: xii; Taylor, 2007: 136). The aristocratic former should then have precepts for the guardian to maintain power as a successful ruler concerned with protection and territory and the latter for the trader to successfully enter a market through profit and networks, but both to ensure "immediate and long-term social reproduction" (Arrighi, 1994; Taylor, 2007: 135-136, 143; Taylor, 2008: 153). It is important to note here that we will continue to use the labels of "guardian" and "trader" to denote the essences of these two roles that people can play and we do not identify people based on these roles alone. That said and taken into account, we do see that the guardian syndrome so much revolves around territorial affairs and is juxtaposed with the commercial syndrome, that the need arises to dig a bit deeper into both.

\footnotetext{
${ }^{6}$ Note that Jacobs $(1992: 215,218)$ first thought that the guardian moral syndrome was one for raiders, but that she choose to go for the political instead of personal use of the syndrome.

${ }^{7}$ See for the precepts of the guardian syndrome for instance: Davies (1612/1988), Bartlett (1994), Shuger (1997), Cartledge (2001), Whitby (2001), LeBlanc (2003), Turner (2003), Arnold (2006), Cowell (2007), and van Creveld (2008). See for the precepts of the commercial syndrome for instance: McCloskey (2006) and Seabright (2010).
} 
As shown by Taylor (2007: 136) ordered Table 1 below, then in each syndrome the key virtue (i.e. loyalty, honesty) comes "with 14 other precepts to create coherent systems of normative behaviour".

Loyalty and honesty are the key virtues, "because the two ways of making a living would break down if the precept were sufficiently violated" (Taylor, 2007: 136). That is, the taking of guardians requires group solidarity and the producing and selling of traders can only be sustained through honesty between market participants (Taylor, 2007: 136). Other basic precepts back up these key virtues; "for instance, in the guardian syndrome trading is shunned (it leads to corrupt transactions); in the commercial syndrome force is shunned (it leads to unfair transactions)" (Taylor, 2007: 136). There is more involved than these basics though, as the clusters of precepts above show two oppositional and complete

Table 1. Syndromes by clusters of precepts.

\begin{tabular}{|c|c|c|c|}
\hline \multicolumn{2}{|c|}{ Commercial syndrome } & \multicolumn{2}{|c|}{ Guardian syndrome } \\
\hline Clusters & Precepts & Clusters & Precepts \\
\hline "Key virtue" & Be honest & "Key virtue" & Be loyal \\
\hline \multirow[t]{4}{*}{ Other basic cluster } & Shun force & Other basic cluster & Shun trading \\
\hline & $\begin{array}{l}\text { Come to voluntary } \\
\text { agreements }\end{array}$ & & Exert prowess \\
\hline & & & Adhere to tradition \\
\hline & & & $\begin{array}{l}\text { Be obedient } \\
\text { and disciplined }\end{array}$ \\
\hline \multirow[t]{4}{*}{ Operating cluster } & $\begin{array}{l}\text { Collaborate with } \\
\text { strangers and aliens }\end{array}$ & Action cluster & Take vengeance \\
\hline & Compete & & $\begin{array}{l}\text { Deceive for the sake of } \\
\text { the task }\end{array}$ \\
\hline & Respect contracts & & \\
\hline & $\begin{array}{l}\text { Use initiative and } \\
\text { enterprise }\end{array}$ & & \\
\hline \multirow[t]{5}{*}{ Progress cluster } & $\begin{array}{l}\text { Be open to inventiveness } \\
\text { and novelty }\end{array}$ & Lifestyle cluster & Make rich use of leisure \\
\hline & Be efficient & & Be ostentatious \\
\hline & $\begin{array}{l}\text { Promote comfort and } \\
\text { convenience }\end{array}$ & & Dispense largesse \\
\hline & $\begin{array}{l}\text { Dissent for the sake of } \\
\text { the task }\end{array}$ & & Be exclusive \\
\hline & & & Show fortitude \\
\hline \multirow[t]{3}{*}{ Capital cluster } & $\begin{array}{l}\text { Invest for productive } \\
\text { purposes }\end{array}$ & Life cluster & Be fatalistic \\
\hline & Be industrious & & Treasure honour \\
\hline & Be thrifty & & \\
\hline Life cluster & Be optimistic & & \\
\hline
\end{tabular}


logics: while for instance "rulers need to control dissent[,] markets need to control deception", and while "ostentation and largesse help rulers rule[,] thriftiness and productive investment pays off in markets" (Taylor, 2007: 136). These two radically different moral codes therefore prescribe two totally unalike ways of behaving.

We then just as Taylor (2007: 137) accept Jacobs' (1992) dual ethics model as essentially sound. Yet, it is her further insight that leads our investigation in the territorial affairs of the European Union. And this is not so much her understanding that each way of living needs the other, due to that "guardians need the wealth creation from making and trading [and] markets need to protection and order provided by guardians"; a "reasonably working guardian-commercial symbiosis" where both support each other is thus very well possible (Jacobs, 1992: 214; Taylor, 2007: 137). But, moreover, her insight "that the integrity of each moral syndrome must be maintained to prevent corruption", while guardian/commercial hybrids can be disastrous (e.g. a state directing economic change, a mafia controlling territory for profit) (Taylor, 2006; Taylor, 2007: 137). Hence, when Taylor (2007: 137) says that the key test is whether Jacobs' (1992) "concepts are ultimately useful in comprehending our modern predicament", we especially focus on how the integrity of the guardian and commercial syndrome return in the territorial affairs of the European Union.

\subsection{Grasping Space for Encircling and Networking Syndromes}

For the usage of the systems of survival as a heuristic tool to easier understand the territorial affairs of the European Union, we first need to know how deep territorial affairs return in the guardian and commercial syndrome. Simply put the answer is that the latter is not (directly) territorial and the former fundamentally so. According to Jacobs (1992: 29), the guardian syndrome namely covers many territorial responsibilities: "the work of protecting, acquiring, exploiting, administrating, or controlling territories" (Taylor, 2007: 139). As Taylor (2007: 137) exemplifies with even the least prominent of the precepts: guardians are fatalists because their "syndrome is predicated on a zero-sum game [in which] one ruler's territorial gain is another ruler's loss of territory", while traders are optimists because an "efficient and free market creates a win-win situation, since the seller agrees a sale and the buyer satisfies a need." Guardians are thus rulers of territory, that is, the standard "someones" who encircle others as noted above (see \$2). One can then straightforwardly argue for how that leads to the oppositional precepts of both syndromes, as shown below with Taylor's (2007: 137) (Table 2).

One could for instance say that guardians should respect hierarchy and adhere to tradition because they encircle and keep a circle, and are most often encircled by a higher ruler as well, and are thus contained in a larger circle too, what entails a social structure that becomes unstable without the hierarchy innate to encircling and the keeping of traditional borders. In the commercial world, however, "contracts cancel out hierarchies" and inventiveness is promoted for higher 
Table 2. Syndromes by paired precepts.

\begin{tabular}{ll}
\hline \multicolumn{1}{c}{ Commercial syndrome } & Guardian syndrome \\
\hline Be honest & Deceive for the sake of the task \\
Dissent for the sake of the task & Be loyal \\
Shun force & Exert prowess \\
Come to voluntary agreements & Shun trading \\
Collaborate with strangers and aliens & Be exclusive \\
Be open to inventiveness and novelty & Adhere to tradition \\
Use initiative and enterprise & Be obedient and disciplined \\
Respect contracts & Respect hierarchy \\
Be industrious & Make rich use of leisure \\
Be thrifty & Be ostentatious \\
Invest for productive purposes & Dispense largesse \\
Promote comfort and convenience & Show fortitude \\
Be efficient & Treasure honour \\
Compete & Take vengeance \\
Be optimistic & Be fatalistic \\
\hline
\end{tabular}

yields (Taylor, 2007: 138). Likewise, guardians cannot trade what they have (i.e. territory) without losing (i.e. land or traditional borders) and could need to exclude others to rule alone and exert prowess for sovereignty in their territory. As put in a nutshell by Taylor (2007: 137), Jacobs (1992) provides a framework for thinking about the moral foundations of politics and commerce.

Taylor $(2007: 138,139)$ then follows Jacobs' (1992: 29) observation in that the guardian syndrome covers many state activities (i.e. protecting, acquiring, exploiting, administrating, and controlling territory), but seems to stretch it too far. His starting point can be right: states might indeed be "the prime habitat of the guardian syndrome" and cities "constitute the prime habitat of the commercial syndrome" (Taylor, 2007: 138). Still, his interpretative treatment of "states as constellations of guardian practices [and] cities as constellations of commercial practices" that builds forth on that starting point (Taylor, 2007: 133, 135, 138, 147), a homogenisation within geographic containers on different scales (i.e. state, city), arguably consists of a too gross generalisation. Simple but fundamental is namely that, as we said in the beginning, cities have their own territory, and, if dealing with territory bases the guardian syndrome, cities therefore have their own guardians too.

Nonetheless, Sidaway (2008: 149) could be right in saying that Taylor's (2007) interpretation of Jacobs (1992) can be "productively engaged with". His geographical interpretation of the two syndromes for instance gives us the simplest form for the basics of how traders deal with space in contrast to the encircling done by guardians. The commercial world is namely one "of connections, of 
mutualities within networks of cities covering different cultures and environments where trading thrives and through which novelties diffuse" (Taylor, 2007: 138). While traders deal with networks within a city too, Jacobs (1969: 35) already noted that "a city does not grow by trading with a rural hinterland [, it] seems always to have implied a group of cities, in trade with one another". We might experience this in a more extreme form today, when cities fragment "with relations with distant places sometimes becoming more important than those with contiguous ones" (Faludi, 2013b: 1310). The cast of mind of traders is therefore cosmopolitan (Taylor, 2007: 138), in contrast to the guardians' territorial way of thinking which is limited in nature. Hence, instead of the guardians' circles and cones (Figure 5(a), which is the same as Figure 2(b)), the simplest form for the basics of how traders deal with space, is networks (Figure 5(b)).

We can then see an agonistic dynamic of both differentiation and contestation between the ways the two systems deal with space: guardians encircle and traders network. The territoriality of the guardian syndrome would, according to Taylor (2007: 138), cultivate the exclusive authority of hierarchy, a centred hard power, while the commercial syndrome would instead cultivate mutuality through networks, a diffuse soft power. Yet, you could argue for the existence of domination in the market as well, based upon richness or monopoly for instance. When Taylor (2007: 138) holds that the guardian's "cast of mind is irrecoverably bounded for control purposes" (Taylor, 2007: 138), we could likewise argue that traders try to control as well. That is to say, instead of controlling others by encircling (Figure 6(a), which is the same as Figure 1(c)), traders control others in and through networking (Figure 6(b)).

Other differences come with these visual basics. A fundamental one is what Scott (1998) shows for how states make society legible (for control), what could well hold for the guardian syndrome in general. They through abstraction create

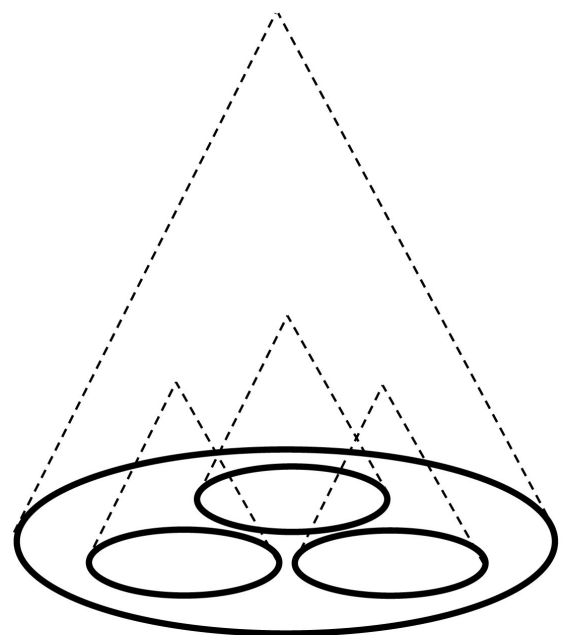

(a)

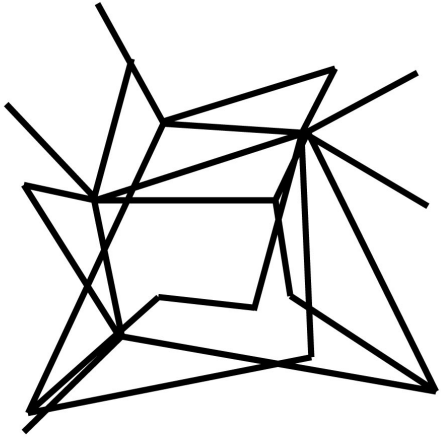

(b)

Figure 5. The ways guardians (a) and traders deal with space (b) in simplest forms. 


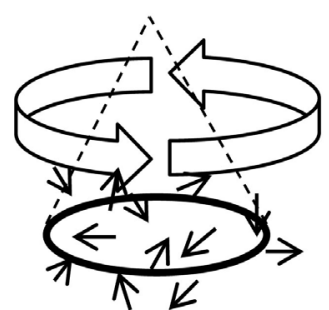

(a)

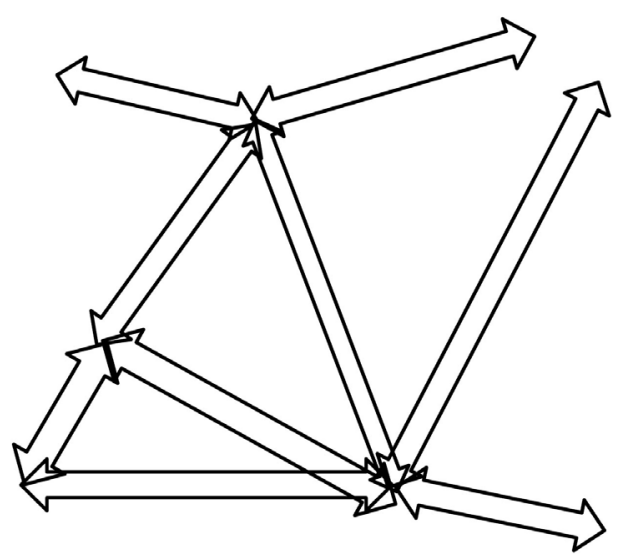

(b)

Figure 6. The ways guardians (a) and traders (b) control in simplest forms.

"social simplifications" of "facts" that are "purposive, documented, static, aggregated and standardized" (Scott, 1998: 2, 3, 80; Taylor, 2007: 139). The world of the commercial syndrome on the other hand implies an innate complexity (Taylor, 2007: 138) of in principle limitless webs of traders where each with his own perspective tries to influence others. No wonder Taylor (2007) holds that the two syndromes entail different social spaces.

That is to say, according to Taylor (2007: 133) the guardian and commercial syndromes create spaces of places and flows respectively. We then do not have to agree with Taylor (2007: 138) that, or understand in detail why, the "political mosaics" that guardians build come with places, but that traders create "economic chains" in which resources and capital flow seems to follow more straightforwardly. The syndromes and social spaces then interlock, making these spaces "necessary for the successful operation of these different ways of making a living" (Taylor, 2007: 138). Although Taylor's (2007: 139) view that the space of flows is more difficult to control than the space of places is not our viewpoint, our point does derive from what he says. That guardians and traders need different social spaces for us namely means that guardians control others through (simplifying) encircling and traders through (complexing) networking.

Even though guardians and traders could have their own social spaces of places and flows, as both live in the same physical space (i.e. "spatial space"), these social spaces do come together. They for instance already collide when it concerns movement trough this spatial space. Simply put, while commercial networks can in principle spatially extent themselves infinitely, guardians set up borders, which traders thus cross. You can imagine that this dynamic quickly becomes more complicated, as history proofs us (see \$3.4). For now though, we can already in the abstract note how Jacobs' (1992) systems of survival could be used as a heuristic tool to understand the territorial affairs of the European Union (see $\$ 4$ ).

With them as heuristic tool we can namely recognise the oppositional behaviours in which guardians and traders treat space (e.g. encircle/network, simpli- 
fy/complexify), that the former is territorial in nature, and that both might be identified in the-not simple, but-exceptionally complex territorial affairs in the European Union. However, when we would start to identify these oppositional behaviours in the territorial affairs in the European Union from scratch, a vacuum, we would give them neither an easily comprehensible nor particular place. We should therefore first sketch how these behaviours can be identified in the territorial affairs appearing in the European Union before its existence, both to give a context to be able to assess how they return in those of the European Union and because the territorial affairs of the European Union work through those within it (see $\$ 2.5$ ). This also adds the benefit of familiarising ourselves with using the guardian and commercial syndromes as heuristic tool to more thoroughly understand territorial affairs, as it does so for the more simple territorial affairs we already grasp easily.

\subsection{Sketching a Brief European History of Changing Guardian and Tradership}

For the territorial affairs of the European Union those in it are essential, and have a long history. What is more, the ways in which through guardians and trades the guardian and commercial syndromes played different roles in modifications of the territorial logics existing throughout European history can be seen as setting up the reconfigurations of the territorial affairs in today's European Union too. Taylor (2007: 141) in this light poses that at the centre of the agonistic dynamics of guardian and commercial syndromes there "can be found attempts by political elites to control economic elites". What was also treated above (see \$2) are the generic means in this process, which would be containerization (Taylor, 1999: 18), its concrete expression, territoriality, and the critical modern example of it, the nation-state (Taylor, 1994; Taylor, 2007: 141). On the other hand though, studies in political economy (e.g. Harvey, 1982) and capital's usage of the state apparatus to, for instance, institutionalise a spatio-temporal fix (Jessop, 2002) are all about the other way around (see $\$ 4.2$ ), that is, about attempts by economic elites to control political elites. Then traders do not only play their commercial networking game within and between the containers set up by the guardians (e.g. city walls), but play the circles (i.e. territories) as well. Therefore, although only guardians might solely try to control through encircling, traders can use these controls (indirectly) as well, as is shown below with European history.

We start our sketch of the origins (i.e. Herkunft) of the territorial logics in the European Union in the Middle Ages, as this era shows the least institutionalisation of worldly rule when we look backward through time (e.g. Bartlett, 1994). Ruggie (1993) then argues that this "medieval system of rule was structured by a non-exclusive form of territoriality, in which authority was both personalized and parcelized within and across territorial formations" (Ansell, 2004: 3). This entailed that "[i]n 1450 Europe was a localized world of feudalisms largely linked to wealthier worlds via Mediterranean cities (Genoa, Venice)" (Taylor, 2007: 
140). The territorial logic was thus basic in that local guardians, territorial ones, set up circles and, most often, inferior traders deal within and between them.

This medieval world changed to a modern one in the "long sixteenth century" between 1450-1650 (Wallerstein, 1979; Taylor, 2007: 140). In 1650 Europe was namely "an expansive world of sovereign states with extra-European empires, and North Sea cities were in the ascendancy (Amsterdam, London)" (Taylor, 2007: 140). What happened following Ruggie (1993: 159), is that "after the Black death decimated the landed elites and forced the Catholic Church into sharing sovereignty with a rising class of entrepreneurs", the "single" perspective state rose which "viewed from the interests of the new political and commercial classes" and "political space came to be defined as it appeared from a single fixed viewpoint” (Berezin, 2004: 6). "Singular sovereignty [r] eplaced multiple overlapping sovereignties" (Faludi, 2013b: 129). This transition implied that in Europe we went from the territorial logic of local territorial guardians to intermingling it with logics from spiritual guardians (e.g. the loyalty, hierarchy, and tradition in, especially Romanised, Christendom) and traders, leading to more centralised territorial guardianship with a downwards swirling encircling and circles, cones, and encirclements also set for commerce (e.g. to act as the "teeth" of civil law, protect trade routes, mercantilistically colonise, wage trade wars).

Then again, the territorial logic this would give rise to did not come through straightforwardly, especially since the removal of kings as territorial guardians and the separation of the state and church moved spiritual guardians away from territorial guardianship. For the political fundaments of modern societies the natural way of thinking was invented, whereby, following Neocleous (2003: 410), not the swords of lords created territories, but a never really signed social contract created the civil society that authorised the political space, "whether bounded by absolute authority (Hobbes), private property (Locke), or the general will (Rousseau)" (e.g. Hampsher-Monk, 1992). The inventiveness needed to philosophically come up with such a contract, the voluntary trading of freedoms for security from violence it imagines, and respecting this contract in reality thereby all follow precepts of the commercial syndrome, or, said differently, befit the homo economicus (Foucault, 2003: 196). That social contracts never mention borders can be expected when they derive from networking traders as well. Yet, this lack of territorial fundaments becomes harder to understand when you consider that nation-states were instituted based upon them.

And the nation-state implies a "territorialization of social relations within state borders according to the 'rational and political principle of unification, which subordinates and totalizes the various aspects of social practice [within] a determinate space"” (Lefebvre, 1991: 281; Brenner, 1998: 468). According to Andersson (1996: 141) this formation of the modern state also involved "a territorialisation of politics, with a sharpening of differences at the borders of states and of nations between 'internal' and 'external'” (Faludi, 2013b: 129). No wonder that when Ruggie (1993) contrasts this modern system with the medieval one, "the distinctive feature of the modern state system of rule is that it 'differen- 
tiated its subject collectivity into territorially defined, fixed, and mutually exclusive enclaves of legitimate domination"' (Ansell, 2004: 3). Moreover, with this downwards swirling and unified subordination and totalisation within fixed circles came specifications in what can be called "territorialism", that is, the organisation of the whole macro social space in specific "units such as districts, towns, provinces, countries and regions" (Scholte, 2000: 47; Faludi, 2013a: 1595). While this displays the territorial logic most familiar to us, as shown and mentioned above (Figure $2(\mathrm{c})$ and $\$ 2.4$ ), in terms of the guardian and commercial syndrome, it also shows that the territorial affairs became more multifaceted with the nation-state than in the feudal and royal centralised state systems.

We can for instance now already start to imagine that the nation-state does not necessarily lead to logical affairs for territorial guardians, possibly quite the opposite due to the spiritual and commercial origins of the territorial logic involved. A centralised territorial guardianship then namely does not only unify and specify to encircle and set circles, cones, and encirclements for commerce, but also on the basis of a way of thinking that follows the precepts of-not the guardian, but - the commercial syndrome (i.e. the homo economicus' contracts) (see \$4.3). This could remind us of that Jacobs (1992) foresees disasters with guardian/commercial hybrids (also see \$4.4). In the European Union the territorial logic becomes even more confusing though, because this territorial logic of the nation-state does not hold anymore, at least not exclusively (see \$2.5).

For the territorial logic of the European Union, Ansell (2004: 227) poses that its variable geometry (e.g. different territorial systems and scales for different tasks) reveals weak territoriality at best. Yet, when the rule involved is added to the one of a nation-state, you can also wonder whether its territoriality is then merely weak relatively seen, even if the European Union would undermine the territoriality of the nation-state. Besides, even "if the state were to lose its monopoly of internal and external violence, it would still be a much more coercive organization than any political form in the Middle Ages" (Axtmann, 2004: 124-125). What is more, less of such rule according to the guardian syndrome does not automatically mean less rule in total, as rule according to the commercial syndrome can increase. From the European history sketched above then comes the question to us whether the same can apply for the rule in territorial affairs. In the history towards the European Union we namely see an ascendency of the role of the commercial syndrome in them. We thus already start to identify oppositional guardian and commercial behaviour in the previously existing territorial affairs through which those of the European Union work.

\subsection{An Alternative Way to Look at the Territorial Affairs of the European Union}

Hence, when we now look at the territorial affairs of the European Union, they might still be complex, but with Jacobs' (1992) guardian and commercial systems of survival we do have an alternative way to look at their fundaments. Understanding these affairs more thoroughly in the simplest forms for territorial 
basics (see $\$ 2$ ) with the syndromes makes the complicated territoriality involved easier to grasp too. That is to say, when considered from the viewpoint of the guardian syndrome alone, the European Union's territoriality might seem to work in puzzling ways. However, with the syndromes of survival as a heuristic tool, we can try to get to the underlying essentials of the territorial logic involved by also taking the commercial syndrome into account. Our familiarity with both using these syndromes as heuristic tool to understand territorial affairs more thoroughly and already identified guardian and commercial behaviour in the previously existing territorial affairs will thereby also make the particular place we give to these oppositional behaviours in the territorial logic of the European Union more easily comprehensible.

\section{Solving the Territorial Puzzles in the European Union with Commercial Territoriality}

\subsection{Towards the Market of Territories}

The complicated territoriality of the European Union is easier to understand when its territorial affairs are portrayed as a market of territories, as done below. This would entail a more fundamental reconfiguration in European territorial affairs than simply the continuation of the ascendency of the commercial syndrome within them (see \$3.4) though. To get to this market, we will first put the movements of the base figures in the European Union in our mind, after which we will see how non-territorial ways of doing rule territories today. Such an attempt namely links two orderings of the social world that exist simultaneously, but have different logics and can hardly be seen both at once. We therefore face a kind of Gestalt-switch between territorial and non-territorial rule (\$4.2); what at the end leads to a complication for seeking to answer the question of who the "someone" is that rules a territory these days as well (see \$2.2). Our main point is then not so much that non-territorial rule holds sway over territorial rule, but that territorial rule is also carried out according to the commercial syndrome, that is, with a traders' territoriality and its commodification of territories (\$4.3). This thus entails a fundamental reconsideration of the guardian and commercial syndromes, their division of labour, as presented by Jacobs (1992), as the guardian one came into existence for organising and managing territories (see \$3.2). And even though the traders' territoriality already complexes who the someone is that rules a territory, the argument below is that to understand the territorial affairs of the European Union we have to take the dynamic between the guardian and commercial syndromes that develops within them into account as well (\$4.4), due to which we will henceforth critically differentiate territorial affairs “in” and “of" it, just as the ensuing cognitive dissonance (\$4.5).

\subsection{Linking the Gestalt-Switch of Territorial and Non-Territorial Rule}

Guardian and commercial behaviours differ (see $\$ 3.2$ ), even oppose each other 
in how they treat space (see \$3.3), and the role of the commercial syndrome appears to ascend in European territorial affairs before the European Union came into being (see $\$ 3.4$ ), while these affairs were solely the guardians prerogative. Yet, to understand how this plays out in the much more complicated territorial affairs in the European Union today, we first need to take a step back due to the non-territorial background of the commercial syndrome. Besides that concrete spatial reality is not territorial in nature, neither the real-life experiences of people in social space are namely predefined according to territories, with their fixed borders that define the reach of the authorities responsible (Scholte, 2000; Rosenau, 2004: 35; Delanty \& Rumford, 2005: 123; Faludi, 2013a: 1595). Faludi (2013a: 1601) even holds that " $\mathrm{t}]$ he networks in which citizens live cannot be contained." Social space can thus be seen as a social construct, both with territories and networks (Haughton et al., 2010: 52; Faludi, 2013a: 1594, 1595), due to which it cannot be "understood in terms of territorial geography alone-not in terms of districts, towns, provinces and so forth" (i.e. territorialism) (Scholte, 2000: 47; Faludi, 2012: 204). Then again, we could argue this has always been the case and that social space cannot be understood without terms of territorial geography either.

Nevertheless, Scholte (2000: 47) holds that "current history has witnessed a proliferation of social connections that are at least partly [detached] from a territorial logic of [territorialism]" (Faludi, 2013a: 1600). Laffan et al. (2000: 29) put it even stronger by stating that these days "the congruence between bounded territory, identity and function is being eroded" (Faludi, 2003: 129). To then understand social space, Dangschat (2006) argues to conceive it "as a jumble of overlapping networks" (Faludi, 2013a: 1601; Faludi, 2013c: 6). We thereby encounter a relational space of continuous flows of people, resources, and knowledge (Davoudi \& Strange, 2009: 38) that coalesce, interconnect, and fragment (Urry, 2000; Richardson \& Jensen, 2003), a space where "each area [forms] the point of intersection of numerous configurations" (Faludi, 2013a: 1594). Obviously, to control this non-territorial social space, a form of territorial rule would not seem to match that well.

What then comes in handy is that, as shown above (see $\$ 2.4$ ), systems of rule do not only not need to be territorially fixed or entail mutual exclusion, but, first of all, "systems of rule need not be territorial at all" (Ruggie, 1993: 149; Mamadouh, 2001: 422). To understand how this returns for our interest in territorial affairs, Taylor (2007) directs us to a useful Gestalt-switch ${ }^{8}$ with the example of two spatial interpretations of globalization. One can namely see it either as "up-scaling" or as "intensified networking", while globalization incorporates both. His point then is that the starting point used conditions what you will see: "analysing globalization through geographical scale maintains a territorialist position to the detriment of the intensification of flows that is globalization" for in-

${ }^{8} \mathrm{~A}$ Gestalt-switch means that in a single pattern you at one time see one form/shape and another time another form/shape. The pattern itself does not change, but our perception of it. A well-known example is Jastrow's (1899) duck-rabbit figure. 
stance (Taylor, 2007: 148). This duo sounds familiar to us, as it follows Jacobs' (1992) two systems of survival (see \$3.3) that can also be used to differentiate rule according to the guardian syndrome meant to control territories (e.g. encircling against dissent) and rule according to the commercial syndrome to control trade (e.g. networking against deception) in market places. Below we can thus use these systems as heuristic tool to recognise territorial and non-territorial commercial logics of rule respectively.

Seeing in this double way allows us to build upon what Faludi (2014: 182) says about representative government: it "may lead to the construction of make-belief worlds", because it requires putting clear choices "before territorial constituencies as the ultimate arbiters, through the electoral process, of policies" (Faludi, 2014: 182). This would namely assume that "present-day reality could continue to be contained with the existing territorial-administrative complex" (Faludi, 2014: 182). After the above, we can then see the possibility for the existence of a-not territorial, but-commercial-administrative complex as an alternative. But how would commercial rule in such a way enlighten the territorial besides non-territorial affairs in the European Union?

Here we will start to explain this by going through what one might call a continuum of territorial to non-territorial rule in the European Union, while seeing them with the double, or rather: splitting, light of the systems of survival. To begin with territorial rule, again (see \$3.4), the nation-state government’s control is diminishing, relatively at least, through European integration and regionalisation and the application of state power is thereby changing (Faludi, 2014: 180). Insofar this with new territorial units and identities challenges the nation-state's "fixed envelope of all major aspects of social and political life" and its sovereign control over it, the challenge remains territorial (Faludi, 2014: 180, 181). A territorial rule then appears that goes against the nation-state and its hierarchy.

What is more though, more diffuse forms cross-cut the nested hierarchies in the European Union. " $[R]$ elational tunes in the deliberations on regions" for instance came up in the 1990s (Jones \& Paasi, 2013: 2; Faludi, 2013c: 8), soon followed up by the European Union sponsoring co-operation between cities across national borders, what according to Jensen \& Richardson (2003: 84) suggests "the emergence of crack and holes in the established territoriality". Faludi (2014: $180,181)$ sees this as "negotiated territoriality", that is, control over territories must be negotiated, reflecting "the reality of an interconnected world". The new kind of territorial rule involved thus appears not only to challenge the nation-state's hierarchy, but through negotiated interconnections, a networking that is, also an aspect of the guardian syndrome in general, its hierarchy to be exact.

However, the essential step for seeing how commercial rule enlightens the territorial affairs in the European Union is of course the step towards rule with a non-territorial logic. Here we see the meaning and importance of geographical space changing with, in Olsen's (2002: 926-927) words, "the growth of functional networks with no centre of final authority and power [while] non-territorial 
forms of political organization" have increased (Stone Sweet \& Sandholtz, 1998; Kohler-Kock \& Eising, 1999). Challenges to the nation-state thus also come from "non-state actors, including public and private service providers exercising control over resources and people in ways where functional logics dominate over territorial ones" (Faludi, 2014: 180). And again (see \$2.5), some theorists therefore proclaim an accelerated unbundling of territoriality, towards a postmodern political space without independent statehood and with multiple and overlapping sovereignties (Andersson, 1996; Jensen \& Richardson, 2003). Our point here though, is that the challenging territorial and non-territorial rule both work in the same direction, with networking against the territorial logic of the modern state system that is. Instead of a hard Gestalt-switch between territorial and non-territorial logics of rule, this opens up a passage from the latter to the former. In which way this networking-passage is taken then forms the linkage between both.

We can look at what political economists say to broadly see in which way in capitalism the usage of guardian rule by commercial rule has linked the territorial and non-territorial Gestalts, as traders network too, to deal with space for instance (see \$3.3). In Harvey (1982: 423) our contrast between limited territories and unlimited networks (see $\$ 3.3$ again) returns when he poses that capitalism, which is at least primarily an economic system (e.g. with public debt and equity markets), has continually modified arrangements to assuage and contain the tensions between fixity (e.g. borders) and motion (e.g. flows). Its market exchanges namely come with capital as a set of social relations (e.g. determining when a tool counts as capital) that, following Jessop (2002), requires regulation for its reproduction. A mode of regulation then helps to secure the structural coherence in managing the internal contradictions of capitalism (e.g. paying labourers less, for profit, leads to decreasing demand for goods, against profit), and as social fix it includes a spatio-temporal fix (Jessop, 2002). The spatiality of this fix is of course especially interesting for us.

When we follow Jessop (2002) further, the spatio-temporal fix namely becomes the framework of also spatial boundaries in which an accumulation regime co-evolves with its mode of regulation. We could then say that a spatial form of rule limits commercial rule in institutionalised practices and rules. This accumulation regime and mode of regulation namely depend upon a spatial fix that facilitates the securing of structural coherence by delimiting the accumulation and regulation (Jessop, 2002). Our focus then is on that, according to Jessop (2002), this spatial fix comes to embody the institutionalised compromises of capitalism in the effort to strategically coordinate accumulation, state activities, and social formations for it. That is to say, non-territorial commercial rule does not only depend on territorial guardian rule, but uses it for ruling spatially as well.

Besides, according to Harvey (1982: 423), for capitalism to work, the local needs to be linked with the achievement of abstract labour on the world stage, which (first) led to nested hierarchical structures. Capitalism's internal contra- 
dictions namely cannot be solved in the abstract (e.g. when nothing can be externalised and e.g. the decrease in labour costs equal the decrease in demand for goods), but only partially and provisionally in particular contexts (Jessop, 2002). No wonder that guardian territorial rule is used for that, as it is specific and hierarchical through encircling (see $\$ 3.3$ and $\$ 2.3$ ).

Note that the primary scales used thereby vary over time (Jessop, 2002). Brenner (2004: 141) hereby more than a decade ago already held that "the process of capitalist urbanization has expanded to encompass not only individual cities and towns but also large-scale urban regions, cross-border metropolitan agglomerations, national city-systems, and supranational urban hierarchies." We can thus imagine that through the remaking of urban governance as state rescaling in the European Union (Brenner, 1999, 2004), commercial rule uses the borders and scales of territorial rule to secure structural coherence of accumulation and regulation in specific spatial contexts.

The Gestalts of territorial and non-territorial logics of rule seem thus to be linking (e.g. mingle) in the European Union. While regionalisation and European integration challenge the territorial rule and hierarchy of the nation-state, networking territorial rule challenges guardian hierarchy in general and functional networking the guardian encircling involved in territorial rule. This then opens up a networking-passage between the logics of territorial rule and non-territorial rule, one which commercial rule takes to secure capitalism's structural coherence in specific spatial contexts through territorial rule. Hence, the complicatedness of answering the question of who the "someone" is that rules a territory today, since commerce-if not solely, then at least also-uses territorial rule or might even become territorial by limiting spatially. And this is important for understanding the complicated territorial affairs in the European Union, because it would for the essentials of the territorial logic involved mean that the rule to control trade enters the rule to control territories.

For now though, we more ponder over that no sharp Gestalt-switch is needed anymore to go from seeing territorial to non-territorial rule. We specifically wonder what happened to the contradictions between the precepts of the guardian syndrome, meant to deal with territories, and the commercial syndrome, meant to deal with trade. Because above, both appear to merge with networking, as shown by the usage of guardian rule by commercial rule. Yet, we can only treat these contradictions in the territorial affairs in the European Union (see $\S 4.4$ ) when we first portray the market of territories. We namely seem to be experiencing more than merely an unbundling and re-bundling of territoriality in the European Union (see \$2.5) today, the formation of another territoriality, a commercial one, that is.

\subsection{Commodifying Territories for Market Exchanges with a Commercial Territoriality}

When we tried to picture the territorial affairs of the European Union in simplest forms, we through mind-bending puzzlingly came up with multiple terri- 
torial levels, but different territorial scales on the same level, a highest level that territorially frames policies, but for political decisions and implementation of policies depends on the territories of its member states, and the functioning of both changing and overlapping territories (see $\$ 2.5$ ). Now, this image of what we could together call fluctuating, mediated, flexible, and multiple territoriality respectively, became even more complex when seen through the light of territorial guardian and non-territorial commercial logics of rule (see \$4.2). The often national hierarchy of territorial guardian rule is in the European Union then challenged by networking territorial rule, its encircling by functional networking, and the usage of its territorial rule by commercial rule. Considering that this makes the territorial affairs in the European Union even more complicated than as we pictured them before, we might start to wonder in which way further usage of Jacobs' (1992) guardian and commercial systems of survival as heuristic tool can help us to get to the underlying essentials of the territorial logic involved for an easier understanding?

Remember that guardians want to simplify to control space (see \$3.3). Taking both systems of survival into account then showed us in the above (see $\$ 3.5$ and $\$ 4.2$ ) how, especially when seen through the eye of guardians, territorial affairs became more complicated. But what if it is not the guardians' world anymore and commercial ways of thinking dominate today? Above we for instance understood that already nation-state development did not lead to logical affairs for territorial guardians (e.g. as they are philosophically based on contracts; see \$3.4). Taylor (2007: 148) also considers "contemporary Western societies [to] be essentially 'urban societies', and do note that he sees cities as constellations of commercial practices. Plus Jacobs (1984: 32 ) argues that only cities" generate the economic forces that "shape and reshape the economies of other communities" (Taylor, 2007: 139). And as complexity is innate to the world of market exchanges (see $\$ 3.3$ ), traders might thrive in it, also when it concerns complexity in territorial affairs.

Modernity might then not so much have been "premised upon a guardian taming of cities" - a nationalizing of the urban through containment in nation-states through the twentieth century-as Taylor $(2007: 141,142)$ holds, but instead by an urbanisation, or rather: commercialisation, of the state. When Taylor (2007: 147) in the end dooms "the modern modus operandi of city/state relations that has evolved over half a millennium", we therefore wonder whether these relations did not exists thus or that that modus operandi vanished a long time ago. Instead of continuing further in the blind ally of understanding the territorial affairs of the European Union through the eye of the guardian, even though this syndrome revolves around controlling territories, we will further thus see how much simpler it looks through the eye of the trader below.

Many precepts of the commercial syndrome (see \$3.3) lead us, in contrast to the opposing guardian precepts, to see the complicated territorial affairs of the European Union mentioned above (see $\$ 2.5$ ) in another way. While pointing this out below, also by literally underlining these precepts, we will first go into 
the flexible territoriality of these territorial affairs $(\$ 4.3 .1)$, because it is most essential, as one could argue that when people do not follow set borders, there are no territorial affairs to speak of (see $\$ 2.5$ ); it is therefore not surprising that most of the syndromes' opposing precepts can be associated to this feature without (too) much speculation. Their multiple and fluctuating territoriality will be treated next $(\$ 4.3 .2)$, as they are concerned with what would immediately derive from such set borders, the "someone" that rules a territory that is. The fourth feature of these territorial affairs, mediated territoriality, then concludes how the other features face-off $(\$ 4.3 .3)$. In doing so, we argue that when territorial affairs are carried out according to commercial precepts, commercial territoriality commodifies territories into a market (\$4.3.4).

\subsubsection{Flexible Territoriality for Task-Led Enterprise}

First of all, to control territories, guardians first have to obey set borders. Traders on the other hand use initiative and enterprise for profit, and could consequently more follow borders that increase yields than simply follow borders because they are set. Nowadays, in global transactions for instance, "place' is not territorially fixed, territorial distance is covered in effectively on time, and territorial boundaries present no particular impediment” (Faludi, 2013c: 7). Instead of being loyal as a guardian to an authority, including its official territorial limits, traders therefore dissent for the sake of the task. This task-led enterprise plays a central role, as tasks differ, and different tasks may also need different limits.

The guardians' all-encompassing boundaries thus "have been replaced by shifting borders that delimitate variable territories" (Mamadouh, 2001: 34; Faludi, 2013b: 1309). Traders namely do not adhere to traditional limits as guardians do, but must be open to inventiveness, also, arguably, when it concerns the creation of new territorial constructs; territorial constructs, as what is created is not always and does not always need to be a territory (see \$4.3.3). Instead of honouring territorial limits for the territory's sake, or simply accepting them fatalistically, territorial parcels should then be made to function efficiently for the credited task, for which traders can optimistically enhance or use redrawn borders. Following the commercial syndrome in territorial affairs therefore does not so much lead to, in Amin's (2004: 33, 34) words, “a world of nested or jostling territorial configurations, of territorial attack and defence, of scalar differences, of container spaces". Instead, it would lead more to the production of a world of "cities and regions without prescribed or proscribed boundaries" (Faludi, 2013b: 1306). Or, said in a more affirming way through the trader's eye, the flexible territoriality of the European Union gives room for initiative to enterprisingly use territories and inventively create territorial constructs that function efficiently for profitable tasks.

\subsubsection{Multiple and Fluctuating Territoriality for Trading Room}

Multiple and fluctuating territoriality result from the above shown flexibility (see §4.3.1). When tasks define territorial constructs and with multiple tasks at hand, 
they will already overlap. While guardians shun trading, because it could corrupt territorial exchanges and thus (the firmness of) borders, when one trades, one, needless to say, comes to voluntary agreements. Voluntariness in territorial affairs could then ground that there is not a single encircling from one "someone" within a space, but numerous ones to pick from. Dangschat (2006) for instance argues for an understanding of space as overlapping networks instead of as contiguous jurisdictions (Faludi, 2012: 206). Yet, one could say as well that jurisdictions also overlap when there are numerous territorial constructs covering the same space for different tasks.

When Dangschat (2006) further replaces the "container view", where with contiguous jurisdictions "responsibility ends at the border" (Faludi, 2012: 206), this could thus also hold for that multiple territoriality. Indeed, instead of being exclusive as a guardian, traders collaborate with strangers, which in territorial affairs could lead beyond responsible collaboration that crosses borders towards even seeing borders as opportunities for cooperation. In fact, Mamadouh (2001: 34) says that in the European Union "borders are not conceived as dividers any more [, but c] ross-border co-operation is stimulated" (Faludi, 2013: 1309). We could even follow Healey (2010:32), in that those with stakes in a place, such as local residents and a specific administrative-political jurisdiction as the familiar stakeholders, may come from other places as well (Faludi, 2012: 207). If we see the always existing external links that can create what some call "soft" spaces (Allmendinger \& Haughton, 2009, 2010; Haughton et al., 2010; Faludi, 2012: 205-206) and numerous optional territorial constructs providing many borders as opportunity through the traders' eye, we can look forward to the multiplication of collaboration possibilities beneficial for trade.

With so many overlapping territorial constructs with which every collaboration can make new borders, the question becomes what organisation these countless changing constructs have. Differentiating in scale, which comes with territories as their size (see $\$ 2.3$ ), could order them. For traders this comes with a benefit, because, according to Taylor (2007: 141), multi-scalar in itself equals a very porous container, making their limits less fixed and more flexible too. Also the drawing of boundaries can then jump scales; and more scales leads to more flexibility and more opportunities for this jumping. Hence, just as traders can see borders as opportunity for beneficial territorial collaboration, they can see jumping scales as profitable option in their task-led enterprise too.

Do note though, that where guardians much respect hierarchy of dominance between territorial scales, traders would not, what still leaves it open what organises territorial affairs beyond a hierarchy of incorporation with (possibly) many and changing scales. Healey (2010: 226) gives us an idea when she states that "it is important to move away from conceiving [people's] relations as a kind of nested hierarchy of systems" and towards imagining these systems "as overlapping, loosely bounded and loosely coupled sets of relations" (Faludi, 2012: 207). Although this does not give use much organisational direction, territorial systems with loose sets of relations can loosely scale territorial levels, even when 
this concerns encirclings ${ }^{9}$ for the same task, what can lead to several scales per level (e.g. a nation-state on a par with a city). The traders' lacking respect for hierarchy thus opens the door for a fluctuating territoriality.

Traders do respect contracts though, and these could organise territorial affairs without ordaining them hierarchically. What is more, this might leave these affairs without an order altogether, as contracts are voluntary, can be changed, depend upon the task at hand, and make the parties signing it equal (i.e. many, changing, and perspectival orders). In the European Union this returns in France for instance, with their covenants between the state and region (contrats de plan Etat-Région) and tripartite contracts, including the (local) community, which are also linked to policy for the European Union level, the European Spatial Development Perspective (CEC, 1999) that is (Faludi, 2004a: 1351). Although this aligns with what Faludi (2014: 180) calls "negotiated territoriality" (see $\$ 4.2$ ), as contracts can record the outcomes of (obligatory) negotiations about the control over territories, neither the encircling itself is nor works through negotiation, due to which we would not label it thus (yet). Still, traders can organise multiple and fluctuating territoriality without having an order that inhibits trade, because contracts organise territorial affairs and room for trade together. The European Union would thus with contracts not order but organise territorial trade affairs.

\subsubsection{Mediated Territoriality for a Market}

Following the commercial syndrome in territorial affairs would from the above (see $\$ 4.3 .1$ and $\$ 4.3 .2$ ) lead to flexible territoriality for task-led enterprise and multiple and fluctuating territoriality to organise room for the border-crossing and scale-jumping territorial trade involved. In the European Union this business has limits of course, as it has a territorial outside. One could then argue the European Union level as highest scale contains all these territorial affairs, as they take place at lower scales. However, besides that such a broad scale could also mean a weak containment, the European Union level does not have an own "container" either, as it has no own territory of course. Commercial precepts can also be followed for the way in which this non-territory with a territorial outside works in territorial affairs though.

Arguably, the European Union's mediated territoriality adds a level of abstraction in territorial affairs that makes territorial rule flexible, multiple, and fluctuating. Instead of a zero-sum game, where guardians take vengeance for territorial loss, the logic is the one of a market in which territorial constructs are made and enhanced to compete. Davoudi \& Strange (2009: 38-39) come close to this point when they say that space "can be seen as both a nested hierarchy with fixed boundaries determined by movements, networks, nodes and hierarchies as well as an interconnected web with contingent boundaries, constantly territorialized, and a site of political contestation" (Faludi, 2012: 206; Faludi, 2013a: 1601).

${ }^{9}$ This word does not exist, but we still use it, as we do not want to denote more than one encirclement, the plural of the noun, but more than one encircling, the plural of the verb we use as a noun. 
When we link the Gestalt-switch between territorial and non-territorial logics of rule though (see $\$ 4.2$ ), we see an encircling of networks that with their movement and nodes leads to constant re-/territorialisation, which is a site that looks more as economic competition than as political contestation. The abstraction leading to this makes sense, because the commercial syndrome is not for controlling territories themselves, such as a territory of the European Union's would be, but for controlling trade, and thus also for controlling trade in the market of territories portrayed above.

The European Union's territoriality therefore is not meant to control territorial affairs directly, but indirectly to rule them as one rules a market; just as one rules trade with product requirements for instance. And insofar the geographical extension of this market is called a territory, it surely "differs from the territory of the state", what is also shown in that it expands "without threatening other states" (Mamadouh, 2001: 433; Faludi, 2013b: 1309); although some people and/or states might, rightly or wrongly, feel threatened nonetheless (e.g. as with Russia, Ukraine, and Crimea in 2014). In that way, there is no prowess exerted as guardians do and force is shunned. Hence, instead of having and taking territory for which force is needed more or less directly (e.g. to protect it), territorial affairs of the European Union would then be mediated by the usage of a market territoriality.

\subsubsection{Constructing Territories as Semi-Finished Products for Commodification to Market}

With the above we argue that when seen through the eye of the trader, the European Union's complicated territorial affairs (i.e. combining no own territory, multiple levels, various scales per level, overlapping territories, and flexible borders; see \$2.5) simply looks like a market of territories, formed with flexible (see $\$ 4.3 .1$ ), multiple and fluctuating (\$4.3.2), and mediated (see $\$ 4.3 .3$ ) territoriality, what we can together call "commercial territoriality". And this also entails a commodification of territories for trading. Although such a commodification appears to go against the guardian syndrome, according to Soja (1971: 9), "Western perspectives on social organization are powerfully shaped by the concept of property, in which pieces of territory are viewed as 'commodities"' (Elden, 2010: 805; Faludi, 2013b: 1303). Then again, the commodification of territories with a commercial territoriality would go beyond merely the ownership of territorial pieces and towards turning their encircling utility to profitable advantage in competitive trade. For this, they are demarcated according to task, and collaboration is played out for trade constantly. That is, while territories were thus always socially constructed, these days they can be seen more as-if not continual work in progress, then at least-a semi-finished product than an endproduct as base to start from (e.g. for making territorial constructs).

In that case both territorial and-if not non-territorial in general, then at least-commercial affairs would be conducted with the commercial syndrome, while the guardian syndrome would have no role (see $\$ 4.4$ though). In this light 
we can revisit what Taylor (2007: 141) declares, that is, "[g]uardianship in its modern guise deals [with] security, discipline, regulation, orderliness and order", whereas tradership "is associated [with] danger, liberty, emancipation, ambivalence and chaos". We could now namely pose that the European Union's territorial affairs are chaotic, with many, overlapping, and changing territorial constructs on multiple levels, and ambivalent, by setting moving limits and porous boundaries, separating to unite, levelling to fluctuate, organising without order, and territorialising without territory, for the reason of commerce. Hence, when we use Jacobs' (1992) systems of survival as heuristic tool to understand the territorial affairs of the European Union, the essentials involved become easier to grasp, because after thorough reflection a clear territorial logic comes forward through their complicatedness. That is say, they show a fundamental reconfiguration towards a market of territories with commercial territoriality.

Then again, Taylor (2007: 141-142) also warns that although commercial territories (note that for him this are cities only and we can see beyond these) in globalisation "are becoming free from a one-scale world", they do not become "free from a need for guardian practices" (Taylor, 2007: 141-142). The portrayed market of territories nevertheless shows no guardian, no (central) "someone" ruling territorially, what poses the danger that no one rules it, with lacking security, discipline, and regulation as a consequence. Commercial territoriality seems then to fare without a leader and to follow the emancipated logic of the horizontal exchange of trading, which always entails more than one that defines what happens (i.e. no leader). Indeed, why bother to have such a guardian someone, when traders are free to manage their territorial affairs according to their own system of survival as shown above?

\subsection{Seeing the Territorial Affairs in the European Union with a Commercial Territoriality}

Notwithstanding the commercial territoriality we exposed above (see §4.3.4), within the European Union, territorial affairs are also carried out according to the "old fashioned" ways of the guardian syndrome, an encircling with set and hierarchically nested territories amongst others. Moreover, we can only understand the territorial affairs of the European Union when we take other territorial affairs within it, such as national guardian ones, into account as well, because they for starters form an essential part of them when involved in the European Union's mediated and fluctuating territoriality. But when we then use the reconsidered guardian and commercial syndrome as heuristic tool to understand how both are abided by and lived up to in territorial affairs, such as the ways of territorial constructing they entail, this makes it even more difficult to picture the basics involved in simplest forms, let alone to answer the question of who the "someone" is that rules a territory today (e.g. a guardian or traders). To follow Jacobs (1992) and say that human affairs are conducted in the ways of the two syndromes is thus one thing, but to go further and say that even territorial affairs, formerly a prerogative of guardians, are conducted in both ways is funda- 
mentally something else indeed.

To peak a little forward already, this duality, or rather: ambiguity, might also increase chances on that there will be hybrids of guardian and commercial rule, what could according to Jacobs (1992) be disastrous due to the involved corruption of the integrities of the two moral systems this implies. We then see how the ambiguity of having both systems conducting territorial affairs in the European Union would lead to the systemic corruption of the guardian and commercial syndrome (see \$4.5). The more so because it is territorial rule that bases both, either positively in an explicit way (i.e. guardians are defined by ruling territories) or negatively in an implicit way (i.e. traders are thus defined by not ruling territories). That is to say, what happens in these territorial affairs in the European Union seems to hint at a more fundamental process.

The commonality between the hybrids of the guardian and commercial syndromes mentioned above (see \$3.2), which were a state directing economic change and a mafia controlling territory for profit (Taylor, 2006; Taylor, 2007: 137), is then noteworthy for the direction of our attention. While in the former a territorial organisation is mobilised for economic objectives, in the latter an economic organisation uses territorial means to further its intentions, that is, in both guardian encircling behaviour (i.e. territoriality) functions for commercial purposes (i.e. economics). We can then start to wonder whether commercial territoriality in the European Union leads to systemic corruption in the territorial affairs within it in the same fashion. We should take some steps back before we can even hesitantly begin to answer this question though. We namely first have to overview the guardian and commercial territorial landscapes (\$4.4.1) and have the building blocks and structure of the territorial affairs in European Union in sight (\$4.4.2) to describe the associated dynamics between the syndromes (\$4.4.3) and what this in general entails for these territorial affairs as a consequence (\$4.4.4).

\subsubsection{Overviewing the Guardian and Commercial Territorial Landscapes}

We first note that, of course, "territorial and relational viewpoints are not mutually exclusive" (Faludi, 2013b: 1311). Moreover, one can see "[t]erritorially embedded" and "relational and unbounded" conceptions of regions [as] complementary alternatives, and actually existing regions [as] a product of a struggle and tension between territorializing and de-territorializing processes" (Varrò \& Lagendijk, 2013: 21; Faludi, 2013c: 21). Just as social forces do not only contest through the encircling involved in territorial embeddedness (see $\$ 2.3$ ), they then neither only do so through that plus the networking involved in relational unboundedness either. The point for us here is though, that these networking processes would now do more than de-territorialise only, because they would, however paradoxical it seems at first, also rule territorial affairs. Hence, when (Varrò \& Lagendijk, 2013: 27; Faludi, 2013c: 8) think that the way forward for understanding our spatial affairs is to "think of regions, and by extension, of 
all-thus also national-spaces as constituted relationally through agonistic struggles", we may hold that this agonism does, at least partly, not only constitute territories, but enters the way in which territorial affairs are conducted as well.

But before we will imagine how the guardian and commercial syndromes might ambiguously return in the territorial affairs in the European Union together (see \$4.4.3), we first briefly contrast their territorial logics again to be able to see the dynamics involved with clarity. In the guardian logic the classic notion of territorial construct, that is, a territory, then holds sway: it is an area that has been appropriated, "over which government formations exercise jurisdiction" (Faludi, 2012: 205), "with borders marking the limits of control" (Baudelle et al., 2011: 16; Faludi, 2013b: 1305). Due to this "rendering of 'space' as a political category" (Elden, 2010: 810), "space overall is filled to the brim with such [container] units" (Faludi, 2012: 205) that are "owned, distributed, mapped, calculated, bordered and controlled" (Elden, 2010: 810; Faludi, 2013b: 1305), making space overall "neatly divided, allocated, investigated and taxed" (Faludi, 2012: 205). It is in this order of circumscribed jurisdictions (i.e. territorialism; see \$3.4) that "political and bureaucratic elites rest their case for exercising power" (Faludi, 2012: 205). With the guardian logic, contesting social forces in territorial affairs thus work themselves out through political and bureaucratic elites functioning in a landscape that, seen in most simplest forms, consists of encirclings in nested cones marking areas (see $\$ 2.1, \$ 2.2$, and $\$ 2.3$ ). Again, this (Figure $7(\mathrm{a})$, which is the same as Figure 2(b) and Figure 5(a)) is a traditional picture indeed (see §3.4).

In the new logic of commercial territoriality, however, the notion of territorial constructs differs, in that: it is an area constructed through trade and for task-led enterprise, on which governance formations inclusively exercise jurisdiction, with borders marking opportunities to expand control by cooperative networking. Due to this rendering of space as an economic category, space overall increasingly complexes with ever developing relational units that are owned to be

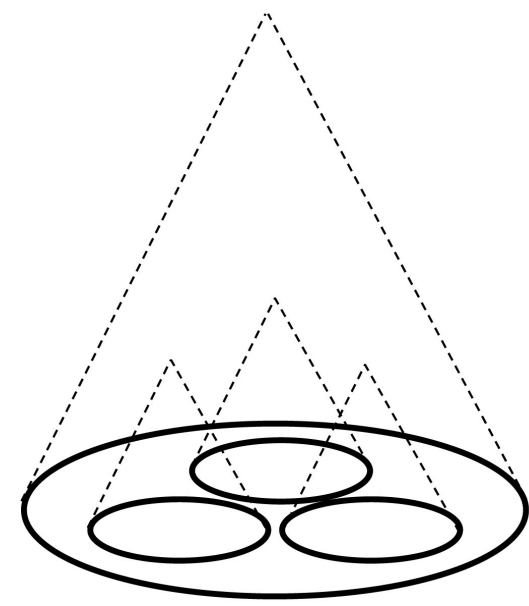

(a)

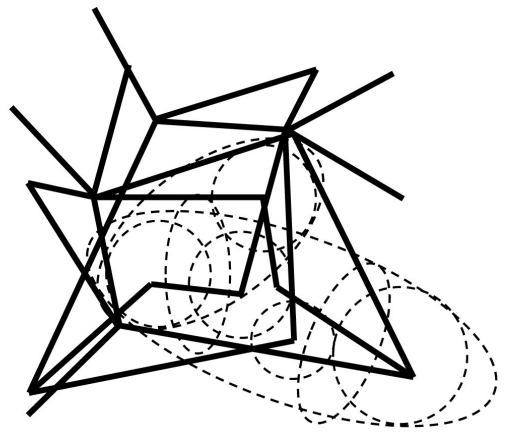

(b)

Figure 7. Landscapes of guardian (a) and commercial (b) territoriality in simplest forms. 
traded, making space chaotically allocated and tangled. Such a juridical organisation of networks' encirclings (see \$4.3.3) is probably less familiar to us.

Also these relational units of networks' encirclings can be distributed, mapped, calculated, bordered, and controlled, opening up this space for investigation (and possibly taxation) too. Moreover, such investigations require a more herculean effort, as with this commercial logic space becomes more intricate. Befittingly then is, that Sabel \& Zeitlin (2010) hold that networked decision-making "often involve[s] technical elites" when compared to territorialism (Faludi, 2013a: 1603). Especially useful for us is that "deliberation involving technical elites, including deliberation on issues transcending boundaries [, has] always been an element in discussions on European integration" (Faludi, 2013a: 1603). With the commercial logic, contesting social forces in territorial affairs thus work themselves out through technical elites functioning in a landscape that, seen in simplest terms, seems to consist of networked encirclings of complexly developing and entangled areal-trade constructs.

In the "old fashioned" state, the technical elites and their role were well known, that is, they were distinguished bureaucrats who, simply put, implement the political decisions taken by the sovereign (Hissink Muller, 2016). For the territorial affairs in the European Union however, that "someone" who hierarchically rules remains hard to find no matter-or arguably: because of-how bureaucratic the make-up of this polity is (Hissink Muller, 2016). Without "someone" making political decisions there would be no demand for implementation by technical elites; what of course begs the question of what their role is. Then again, the intricacy of these territorial affairs does lead to a high demand for technical elites, due to which it could be said that they further their investigative business through commercial territoriality indeed.

The landscape of commercial territoriality cannot really be visualised in simplest forms for instance. When nonetheless an attempt is made to understand the basics involved in that way, both a network and circles are the least to be drawn, just as circles that overlap and join together (Figure 7(b)). Yet, besides that this leaves much outside the picture (e.g. the encircling by nodes, scattered territorial constructs, a dimension to connect overlapping networked encirclings), it is impossible to even sketch the development so essential for networks' encirclings (i.e. inventing new limits instead of obeying traditional ones, e.g. flickering territorial constructs) due to the static nature of such figures. What leaves us in the dark about the ways in which networking and encircling relate in commercial territoriality, what seems to underline our dependency on technical elites, such as those who we might ascribe the vague role of "commercial technocrats", to enlighten us in territorial affairs.

Although the territorial logics of the guardian and commercial syndromes thus come with-if not diametrically opposed, then at least-completely different landscapes (e.g. possible to be captured in a picture or not) in which elites function to work out contesting social forces, the technical elites (yet again) can be seen to form the connection between the two territorialities. The networking 
of both the government bureaucrats and the commercial technical elites would namely link the territorial logics of the guardian administrative state on the one side and commercial territoriality on the other. This linking aligns with how networking rule might open up a passage between territorial guardian logics and non-territorial logics of rule that can be taken by commercial rule (see \$4.2). When these different kinds of rule and territorial logics merge, then not only can both the guardian and commercial syndrome return in territorial affairs, and more or less ambiguously so, but also (various) hybrids of them can. But how, then, does the dynamic between them play itself out in the European Union?

\subsubsection{The Building Blocks and Structure of the Territorial Affairs in the European Union}

To grasp the dynamic between the guardian and commercial syndrome in the territorial affairs in the European Union, we will need to, firstly, see the building blocks and, secondly, the structure involved. We will begin to have a look at the building blocks of the guardian and commercial syndromes in the territorial affairs in the European Union that appear through time from 1952 onwards. It was according to Ansell (2004: 234) namely already since then, the beginning of the European Coal and Steel Community that is, that European integration has "been conceived of in terms of the integration of economic rather than military space." In addition to the already existing national-military, or rather because broader-political spaces ruled with guardian territorial logic, this thus entails a supranational economic space ruled according to the commercial syndrome.

Whether due to this European integration or otherwise, during the 1980s more commercial territoriality developed. According to Brenner (2004: 156), national, regional, and local governments then namely also "introduced new territory- and place-specific institutions and policies [designed] to reconcentrate or enhance socioecomic assets within cities." For us it does not matter much that Brenner (2004: 156) emphasises cities for these assets, even though Taylor (2007: 138) sees cities as constellations of commercial practices. More of interest to us, is that Brenner (2004: 156) says that such territorial institutions "have often been autonomous from local state institutions and controlled by unaccountable political and economic elites". It seems thus that in the European Union new territorial constructs appear, while the unaccountability with which they are ruled makes it hard to identify their "someones". That is to say, on the subnational level both the inventiveness in making new territorial constructs, the control exercised over them by economic besides political elites, and their (thus) inclusive governance formations without hierarchy (e.g. not having a someone at the top) follow the commercial syndrome.

Moreover, Ansell (2004: 234) for the European Union says that the conceptual shift since 1993 "from common market to single market in the Single European Act indicates the movement toward a unified single-point perspective on economic territoriality." While commercial territoriality is of course an economic territoriality, and more (e.g. normative, a life condition), it would be hard to 
understand this single-point perspective as the territorial rule of a "someone", as we have much difficulties in finding such a point. Our alternative reading would then be that this unification into a single market came without a single-point perspective. Instead, commercial territoriality organises multiple perspectives according to one and the same logic (i.e. not a point, but a logic), one with which territorial affairs are regulated as if it were a market, such as those new subnational territorial institutions in the added supranational economic space.

Hooghe \& Marks's (2010) two types of multi-level governance are then useful to analytically structure the territorial affairs in the European Union with these building blocks of, on the one hand, guardian national spaces and, on the other hand, also the added commercial subnational spaces and at least mostly commercial supranational space. Their Type I thereby relates to federalism and Type II to specialised jurisdictions. In Type I every citizen is located in a Russian Doll set of nested jurisdictions, in "hard" spaces, boxes (Hooghe \& Marks, 2010; Faludi, 2013a: 1599), in which we recognise the guardian way of doing. Even if the European Union would also follow this type of governance, its territorial affairs are surely not ruled in a federal way, and this type thus only holds for the member states and their subnational territories, and the latter only insofar the guardian syndrome is followed to rule.

It is nonetheless interesting to think about what Hacker \& Pierson (2002: 303) pose for the United States, namely, that "[o]ne of the distinctive consequences of federalism is the way in which it activates the territorial component of economic interests". It does so by the representation of particular economic interests via a political structure that is territorially based, due to which states where, for instance, the automobile industry is located would surely show their economic interests therein through political representation on the national level; simply put: guardians rule territorially while representing their traders' economic logic. Besides that such a territorialisation of economic interests obviously holds for national federations and their subnational territories (e.g. Germany), this can hold for the European Union as well with the representation of national economic interests on the supranational political level of course; insofar this union regulates a European part of the global market for instance-not to speak of the non-political representation of subnational economic interests on the global market. Yet, while federalism can already lead to this fusion of territorial and economic affairs, and thus to hybrids between guardian and commercial rule, our point is that in the European Union less "hard ways" than federative multi-level governance are enough for this territorialisation of economic interests to occur. Moreover, when it concerns its territorial affairs, we can due to its commercial territoriality also expect a fusing of logics the other way around, that is, an economisation of territorial interests.

What brings us to Hooghe \& Marks's (2010) multi-level governance Type II. They relate this type to specialized jurisdictions whose "number is potentially huge and the scales vary" (Faludi, 2013a: 1599). We recognise both this large number, potentiality, and jumping in scale from the commercial territoriality we 
described above (see \$4.3.2). In first glance such recognition largely continues with that in Type II "jurisdictions tend to be lean and flexible and task specific and their intersecting memberships criss-cross judicial boundaries" (Hooghe \& Marks's, 2010; Faludi, 2013a: 1599). However, we cannot simply see Type II as merely a more general definition of commercial territoriality though, as it shows us a detai ${ }^{10}$ by separating jurisdictional (i.e. the extent of control/authority) and judicial (i.e. belonging to a court/administration of justice) boundaries. These juridical aspects become more far-reaching since both the jurisdictional and judicial relate to the territorial.

We can already clearly notice consequences thereof in the territorial affairs in the European Union due to our usage of Jacobs' (1992) systems of survival. For starters, the judiciary is traditionally based on the state, as the court system that interprets and applies the law in the name it that is. The judiciary then comes with the state's territory, hierarchy, exclusivity, and adherence to traditions, that is, the judiciary thus shows the guardian syndrome. As such, the judiciary protects markets with the guardian's order territorially, what traders need to prosper (see \$3.2); and do note that the Court of Justice of the European Union is not based on territory (see $\$ 4.5$ ). Juridical aspects thus play a major role to understand the territorial affairs in the European Union too.

That said, the two types of multi-level governance of Hooghe \& Marks (2010) already help us to further disentangle these territorial affairs with guardian national spaces and also commercial subnational and supranational spaces as building blocks. It does so in two ways: 1) with the simple structure of Type I and Type II of these building blocks, related to federalism and specialised jurisdictions, for guardian and commercial rule respectively, and 2) by underlining the consequential intricacies of the juridical aspects involved.

A way Hooghe \& Marks's (2010) two types then come to the fore, is with what Rosenau (1999: 292) calls "fragmegration", a simultaneous integration and fragmentation of organisations. Faludi (2013a: 1599) namely links this to "public and private actors [that] collaborate and compete in shifting coalitions" and Sassen's (2006) spaces where the local, regional, national, and supra-national come together as assemblages. For territorial affairs we could see this in the fragmentation of stiff governmental hierarchies, say Type I, into loose parts that form governance assemblages, say Type II, as an integration of units in the market of territories (see \$4.3.4). Do note though, that this is a fundamentally different interpretation than Hooghe \& Marks (2010) give of Type II multilevel governance as resembling pre-modern government (Faludi, 2013a: 1599). While this governance is indeed pre-modern in the sense of that it is not as centralised and large scale (see \$3.4), where then Christian and worldly guardians governed, now the commercial syndrome would namely be followed, even in territorial affairs as well. Hence, the possibility of a territorial landscape where responsibilities are neither competed over nor divided in a hierarchy of nested authorities, ${ }^{10}$ Do note that this now for us comes up as a detail, while for discussions on for instance the Trias Politica it is no detail at all, quite the contrary. 
but are shared (Faludi, 2013a: 1599-1600).

Hence, the use of Jacobs' (1992) systems of survival as an heuristic tool for an easier understanding of the complicated territoriality in the European Union leads to the clear differentiation between two landscapes formed by building blocks structured together. Seen through the lens of the two syndromes, the so puzzling territorial affairs in the European Union namely disentangle into, not surprisingly, two "puzzles": an easy to understand guardian one and a much more sophisticated commercial one. The former namely has a clear-cut amount of centralised (e.g. federal) encirclings of nested cones marking taut national and subnational spaces that are simultaneously jurisdictional and judicial. The later, however, has a potentially huge number of networked encirclings of flexible task specific subnational and supranational trade-jurisdictions that complexly develop and entangle over varying scales and criss-cross judicial boundaries. In the contesting social forces that work themselves out through on the one hand political and economic elites and bureaucratic and commercial technical elites on the other hand, guardian/commercial hybrids can then be identified as a metamorphosis (e.g. a territorialisation of economic affairs and vice versa) in which fragmegration structures stiff pieces of the guardian puzzle into loose and intersectional commercial assemblages that partly integrate in the market puzzle. And it is this disentanglement of the territorial puzzles that finally brings us to the dynamic between the guardian and commercial syndromes in the territorial affairs in the European Union.

\subsubsection{The Parasitical Dynamic within the Territorial Affairs in the European Union}

In general we could now wonder about what in the territorial affairs in the European Union remains to follow the guardian syndrome and what not. We namely already sketched an ascendency of the role of the commercial syndrome in territorial affairs in European history (see \$3.4). The catch for understanding the "puzzles" involved though, is that the easy guardian one and sophisticated commercial one exist simultaneously in the same single socio-spatial space, even for the same parts of it. To understand how this is possible, it is important to remember that these two puzzles show people's patterns of conduct and the logics with which they socially construct them as symbolised spaces (see \$2.2); as centralised encirclings of nested cones marking stiff (sub)national spaces and networked encirclings of flexible task specific sub- and supranational trade-jurisdictions that is. People can namely be flexible in which syndrome they follow in conduct, logic, and symbolisation, and behaviours are not always (totally) in line, just as symbols can (partly) contradict the behaviour they stand for, and both can, of course, contradict logic as well; all of this demonstratively leads to "cognitive dissonance" (e.g. Elliot \& Devine, 1994: 382; Martin, 2018: 183), as shown below for territorial affairs (see $\$ 4.5$ ). The territorial affairs in the European Union therefore revolve around the dynamics between the guardian and commercial syndromes as the two fundamental patterns of conduct for different 
and same parts of social-spatial space.

In addition to the ascendency of the role of the commercial syndrome in territorial affairs, above the dynamic between the systems of survival in general was characterised by calling out the national guardian taming of cities in modernity (Taylor, 2007: 141, 142) and, arguably, stronger commercial taming of the state then (see \$4.3). When this agonistic dynamic continues in the territorial affairs in the European Union, the question is how to characterise the current situation (e.g. as final scene?).

Prescriptively, Taylor (2007: 137, 147) follows the symbiotic dynamic Jacobs (1992) prefers, in that he says, with, again, cities as constellations of commercial practices, that " $[\mathrm{w}]$ hat prosperous cities need is economic autonomy, not political sovereignty". Guardians then protect the order markets need to blossom (e.g. to be secure from physical violence) and traders create the wealth a political unit (e.g. state) needs to remain strong (e.g. through tax revenues). We now know that this modern symbiosis already comes with its hybrids though, such as states directing economic affairs and federalism's territorialisation of economic interests.

Moreover, Faludi (2013c: 11) holds less prescriptively for the "inherently polymorphic and multidimensional" nature of social relations (Harrison, 2013: 71-72), that we need "ever-more-complex configurations in order to make emergent strategies compatible with inherited landscapes of socio-political organization"; emergent jurisdictional strategies could for instance subnationally develop over varying scales and criss-cross judicial boundaries, while the inherited organisation consists of stiff national spaces that are simultaneously jurisdictional and judicial. This need for ever-more-complex configurations then points to that the emerging patterns of conduct Faludi (2013c) describes to deal with, do not fit the inherited symbiosis Taylor (2007) prescribes. And while we thus far merely noticed that the commercial syndrome would suit the complexity of these configurations for commercial strategies and inherited guardian organisations well (see \$3.3), Stone Sweet (2004: 144) even sees a new Lex Mercatoria rising in a reconfiguration of the relationships between states and markets. Below we follow his direction in an attempt to disprove for our focus on the territorial affairs in the European Union what Faludi (2014: 182) says in the general, namely, that "[a]rrangements for dealing with polymorphic and multi-dimensional social relations in a territorial-cum-relational reality are-and are sure to remain-opaque."

More than a decade ago Stone Sweet (2004: 122), then, anticipated traders that govern themselves, and that the institutions that they and (their) lawyers thereby create are "substantially insulated from, while being parasitic on, state authority". The dynamic between the syndromes can then be characterised as a guardian hosting traders that prey upon its political unit (e.g. police protected commerce combined with tax evasion), its corpus that is, which has a territory and thus is territorial as well, while these parasites have their own commercial social 
space shielded from guardian interference too ${ }^{11}$. When it concerns commercial activity, of which much is transnational, political control and sovereignty are thereby "detaching from one another rapidly" (Stone Sweet, 2004: 122) when compared to the model of the Westphalian state (see \$2.5). Simply put, guardians can control traders increasingly less, while guardians keep on hosting parasitic traders.

For territorial affairs this would according to Stone Sweet (2004: 122) mean that space is also "comprised of a patchwork of private jurisdictions, of rules and organizations without a territory", that is to say, as we portrayed above (see $\$ 4.4 .1$, space also comes with a landscape of areal-trade constructs, with territorial constructs that are not "traditional" territories. The point then is that these task specific trade-jurisdictions also base themselves in and on one or more guardian corpora. What is more, traders in that case work in "a system of governance in which national courts and public international law can be used selectively" (Stone Sweet, 2004: 144). And as we may add that taxes can then be selected too, this underlines what Stone Sweet (2004: 144) proclaims: "the sovereign ordained that the sovereign shall no longer rule".

To characterise the parasitical dynamic between the syndromes involved in territorial affairs more precisely below, we thus echo Foucault's (1981: 88-89) advise to cut off the King's head in political theory ${ }^{12}$, leaving us with a headless (royal) body; what makes it difficult to see the "someone" that rules territorially indeed. When we look at the biological basics for that precision, we see that parasitism is widespread in the animal realm, moreover, it is a major aspect in evolutionary ecology ${ }^{13}$. The symbiosis between the guardian and commercial syndrome Jacobs (1992) and Taylor (2007) prefer is then easy to recognise. Long-term coevolution namely "sometimes leads to a relatively stable relationship[,] as, all else being equal, it is in the evolutionary interest of the parasite [(i.e. also read below: trader)] that its host [(i.e. idem: guardian, with its corpus] thrives." This can occur when a parasite becomes less harmful for its host or the host learns to cope with the parasite, even to the extreme that "the parasite's absence causes the host harm." The question of course is whether it is reasonable to characterise the parasitical dynamic between the guardian and commercial syndromes in the territorial affairs in the European Union thus or otherwise.

\footnotetext{
${ }^{11}$ Do note that one could in principle see the host-parasite dynamic the other way around as well, but then with a guardian predator (e.g. who was a raider) sucking "the blood" (i.e. money) out of the commercial corpus with taxes for instance; what might have influenced that according to Foucault the vampire often is portrayed as an aristocrat and the savior as bourgeois (Gordon, 1980: 223). In that case the question of who rules the guardian corpus with what logic becomes the more important.

${ }^{12}$ Note that the focus of Foucault's work underlines this by showing the power at work in, for instance, psychiatry (Foucault, 2006) or prisons (Foucault, 1977), that is, in other realms than the territorial affairs we are interested in. Still, his work is open to our focus on them, as shown by his interest in the intertwinement of the government of self, others, and all (Foucault, 1978, in Burchell et al., 1991).

${ }^{13}$ We follow these basics, also with citations (i.e. those without a source mentioned in the body text), as can be found at: https://en.wikipedia.org/wiki/Parasitism, visited on 30 August 2018.
} 
What then also holds for the guardian and commercial syndromes, is that when "hosts and parasites evolve together, their relationships often change" (see \$3.4). It is important to thereby distinguish the syndromes as general labels for guardian and commercial ways of doing and thinking and the particular guardian corpora and traders involved. That is, both syndromes co-evolved, but there were many and changing traders for each guardian corpus. This is important for their dynamics, because when "a parasite is in a sole relationship with a host, selection drives the relationship to become more benign[,] as the parasite can reproduce for longer if its host lives longer", but "where parasites are competing, selection favours the parasite that reproduces fastest, leading to increased virulence.” And as the commercial syndrome drives on competition (see §3.2), competing traders can thus as parasites speed up the deterioration of the guardian host's corpus.

Traders could then weaken the guardian corpus insofar they become stronger than their host, a more relative weakening shown by companies with more financial weight than states, or receive more from the guardian corpus than it can give, a more absolute weakening shown by states increasing national debt to bail out banks (i.e. a specific type of company). This then means that the dynamic between the guardian and commercial syndromes in the territorial affairs in the European Union does not so much follow the symbiosis Jacobs (1992) and Taylor (2007) prefer. Instead, with their corpora guardians would host traders that as competing parasites weaken their host.

Do note, however, that although traders are insulated from and parasitic on guardian corpora and always use space in a guardian's territory, this dynamic is not concerned with territorial affairs in themselves yet. The commercial syndrome is hitherto namely in no way involved in encircling space through marked cones (see $\$ 2.2$ ), nor in the associated incorporation (see $\$ 2.3$ ) or swirling behaviour (see $\$ 2.4$ ). Insofar traders are then involved in territorial affairs, these are for them far less important and in their own social space insulated from the ones of guardians; just as parasites have a, compared to their (potential) hosts, potentially huge number of flexible task specific encirclings, such as the spaces they encircle to catch a host. The dynamic between the syndromes whereby commercial parasites relatively and absolutely weakening guardian corpora for so far therefore takes place within the context of the simple territorial landscape of a clear-cut amount of encirclings of nested guardian cones marking stiff spaces, while traders thereby parasitically deal with for them relevant affairs that come with these (sub)national territories, but without their own commercial territoriality that leads to a more sophisticated "puzzle".

Nonetheless, that traders relatively and absolutely weaken guardian corpora is relevant for the dynamic between the two syndromes in territorial affairs. What is more, we already come closer to these affairs when we consider that there are not only many, but also changing traders for each guardian corpus. That traders are less tied to a place than guardians are, as Taylor (2007: 139) suggests with their space of flows and space of places respectively (see $\$ 3.3$ ), namely reinforces 
the dynamic described above. That is to say, also "parasites whose reproduction is largely tied to their host's reproductive success tend to become less virulent[,] so that their hosts reproduce more effectively". Now, even though traders need a guardian host with, amongst others, its military, police, and judiciary to have a secure order for market transactions, they are barely tied to a specific guardian corpus or its reproductive success, that is, they are footloose ${ }^{14}$.

Commercial parasites thus do not only relatively and absolutely weaken guardian corpora, on top of that they can also leave a specific one when it breaks down. This gives traders less limits and more room for their weakening of a guardian corpus, as they only have to think of their margins and the costs of such damage for themselves (e.g. investments in real estate for own use). When we consider that traders can change from one guardian corpus to another, we come closer to dealing with territorial affairs, as we do so in a negative way. That is, traders then do not need the stable reproduction of territorial affairs of a specific guardian, moreover, they do not always need specific guardian territorial affairs. The dynamic between the guardian corpus hosting competing and footloose commercial parasites thus less points to a mutually beneficial symbiosis between the syndromes in territorial affairs than one which favours the reproduction of the commercial one over, and to the detriment of, the guardian one.

In biological terms, traders can thus be seen as showing facultative parasitical behaviour weakening one or more guardian hosts, as they can select their host(s) from guardian corpora, multinationals even several at once, and leave a guardian's territory, or even guardian territorial affairs in general, to further their own benefit. Yet, this dynamic between the guardian and commercial syndrome goes even further when traders are positively concerned with territorial affairs, as shown below. This comes with the question of how far traders are endo- or ecto-parasitic, that is, whether they reside within or outside a guardian's corpus, as its political body always comes with the encircling of space through marked cones and the associated incorporation and swirling.

Traders arguably most often reside outside a guardian corpus. Yet, they as more or less footloose ectoparasites can then also profit from their host beyond the security it ensures them without proportional reciprocation (e.g. by creating jobs), this simply by tapping in on subsidies while they operate within a guardian's territory for instance. When traders do reside within a guardian corpus, as shown in lobby groups and inclusive governance structures (see \$4.4.2), especially in the European Union polity with its many governmental and non-governmental centres (Hissink Muller, 2016), they as endoparasites consequentially deal with territorial affairs too. The actions of a political body are namely always inherently territorial, at least as they apply to a certain territorially demarcated jurisdiction. This adds to the parasitical dynamic between the guardian and commercial syndromes, because traders then do not only simply weaken guardian corpora within the context of the simple territorial landscape where

${ }^{14}$ Do note that people that are traders might not be footloose in other aspects of their lives (e.g. their family, friends, house). Yet, insofar the are a trader, they are footloose. 
nested guardian cones mark stiff spaces, but they also at least passively take part in the encircling associated with a political body.

The more striking point is then, that traders can change from ecto- to endoparasite and back when they want to, moreover, they can simultaneously be an ecto- and ectoparasite. How traders come into the guardian corpus could for instance be similar to how parasites are trophically transmitted with food: guardians might have need for more of the traders' finances, who then enter its political unit with or without a "Trojan Horse tactic". The selectivity and fluidity for parasitic traders within and outside guardian copora might however be easier to imagine when one takes social parasitism into account. With social parasitism, the parasite uses the interaction between host creatures to prey on them with the use of, for instance, mimicry (e.g. to be raised within another beehive). Note that the parasite is then more of a similar size as it host, they can even be closely related, to the extreme where social parasitism is intraspecific (e.g. use resources without reciprocation), and that the body in which the parasite enters is a social one (e.g. a superorganism ${ }^{15}$ ). Parasitic traders can thus enter and leave the political body they weaken, something the European Union polity's fuzzy limits between in- and outside (Hissink Muller, 2016) might both portray and advance.

Traders are therefore not only footloose and deal with the for them relevant affairs that come with guardian (sub)national encirclings, but they can passively take part in these territorial affairs in selective and fluid ways too. Hence, the scene in the guardians' simple territorial landscape set for the use of commercial territoriality seems to show dynamics in which guardian corpora appear increasingly weakened relatively and absolutely by parasitic traders inside and on them.

\subsubsection{How Commercial Territoriality Leads to Corruption in Territorial Affairs in the European Union}

The question then becomes what this dynamic of parasitic traders weakening guardian corpora within the territorial affairs in the European Union leads to for these affairs themselves. Parasitism between traders and guardians does not need to imply a corruption of the integrities of their syndromes for instance. Traders might namely benefit from a guardian order (e.g. its judiciary) whilst evading taxes, but in itself this does not lead to hybrids, such as a state-led economy, where encircling behaviour (i.e. territoriality) functions for commercial purposes (i.e. economics). For there to be a territorial hybrid that corrupts the syndromes' integrities, moreover, the dealing with territorial affairs that was previously the guardian's prerogative should be carried out according to the commercial syndrome as well. When we go a bit further in precisely characterising the parasitical dynamic between the guardian and commercial syndromes, we finally reach the point where this more sophisticated commercial territoriality can come into

${ }^{15}$ That is, a group of organisms functioning as one organism, of which the members seldom are able to survive on their own. 
play $^{16}$. This is with how parasites in many ways modify the behaviour of their host(s) when they are inside or tap in on their host; with hormones for instance that make the host less careful and easier caught by a predator that will be the new host for the parasite's next phase in life.

Of course, traders can also modify political behaviour by using their host's corpus with its guardian territorial affairs. One can see this insofar governmental objectives (e.g. economic policies) benefit traders more than they do guardians, especially when these objectives are accepted due to commercial discourses (e.g. on, disputably, bailing out banks because they are too big to fail, have open borders in pandemic times to keep the economy going); one can then see discourses circulating in a political corpus as the equivalent of hormones circulating in an animal body. Besides, we already saw the example of the modern "single" perspective nation-state that with commercial precepts unifies and specifies to set circles, cones, and encirclements in a guardian way for traders too (see $\$ 3.4$ ), and that non-territorial commercial rule uses territorial guardian rule for spatial rule by traders (see $\$ 4.2$ ). When one also sees capitalism, as explained above (again, see \$4.2), in the actions of both the parasites and guardians with their corpora, then the spatial fix of territorial affairs embodies the institutionalised compromises, which try to coordinate accumulation, state activities, and social formations strategically, in the symbiosis between the guardian and commercial syndromes. Although this surely can be seen as the corruption of the integrities of the syndromes, as guardian encircling then functions for commercial purposes, this does not corrupt them in the territorial affairs themselves. It does not do so, because they are then an sich still completely carried out in guardian ways. Yet, this parasitical dynamic of traders using guardian corpora for their own ends does provide a fertile soil for the growth of commercial territoriality.

Traders themselves can of course encircle space in their commercial ways, leading to multiple levels, various scales per level, overlapping areal-trade constructs, flexible borders, and this without an own territory. Yet, to repeat, just as parasites need hosts to survive, traders can only encircle space thus when supported by the guardians territorial order that protects the markets' functioning. In addition to the parasitical dynamic between the syndromes characterised precisely above, however, traders can cooperate and coordinate actions as well-and more people trade than guard (e.g. are self-employed). Besides that this certainly helped the development of the sophisticated landscape of networked encirclings of flexible task specific sub- and supranational trade-jurisdictions, it also enforces the relative and absolute weakening of guardian corpora by parasitic traders inside and on them. What is further intensified by that traders are footloose and not only passively take part in guardian corpora selectively and fluidly, but even modify the guardians' behaviour, including their territorial affairs, too. We thus wonder in which ways commercial territoriality then generated corruption

${ }^{16} \mathrm{We}$ still follow the basics of parasitism, also with citations (i.e. those without a source mentioned in the body text), as can be found at: https://en.wikipedia.org/wiki/Parasitism, visited on 30 August 2018. 
in the guardian territorial affairs in the European Union by growing on this fertile modern soil.

Obviously, it initially grew with the addition of a new supranational scale that incorporated the national guardian encircling into commercial territoriality; something that can be seen as a modification of the guardian political behaviour with a commercial logic that sets the stage for a market of territories as if the hosts are perfectly trapped by parasitic traders through their own encircling (i.e. in both meanings of the word "their"). These guardian corpora with exclusive dominion were namely first at least relatively weakened by a supranational trade-jurisdiction that advances (their) commerce without challenges from other issues (e.g. the environment, labour safety). Later on they were weakened more absolutely too, this by the transformation of many national thus territory-led guardian issues into economic ones through negative and positive integration (Scharpf, 1999), that is, by eliminating these issues' restraints on trade (e.g. labour policy) and even their distortions of competition (e.g. industrial policy) and by including issues in the common policies made for how markets operate (e.g. transport policy) respectively. Without the need to control territorial affairs directly, commercial territoriality then parasitically uses the strict national guardian encircling, and selectively so. This to boundly mediate in the fluid direction of supranational policies (e.g. social policy) of which most are functional, thus often economised if not economic already, but territorially framed as well. Hence, here a territorial hybrid clearly emerges that leads to corruption in the national guardian territorial affairs.

In the market of territories that came up thus, not only national economic interests are politically represented and coordinated on the supranational level, but also a dynamic un- and re-bundling of guardian territoriality is given way such as how commercial territoriality sees fit. Task-led enterprise thereby goes beyond merely variably using the strict geometry of fixed national and later on also subnational guardian territories and scales, as it inventively makes new territorial constructs as well (e.g. cross-border regions); a usage and construction that also overlaps in the fragmegration of these territories in a market when they are restructured into areal-trade constructs (e.g. from guardian regions on national borders to commercial cross-border regions). Commercial territoriality thus parasitically uses directing guardian encircling, and again selectively so, on other levels than the national level too, that, is, the regional and transnational level. Such a fluid (com)modification of hierarchical guardian behaviour of course leads to at least a further relative weakening of their corpora due to commercial territoriality, the more so when commerce instead of territory becomes the selection criterion for when they primarily encircle for themselves or as mediators for trade.

No wonder that this commodification of subnational guardian encircling comes with more territorial hybrids on various levels. The remaking of urban governance as state rescaling is then a pluriform way in which fixed subnational territories, or pieces thereof, are selectively restructured into more flexible urban 
regions or city system. The cooperation between other kinds of, respectively, bordering or separated regions (e.g. Alpine or peripheral regions) leads to similar territorial hybrids, and these ways can overlap as well (e.g. regional cooperation in cross-border urban regions). For both holds though, that the more these areal-trade constructs (e.g. trading best practices) are task-led, voluntary, and/or changeable, the more often they as ever developing relational units will cut each other's borders and overlap, also with their mediating guardian territories, the more a landscape filled with territorial hybrids takes shape, and the more commercial territoriality leads to corruption in the formerly only, respectively, all-encompassing, bound, fixed, exclusive, and direct territorial affairs.

In the market of territories parasitic traders can then cherry pick from bound guardian territories, voluntary areal-trade constructs, and hybrid territorial constructs to do business (with), and their ranking in supranational urban hierarchies, branding through commercials, and/or inclusive governance assists thereby. Moreover, on the supranational level also the associated sub- and transnational economic interests are politically represented, in the Committee of the Regions and with lobby groups for certain regions or cities of instance, and coordinated, with the European Regional Development Funds and funded programs for interregional cooperation for instance. Do recall that although economic interests can come with a certain encircling (e.g. as spatial fix), in themselves they are not committed to a certain scale, as traders are footloose without much respect for guardian hierarchies. Thus when one takes the various scales into account together, the market of territories plays out with both the hierarchy of guardian levels in scales on the one hand and the commodification of levels through the fluctuating scales per level (e.g. an urban region on a par with a Bundesland) and the levelling with contracts (e.g. a contrat de plan Etat-Région) to loosely organise levels commercially on the other hand, that is, a plain corruption in territorial affairs.

Hence, the parasitical dynamic between the guardian and commercial syndromes thus appears to fundamentally reconfigure the territorial affairs in the European Union. That the commercial syndrome modified guardian behaviour to set circles, cones, and encirclements in a guardian way for traders too thereby enabled the addition of a new supranational scale that incorporated the national guardian encircling into commercial territoriality. This weakened national territories, whereas commercial territoriality selectively used the strict national guardian encircling for the fluid direction of supranational policies with their own territorial frameworks and inventively commodified subnational guardian territories out of their hierarchy into voluntary areal-trade constructs levelled with contracts, while the economic interests of both are politically represented supranationally. Ever developing task-led, voluntary, changeable, and/or overlapping territorial constructs thus corrupt direct, all-encompassing, bound, fixed, exclusive territories. Territorial affairs in the European Union are therefore full of territorial hybrids. 


\subsection{Dealing with the Cognitive Dissonance of Systemic Corruption in Territorial Affairs}

When we use our exposé of commercial territoriality to easier understand the complicated territorial affairs in the European Union, we come to the insight that it leads to systemic corruption in territorial affairs. This because even for encircling behaviour the question always is when which of the systems of survival is engaged (i.e. one, the other, or both), while each guardian precept is contradicted by a commercial one. Thus we see territoriality unravel in the European Union before our eyes. Traditionally it namely used to be the guardian syndrome (sub)nationally, then the commercial syndrome became to be innovatively followed supranationally, and modern hybrids emerged for regional and transnational levels and between all levels as well. Without a clear division of labour between hosting guardians and parasitic traders, the ambiguity for someone simply standing somewhere remains that he might be simultaneously encircled according to guardian precepts, the contradicting commercial ones, and/or both (e.g. depending on his activities). Although commercial territoriality made the complicated territorial affairs in the European Union clearer (i.e. the two "puzzles", their origins, landscapes and building blocks, the parasitical dynamic involved), it therefore did not decrease their complexity, quite the opposite, and with their ambiguity added systemic uncertainty. We then wonder how there might be dealt with the ensuing "cognitive dissonance" (e.g. Elliot \& Devine, 1994: 382; Martin, 2018: 183).

The territorial affairs in the European Union namely go beyond the chaos of many, overlapping, and changing territorial constructs on multiple levels and ambivalence of setting moving limits and porous boundaries, separating to unite, levelling to fluctuate, organising without order, and territorialising without territory that comes with commercial territoriality alone (see \$4.3.3). We add hereto that the integrities of the guardian and commercial syndromes in these territorial affairs are also systemicly corrupt, in that they are followed to encircle, that is, these affairs can always respectively be either clear-cut or limitless, all-encompassing or task specific, centralised or networked, stiffly (sub)national or flexibly sub-, trans-, and supranational, directing or mediating, and hierarchically nested or plainly entangled, or, most essential, each time both as well.

These tensions remind us of the Gestalt-switch between guardian territorial logics and non-territorial commercial logics of rule. What is more, they especially remind us of the networking-passage of networking territorial rule and functional networking of this switch (see \$4.2) and how it returns in the way the networking of both bureaucrats and commercial technical elites links the territorial logics of the guardians' administrative state and the traders' commerce respectively (see $\$ 4.4 .1$ ). That is to say, it seems that the constant complexification and systemic uncertainty of the territorial affairs in the European Union (i.e. a work in progress without end) and its bureaucratic make-up also point us to our dependence on technical elites (e.g. lawyers, technocrats, accountants) to relate networking and encircling through their understanding for how they in these 
affairs precisely (can) relate when accurately for specifically what.

To wit, these technical elites' use of specialised knowledge (e.g. on law, technology, finances), or rather: diverging expertise, to relate networking and encircling then enables the political and economic elites to have the two territorial puzzles puzzled together piecemeal; with for instance competitiveness as common denominator for territories and businesses, but this generally in appearance only, as how to be competitive might thereby come with contradictory precepts for encircling behaviour. When contesting social forces work themselves out thus, technical elite's detailed functioning, which is logical per task but lacks a converging overview, would secure that the dynamic between hosting guardians and parasitic traders developing in the territorial affairs in the European Union remains on course. This because without such expertise, the cognitive dissonance needed to follow the guardian and commercial syndromes simultaneously, while the precepts of one contradict those of the other, can neither be complexified away (e.g. choose between precepts with each contradicting pair, but not between the two opposing underlying syndromes that bring both into coherent being) nor made uncertain (e.g. swing between precepts bit by bit per contradicting pair to have no definite choice) on an ad hoc basis anymore, what simply opens up chaotic contradiction.

Yet, while the technical elite's expertise would then secure commercial territoriality's systemic corruption of the integrities of the guardian and commercial syndromes in the territorial affairs in the European Union, and this works constructively for the dynamic between hosting guardians and parasitic traders, the corruption involved would stem from their parasitical symbiosis. In this symbiosis many footloose traders namely together relatively and absolutely weaken bound guardian corpora to the extent that they can take part in them fluidly, (com)modify their hosts' behaviour, and in that way direct when their hosting guardians behave for their corpora or for traders. That traders have selectively appropriated guardian corpora for their own encircling uses might nevertheless seem to overstretch our imagination.

However, two other vital guardian operations that in the European Union appear to be seized by the commercial syndrome already indicate the imagining that is needed. These are the judiciary and taxation, both even modernly defined by territory; that is, via the state as its judicial authority and the collection of compulsory contributions to its revenue respectively. For example, while international courts and tribunals only deal with legal issues between states, have jurisdiction only insofar the states that signed the treaty establishing it consent, and their rulings thus do not trump national law ${ }^{17}$, the supranational Court of Justice of the European Union is different.

The rulings of its Court of Justice on the interpretation and application of European Union law namely deal with issues within member states (e.g. go against a policy, such as state aid) and have primacy over all national laws (e.g.

${ }^{17}$ This general information can for instance be found on

https://en.wikipedia.org/wiki/International_court, visited on 14-4-2020. 
Williams, 1996) ${ }^{18}$. A supranational trade-jurisdiction that out of its commercial origins economised other issues (e.g. see $\$ 4.4 .4$ ) therefore for commerce seized the guardian operation of the judiciary with its centralised direction and encircling, and even so to let its hybrid supreme jurisdiction also work against states; not to speak of the Investor-State Dispute Settlement as also proposed in the Transatlantic Trade and Investment Partnership in 2016, which would have enabled companies to sue countries (e.g. Schill, 2017). Moreover, this selective appropriation of judiciary operation thus goes beyond parting it from own territory as base and the rise of a Lex Mercatoria (Stone Sweet, 2004: 144). Such ruling of commercial justice namely both exemplifies and enforces the dynamic in which parasitic traders increasingly weaken hosting guardian corpora and the consequential corruption of the integrities of their syndromes.

To make it more complex, monetary policy is an issue within member states this Court of Justice can rule on for the interpretation and application of European Union law (e.g. Court of Justice of the European Union, 2019). What is more, this law directly governs the European Central Bank where all central banks of the member states have a share in (e.g. Williams, 1996) ${ }^{19}$. The general question for central banks arising from their history (e.g. Selgin, 1996; Zaman, 2019) then becomes to what extent the European Central Bank is a public institution or a consortium of limited (liability) companies (i.e. the national central banks, e.g. with a country's banks as shareholders) operating for public or banking interests or both, that is, does it follow the guardian or commercial syndrome or is it a hybrid (e.g. balance stable trade across borders with guardian policy concerns, such as full employment, within borders). Of course, the European Central Bank cannot tax citizens in the European Union directly as states do, and often do so based upon a territorial demarcation of their population ${ }^{20}$.

In spite of that, the European Central Bank, and the national central banks whose activities it oversees, can via their monopoly of currency-issuing, that is, by fiat creating euros ${ }^{21}$ as the legal tender ${ }^{22}$ in which debts can and taxes must be paid, profit from not all citizens in the European Union, but, due to variable geometry, the euro using many of them. This by fluidly inflating the euro supply beyond the economic output, due to which the citizens' amount of euros loses

${ }^{18}$ This general information can for instance be found on https://en.wikipedia.org/wiki/Court_of_Justice_of_the_European_Union and

https://en.wikipedia.org/wiki/European_Court_of_Justice, both visited on 14-4-2020. Do note that the German Constitutional Court (Bundesverfassungsgericht) might disagree.

${ }^{19}$ This general information can for instance be found on

https://en.wikipedia.org/wiki/European_Central_Bank, 15-4-2020.

${ }^{20}$ This general information can for instance be found on

https://en.wikipedia.org/wiki/International_taxation, visited on 15-4-2020.

${ }^{21}$ Euros are fiat money because they are without intrinsic or use value, but only have value because government regulations establish and maintain it and parties engaging in exchange agree on its value. This general information can for instance be found on https://en.wikipedia.org/wiki/Fiat_money, visited on 20-4-2020.

${ }^{22}$ Euros are legal tender because the European jurisdictions determined that their courts of law are required to recognise euros as a satisfactory payment for any monetary debt. This general information can for instance be found on https://en.wikipedia.org/wiki/Legal_tender, visited on 20-4-2020. 
value, just as that of those states, while the bank itself has an in principal unlimited amount thereof (e.g. to purchase government bonds, i.e. sovereign debt, a debt that is passed on to tax payers). We can thus see the European Central Bank levying taxes indirectly, something national central banks of course already did since their creation; more complicated ways exist as well, such as with the combination of a larger euro supply for banks (e.g. by lowering interests rates) but stricter loan requirements, leading to a surplus on the banks' balance sheet over which the European Central Bank then charges a percentage (e.g. to pressure banks to lend euros to companies and citizens), while banks pass these extra costs to their customers, which are most often citizens in the European Union one way or another as well (e.g. Wellens, 2017). Also this selective appropriation of the taxation operation goes beyond parting it from own territory as base, and as a commercial levying both exemplifies and enforces said parasitical dynamic and consequential corruption as well.

Hence, after the traders' selective appropriation of the guardian judiciary and taxation operations for their own commercial uses, while parting both from own territory as base, territoriality can easily follow. That is to say, traders' likewise appropriation of the encircling operation, that is, territoriality with a market of territories but without the need for an own territory, might be seen as a next logical step to take instead of as an overstretch of our imagination. And insofar territorial affairs are fundamental for distinguishing the guardian and commercial systems of survival, which they arguably are (see $\$ 3.2$ and \$3.3), the corruption of the integrities of the two syndromes in the territorial affairs in the European Union could show that they have become fundamentally corrupted here. That is to say, the integrities of the guardian and commercial syndromes are then not only systemically corrupt in the sense that these syndromes are systematicly corrupted, but also in the sense that corruption of their integrities has become the system.

When the corruption of the integrities of the two systems of survival has become systemic in territorial affairs in the European Union, it becomes impossible to answer the above often posed question of who the "someone" is that rules these affairs in a principal manner. Just as the authorities are hard to find in the European Union as if it were a Kafkaesque Schloß (Hissink Muller, 2016), neither the accountable someone in territorial affairs emerges (e.g. who plays the puppet?). Furthermore, it is not even certain which logic he would then use (e.g. what to play?). We now nevertheless do understand that this role is part of the guardian syndrome with its logic of hierarchy, simplicity, and guarantee, the commercial syndrome through parasitation generated systemic corruption in his territorial affairs with the logic of networking, complexity, and ambiguity, and the commercial syndrome does deal with the uncertain lack of him this results in. Below, the discussions on territorial cohesion policy then exemplarily show how thus our understanding of the puzzling territoriality in the European Union became much simpler, that is, that it is essential for its interrelated territorial "puzzles" that they are not solved. 


\section{Exemplifying the Corruption in Territorial Affairs in the European Union}

\subsection{Towards Discussions on Territorial Cohesion Policy beyond Mediated Territoriality}

Through the above we came to an easier understanding of the complicated territoriality in the European Union. The puzzling territorial affairs in the European Union can namely be disentangled in a guardian and commercial "puzzle". An unravelling territoriality thereby comes forward where both puzzles interrelate in complexity and systemic uncertainty and parasitic traders thus generate corruption in the guardians' prerogative and defining issue of territorial affairs. Commercial territoriality might therefore fundamentally corrupt the integrities of the guardian and commercial systems of survival. To see how such an unravelling of territoriality looks like in the particular would then allow us to get a stronger hold on the matter. Therefore, territorial cohesion policy is used as a crystallising example that clarifies the unravelling in more detail through illustration below, due to which we can also enrich our thorough reflection by drawing more general conclusions too.

To exemplify our easier understanding of the complicated territoriality in the European Union with discussions on its territorial cohesion policy, it might seem useful, prima facie, that it is clear what territorial cohesion is about. However, although territorial cohesion became a cohesion objective of the European Union (OJEC, 2008: 127) after many debates one to two decades ago (e.g. Faludi, 2004b, 2009; Waterhout, 2007), with disputed interpretations it remains an "unidentified political objective" (Faludi, 2005b). Many territorial cohesion meanings which frame its knowledge then discursively correspond to usages of the concept for many issues (e.g. balanced development, services of general interest, coordination of policies), together forming the territorial cohesion discourse (Hissink Muller, 2013, 2016) as a system of knowledge with associated practices (Foucault, 1968). We can therefore still follow Faludi (2013c: 4) in that this allows different interests to interpret the concept differently, something Héritier (1999) considers "subterfuge" when used strategically.

While this vagueness makes territorial cohesion policy less well-defined for us, such systemic uncertainty engrained in it does fit the territorial affairs in the European Union outstandingly well. What does so too, is that this-if not only, then at least-most explicit supranational territorial policy objective appears to play a role outside the centre stage these days (e.g. ESPON, 2019; Marques et al., 2018). The European Commission (CEC, 2017) for instance dedicates a chapter in its Seventh Cohesion Report to territorial cohesion, but although (possible) aspects of it are treated, the word "territorial" is seldom mentioned. This could make the territorial framing of territorial cohesion policy strategically add "stealth" to "subterfuge" (Héritier, 1999), but surely adds substantive to territorial mediation as it then deals with territorial affairs indirectly besides doing so without (own) territory. 
Moreover, though territory is basic to territorial cohesion, it is according to Faludi (2013b: 1302, 2013c: 2, 3) not adequately defined and an "unknown quantity" in debates relevant for the concept, while literature scarcely addresses both; hence the scarcity of sources for the discussions treated below. Perhaps this is because political geographers do not focus that much on territorial cohesion policy and many of the European spatial planning community (e.g. Campbell, 2005; Faludi, 2005a, 2007; ESPON, 2006), of which some even pose that territorial cohesion policy is a form of spatial planning (e.g. Faludi \& Waterhout, 2002: 5), here simply follow one of the four rules of the territorial cohesion discourse, do not mention politics that is (Hissink Muller, 2013, 2016) ${ }^{23}$. Be that as it may, the policy's vagueness, its combination of shared competence and subsidiarity, institutional void, soft spacing, and spatial visioning as shown in the discussions, does demonstrate our simpler understanding of the complicated territoriality in the European Union. Namely insofar it is also mediated (\$5.1), fluctuating (\$5.2), flexible and multiple ( $\$ 5.3)$, and leads to corruption ( $\$ 5.4)$ and cognitive dissonance ( $\$ 5.5)$ in territorial affairs respectively.

\subsection{Combining Shared Competence and Subsidiarity for Fluctuating Territoriality}

When the European Union vaguely and without (own) territory rules territorially with territorial cohesion policy, it just shows the mediated side of commercial territoriality. And when it would do so with an unambiguous competence for this, the hierarchy involved strengthens the guardian side its territorial hybridity. However, "European treaties recognise [ $\mathrm{t}$ ]erritorial cohesion as a competenc[e] that [is] shared between the Union and its members" (Faludi, 2013b: 1302). This is not surprising when you consider the "positioning game" in which the same member states that were opposed to a European Union competence in spatial planning (e.g. Dühr et al., 2010; Faludi \& Waterhout, 2002) were opposed to a role for it regarding territorial cohesion (Faludi, 2010: 165-167; Faludi, 2013b: 1304, 1312). Then the sharing of the competence for territorial cohesion can namely cover the oppositional stances towards a supranational competence for it.

The shared competence for territorial cohesion means that the Council of the European Union and the European Parliament have to approve any European Commission initiative ${ }^{24}$, and that once assumed as a European Union compe-

\footnotetext{
${ }^{23}$ The other three rules are: remain rather vague, always be open to link what you say to what others can say, and follow policies of European spatial planning and/or Cohesion policy (Hissink Muller, 2016).

${ }^{24}$ For those of you who are unfamiliar with these official institutions, the core three standard institutions are: the Council of the European Union, the European Commission, and the European Parliament. The Council of the European Union is the supreme legislative authority. The executives of every Member State meet here (i.e. national ministers depending on the topic). The European Commission can be seen as the executive and civil service. A series of Directorates-General, headed by Commissioners (and their personal Cabinets), make up its bureaucratic structure. The European Parliament is the only legislative institution that is directly elected. This democratic institution has cross-national party groupings (Jensen \& Richardson, 2003: 35).
} 
tence, and this only when other authorities cannot cope, it rescinds relevant member state competences (Faludi, 2013a: 1597; Faludi, 2013c: 5). This makes the sharing involved partly zero-sum at least, due to which Faludi (2013a: 1597) labels it a rival instead of shared competence (i.e. konkürrierende Kompetenz). And while zero-sum games go well with guardians (see \$3.2), Faludi (2013b: 1302) holds that such initiatives "are likely to be controversial", whereas the European Commission, notwithstanding that it is legally qualified to do so, never made such legislative proposals yet (Faludi, 2013c: 5). In combination with the vagueness of what territorial cohesion policy is about, the shared competence for it thus gives room for a constant squabbling over which level territorially rules what territorial issues, such as over the intertwined ones of how active the European Commission precisely is these days, what exactly to endorse as policy later on, and why which authorities can or cannot cope with what specifically (Faludi, 2013a: 1596; Faludi, 2013c: 5). With this constant squabbling in and over territorial cohesion policy, hierarchies are technocratically levelled, due to which national and supranational scales inconsistently operate on the same and different levels for what is more or less the same policy, what exemplarily demonstrates fluctuating territoriality.

Territorial cohesion policy further shows this fluctuating territoriality in how the involved subsidiarity, a general principle of European Union law which comes with the shared competence, frames it territorially. If the European Commission were namely to take initiative in territorial cohesion matters, then the European Union may still only act when individually member states cannot achieve the objectives of the proposed action sufficiently (Faludi, 2013a: 1596). But, although, following Faludi (2014: 180), "the primary frame within which to seek coherence is [thus] the territory of the nation state[,] the nation state may share its territoriality with sub-national administrations and also with the [European Union]". This would mean that it does not matter whether "territorial cohesion is being sought below, above or across [the nation state's] territory", as the policy must then always "go through the sieve of state territoriality and must meet with the approval of the institutions of representative government" (Faludi, 2014: 180). The shared competence for territorial cohesion thus with subsidiarity opens the door for a technocratic sharing of territoriality of a certain scale over various levels. The point is though, that this mediated territoriality can fluctuate differently from one member state to another depending on how thus the needed sieving of the state's territoriality takes place.

What is more, since a decade subsidiarity "applies to the whole government hierarchy", and supranational institutions, especially the Committee of the Regions (CoR, 2010) ${ }^{25}$. Regional and local levels of government and their lobby organisations therefore do not only "encourage relevant initiatives", but when they together "emphasize that subsidiarity implies regional involvement", they "have standing before the European Court of Justice" too (Faludi, 2013a: 1597,

${ }^{25}$ The Committee of the regions acts as a source of interest-representation and decision-making structure for the wide diversity of regions (Wiehler \& Stumm, 1995: 247). 
1598-1599). That is to say, the mediated territoriality of territorial cohesion policy can also fluctuate differently from one region to another depending on how the technocratic sieving of the concerned territoriality takes place. Or, put more in general, its territoriality gives room for a fluctuation galore with different various scales of territoriality per level across each level nota bene.

No wonder, therefore, that Faludi (2013a: 1595) responded to a European Commission (CEC, 2008) statement as he did. The European Commission namely posed that territorial cohesion should assist in the governance of cohesion policy by making it more flexible, adaptable to the "most appropriate territorial scale, more responsive to local preferences and needs and better coordinated with other policies at all levels in conformity with the principle of subsidiarity" (CEC, 2008: 4). Faludi (2013a: 1595) then responded with that what this conformity means is not clear due to the lack of follow-ups. What hereby would not help either, is that literature on "subsidiarity and multi-level governance" tends not to address territory (Faludi, 2013c: 3). Yet, what is clear to us, is that the territoriality of this vague policy is besides doubly mediated indeed very fluctuating as well, while we are also familiar to the resulting systemic uncertainty for how it works.

\subsection{From the State via Institutional Void to Flexible and Multiple Territoriality}

Even with the doubly mediated and fluctuating territoriality of territorial cohesion policy shown above, "the frame of reference [still] is the existing government hierarchy" (Faludi, 2013c: 6) of the modern state. This would of course strengthen the guardian side of its territorial hybridity. Again, state territory namely has all-encompassing boundaries and "the control of the political centre is supposed to be equal in any part of [it]" (Mamadouh, 2001: 423). An example Mamadouh (2001: 423) gives for this is interesting with respect to territorial cohesion, as this state territory would entail that "[i]nhabitants of the peripherical regions have equal access to state-provided services" (e.g. health care, social services). Such a provision of services has namely since long ago and in treaties been connected to territorial cohesion when labelled as "Services of General (Economic) Interest” (Hissink Muller, 2013, 2016). Furthermore, Davoudi (2007) even sees accessibility to these services as one of the two elements of territorial cohesion's territoriality; the other being multi-scalarity, something we treated above (see \$5.2). Territorial cohesion policy then appears to appropriate the operation of providing equal services through the whole territory from guardian corpora, this while parting it from their state territories and, of course, not basing it on any (own) territory.

For this difference between the state's and territorial cohesion policy's operation of providing these services, we can have a look at the dominant aspect of territorial cohesion policy which Faludi (2004b) calls "French thinking". Territory would herein be "constitutive for the identity of a social formation" (Faludi, 2005d: 19). When Husson (2002) for instance holds that the territory founds the 
state and Peyrony (2007) that the state is "the most successful form of cohesion", one can already wonder what other social formations are constituted territorially. Husson's (2002) answer, now unsurprising for us, is that territorial cohesion founds a community. To be exact, territorial cohesion would only do so when citizens of a political citizenry, including those of disadvantaged territories, do not feel negative discrimination in the application of governmental measures (e.g. the provision of services) to their territory (Husson, 2002). Territorial cohesion policy's appropriation of the service-provision operation from states would then part it from state territories, but directly bring them back in for mediation with their political citizenry and governments.

Faludi (2013a: 1596), however, questions this territorialism underlying such territorial cohesion policy; do note that due to the vagueness of this policy such territorialism might vary depending on the territorial cohesion issue at stake. $\mathrm{He}$ does so by asking whether territory "is the fixed property of any state, region or local administrative unit [or] a malleable social construct" (Faludi, 2013c: 2) and by quoting Murphy (2008: 16) to put forward the possibility the European Union offers to overcome "some of the territorial rigidities of the modern state system [in] the European political-territorial order" (Faludi, 2012: 208). Moreover, for considering territorial cohesion, Faludi (2013a: 1595) asks whether "the system of fixed, bounded and exclusive spaces that are the jurisdictions of governmental bodies at various levels is the only frame". And although we are by now also very familiar with the contrast between flexible encircling in (foot)loose relations for inclusive governance on task specific trade-jurisdictions and the state as guardian corpus, how this plays out if the essence of the task is territorial is not.

Marks (1992) then points out that policy making shifts to an "institutional void" when much of it "takes place next to or across established borders" of governmental bodies (Faludi, 2013b: 1308; Faludi, 2013c: 7). In more pragmatic policy making, the analysis of problems might then start less within a territory and cross political structures ${ }^{26}$, and lead to spaces that, in "French thinking", "follow a functional logic" (Faludi, 2005d: 19). However, again, even when territorial cohesion policy is pragmatically formulated by governmental and/or other actors across political structures, the functional logic is territorial, what would lead to territorial spaces, and thus still "involves sharing territoriality" (Faludi, 2014: 180). If one follows Polverari \& Bachtler (2005: 37) though and takes territory "as the geographical space taken into account and the people that live in it"-for departure point of policy making in economic and regional development-, then established borders are not necessary, because this account, and therefore this geographical space and the people living in it, do not have to remain the same. Territorial cohesion policy making thus also takes place in an institutional void where the territoriality that is shared is flexible.

Moreover, this flexible territoriality of territorial cohesion policy allows territorial demarcations to depend on the issue at stake. Vogelij (2006) even poses ${ }^{26}$ Representative of Brussels Capital Region, personal interview, 23rd of February 2006. 
that this is always the case, because no such demarcation holds for all the relevant aspects of that area. Instead of having state territories as frame to consider territorial cohesion, such territorial demarcations can then be agreed upon in cooperation on the basis of a collective formulation of problems and solutions, while governmental borders are merely an option for this, just as existing legitimate authorities merely play a role (Vogelij, 2006). A possibility for territorial cohesion policy arises when he adds that functional connections (e.g. to provide a certain service) then form organisational networks and where many of such networks overlap it even could be called a territory (Vogelij, 2006); do note that such territories would be without a spatial surface, as many lines might appear to be a surface, but they will never be one. The possibility that is, that besides state territories framing territorial cohesion policy, where many of its aspects overlap, this policy can thus also from many task specific trade-jurisdictions form new territorial constructs, which some would not even distinguish from territories. Hence, although the vagueness of territorial cohesion policy shrouds how many functional networks overlap when it forms networked encirclings in that way, and therefore how these new territorial constructs differ from all-encompassing state territories, it clearly starts with multiple territoriality as an option.

\subsection{From Soft Spacing to the Corruption in Territorial Affairs}

Taken together, the mediated, fluctuating, flexible, and multiple territoriality as discussed in the case of territorial cohesion policy noticeably demonstrate commercial territoriality (see \$4.3.4), also shown in the networked encirclings (see \$4.4.1) that with many overlapping networks form territorial constructs. Although each of these constructs is more than merely a single task specific tradejurisdiction, they are not (state) territories either, as they are not all-encompassing. Then again, territorial (state) authorities can according to Faludi (2013a: 1594) not "deal with all aspects of territorial cohesion" either, because "[i]n reality space is relative and each area the point of intersection of numerous configurations." The territorial constructs of territorial cohesion policy that are made in accordance with commercial territoriality would then grasp what escapes the all-encompassing guardian territories.

While it might sound paradoxical that issues escape all-encompassing territories, this parallels the two meanings of the word "contain" we came to terms with when it concerned Taylor’s (2007) "state-cities contest" (see \$2.2). To be precise, although a territory can have all territorial cohesion issues inside its borders, whatever those issues are (e.g. the provision of which services?), this does not automatically entail a control over all of them. We then disagree with Taylor (2007: 147) in that states did not dominate cities in twentieth century Europe, but the commercial syndrome's role ascended in the state's territorial affairs (see \$3.4). We however do agree with that "after this modern spatial development process [a] different modus vivendi [can be] identified" (Taylor, 2007: 147), what we did by portraying the market of territories in European Union (see \$4.3.4). According to Faludi (2013b: 1312), a new understanding of ter- 
ritory and territoriality arose with "soft" cross-border and transnational spaces and scales, where often with active support of the European Commission, keen as it is on transcending borders, much soft planning occurred for its Cohesion policy. The implementation of territorial cohesion policy can therefore be controlled with "hard" spaces that are legally "fixed" (Allmendinger \& Haughton, 2009: 620; Faludi, 2013b: 1311) through guardian encircling, spaces one calls "territories", or soft spaces through commercial networked encircling.

What is more, Faludi (2013a: 1596) even says that "[t]erritorial cohesion must deal with hard and soft spaces", just as planning needs to (Allmendinger \& Haughton, 2009: 620; Faludi, 2013b: 1311). This will then involve hard planning that relies in stator power and government funding and soft planning that relies on relations that reach across borders (Faludi, 2013b: 1309). And although especially spatial planning relates to "control over territory, one of the privileges associated with sovereignty" (Faludi, 2002: 906), when planning literature speaks of soft spaces, it is associated with the promotion of new policy scales with fuzzy boundaries (Allmendinger \& Haughton, 2009: 3; Faludi, 2013b: 1309; Faludi, 2014: 181). These soft spaces would "reflect the more complex relational world of associational relationships which stretch across geographies" (Allmendinger \& Haughton, 2009: 620; Faludi, 2013b: 1311), whereby "[e]ach area on the surface of the globe can form the intersection of many soft spaces" (Faludi, 2013a: 1596). Hence, territorial cohesion policy thus controls territorial affairs through the tandem of hard territorialisation and soft spacing instead of only through the former, what allows it to grasp issues which escape either the guardian one or the commercial other.

This strong because double grip for reaching territorial cohesion with either a hard hand, soft hand, or both (Hissink Muller, 2016) would of course have consequences for territorial affairs though. Just working with the existing nested hierarchy of (sub)national guardian territories to achieve territorial cohesion, including the involved subsidiarity, then turns into what Faludi (2013a: 1604) thinks is conservative territorialism and "an illusionary view of governance in boxes". The view of the European Union "as being neatly divided into the territories of sovereign Member States" therefore, according to Faludi (2005c: 107), needs "to be replaced by one taking account of the emergent transnational cooperation networks." Thus "freed from constraints of territorial jurisdiction", as Amin (2004: 42) announces for relationally imagined regionalism, there for territorial cohesion policy "cannot be just one geographic scale, one spatial framework for integration-the territory for which an administration is responsible-but there need to be several, with each representing a different, and quite likely competing perspective" (Faludi, 2013b: 1310). That is to say, when territorial cohesion policy also controls territorial affairs through soft spacing, it cannot shun from the market of territories anymore.

Also for territorial cohesion policy there thus emerge two landscapes. That is to say, on the one hand we have an easy to understand one for which, according to Faludi (2013c: 2, 3), this policy seeks to harmonise activities within bounded 
territories and between them as stacked containers by being about the qualities of what is inside these fixed and layered jurisdictions. On the other hand we have a more sophisticated one for which, according to Faludi (2013c: 2, 3), this policy seeks to reflect existing complexity and ameliorate inefficiencies and conflict by including the "qualities of the relations within a complex network of socially constructed, sometimes ephemeral constructs" which are ad hoc, depend on the issue concerned, and may overlap with their dynamic and fuzzy internal and external boundaries. Although these two landscapes do not really clarify where territorial cohesion policy is about (e.g. which activities, complexity and inefficiency of what?), we of course do recognise the completely different guardian and commercial "puzzles" in them (see \$4.4.1).

So also for this policy the parasitical dynamic between the guardian and commercial syndromes appears that results in the corruption of their integrities in territorial affairs. In the guardian territorial puzzle we would namely have Faludi's (2013c: 3) conventional territories, while in the commercial one he sees the constructs that are relevant for policy making. Territorial cohesion policy then operates through territorial constructs that are "substantially insulated from, while being parasitic on, state authority" (Stone Sweet, 2004: 122), because its supra-, transnational, interregional, and cross-border spaces are supported by the states’ order of (sub)national territories (see \$4.4.2). Yet, whereas policies are conventionally based upon state authority, this one selectively uses guardian corpora territorially for its own (vague) ends, while it weakens them (e.g. their exclusivity, hierarchy) by constructing a new territorial order (see \$4.4.3). Territorial cohesion policy thus leads to a corruption of the integrities of the guardian and commercial syndromes in territorial affairs, because it is in itself a hybrid with guardian territories and commercial territorial constructs. Due to this, systemic uncertainty ensues about whether the policy's encircling is containing or fuzzy, fixed or dynamic, stacked or overlapping, and bounded or depended on the particular issue at stake, or (each time) both as well (see \$4.4.4). In short, the question is whether territorial cohesion policy's encircling aims to harmonise activity within limits and/or to increase efficiency and agreement in the relational complexity of networked encirclings that cross borders. Hence, with its commercial territoriality this policy contributes to the systemic corruption of the integrities of the systems of survival in the territorial affairs in the European Union.

\subsection{Many Converging Spatial Visions to Divergently Deal with Cognitive Dissonance}

Due to the systemicly corrupted integrities of the guardian and commercial syndromes in territorial cohesion policy, the elites that function to work out contesting social forces with it must therefore either exercise control in cognitive dissonance or have the two territorial puzzles puzzled together for it (see $\$ 4.5$ ). We could follow Faludi (2013a, 2013c) for the puzzling needed to deal with this cognitive dissonance. He namely concludes from geographical and planning li- 
terature that territory "is the object of negotiation and compromise, open to multiple interpretations" (Faludi, 2013c: 8) and he puts forward that "deliberation involving technical elites [has] always been an element in discussions on European integration and also on territorial cohesion more in particular" (Faludi, 2013a: 1603). Territorial cohesion policy surely is vague enough and covers enough issues (Hissink Muller, 2013, 2016) for the technical elites-which here are mostly technocrats, as it concerns policy making-moving inside and outside guardian corpora to make this cognitive dissonance uncertain and to complexify it away. Territorial cohesion expertise, here thus mainly technological knowledge, would then allow the political and economic elites to have the two territorial puzzles puzzled together by relating networking and encircling (again, see $₫ 4.5)$.

However, territorial cohesion policy does not only revolve around functional issues within territories and/or territorial constructs, because it makes these entities themselves a policy issue as well. As Faludi (2014: 182) holds, "the pursuit of territorial cohesion means conceptualising, and re-conceptualising territorial relations." And these relations are between activities on "islands" (i.e. territories) and those in the "sea of malleable ones" (i.e. territorial constructs), in the whole "archipelago", and between these islands and sea themselves (Faludi, 2013c: 13; Faludi, 2014: 182). Territorial cohesion expertise therefore cannot puzzle together the guardian and commercial puzzles in piecemeal fashion, as diverging expertise would accurately do for specific functional policy issues (again, see $\S 4.5$ ), as the territorial as policy issue itself is too general (at least territorially seen).

What is more, territorial cohesion policy then consequentially is also about how territories "deal with tectonic movements potentially changing their very shapes" (Faludi, 2014: 182), while these changes are negotiated over with competing perspectives per scale too (Faludi, 2013b: 1310; Faludi, 2013c: 8), to say the least. To then puzzle the two territorial puzzles together, the issue for technocrats is how territorial cohesion expertise can be converging without engendering chaotic contradiction between many encirclings that follow different combinations of particular guardian and commercial precepts (again, see \$4.5). We are thus not surprised when Faludi (2013c: 13) says that this pursuit of territorial cohesion amounts "to ever-new images of existing and possible future territories [as] counter-points to their apparent isolation". Each convergence of certain territorial and functional issues then namely comes with a specific image that is by principle challenged by another such convergence of issues, especially because it is uncertain what territorial cohesion issues actually entail (Hissink Muller, 2013, 2016). Chiefly technocrats can then with territorial cohesion policy again and again divergently connect the guardian and commercial territorialities in new and even contradictory ways for economic and political elites to rule territorial affairs side by side through many territorially and functionally contrasting variations of encircling and networked encirclings.

As such, these discussions on territorial cohesion policy thereby do not only 
bring the political tensions embedded in contesting social forces to the fore for the European Union, they also give them a spatial dimension (Davoudi, 2007). This policy hereby comes forth from the repositioning of the nation-state, just as the construction of new spatial visions does (Jensen \& Richardson, 2003), while it in its turn supports this change in territorial affairs here too. Therewithal "the structure of territorial stratification and the ways territories are developed and perform different functions" is reconfigured (Davoudi, 2007). We, however, made these reconfigurations easier to understand by starting from the structure of social stratification these social forces shape (e.g. with technical expertise, political and economic elites) "and the ways individuals are socialised and recruited into different social roles" (Martin \& Ross, 2004: 12; Davoudi, 2007), that is, the guardian and commercial systems of survival. We therefore do not so much focus on the territorial changes themselves, but on the underlying ways of territorialisation (i.e. guardian, commercial, hybrid) that bring them about.

Territorial cohesion policy then appears to exemplify the furthering of the investigative business of technical elites through commercial territoriality, a business that grows as long as the territorial puzzles in the European Union remain unsolved (again, see \$4.5). Faludi (2013b: 1312) for instance calls upon planners to "engage in novel "speech acts" taking the positions of various territorial configurations and also of the stakeholders concerned as the points of departure for multiple spatial visioning, this to, in the words of Loriaux (2008: 2), reveal "the contours of Europe that [is] about deconstructing frontiers so as to bring to light a civilizational space that [is] intensely urban, cosmopolitan, multilingual, and less hierarchical than in the past." Except with our understanding of the complicated territoriality in the European Union, we simply see how territorial cohesion policy exemplarily shows the commercialisation of - if not the, than-a fundamental prerogative of guardians with a market of territories that leads to systemic corruption in its territorial affairs.

\subsection{From Territorial Cohesion Policy via General Conclusions to Manners of Territorialisation}

Looking at territorial cohesion policy as above leads to more general conclusions for unravelling territoriality in the European Union too. One is the possibility for doubly mediated territoriality. Territorial framing of policy hereby follows this aspect of commercial territoriality by dealing with territorial affairs indirectly besides via territories of others. Related to this is a form of fluctuating territoriality where a constant technocratic squabbling over which level territorially rules what territorial issues levels hierarchies and leads to technocratic sharing of territoriality of a certain scale over various levels. Flexible and multiple territoriality returns as well, this with the possibility to form new territorial constructs from many overlapping task specific trade-jurisdictions. What comes to the fore through these possibilities within a single policy, is a control of territorial affairs through the tandem of hard territorialisation of guardian encircling and soft spacing of commercial networked encircling. Operations parted from their state 
territories can then nonetheless use their political citizenry and governments in an institutional void, and territorial constructs made in accordance with commercial territoriality could then grasp what escapes the all-encompassing guardian territories. Yet, the most general conclusion that comes forward from territorial cohesion policy, is that our usage of the guardian and commercial syndromes to make sense of the reconfigurations of the territorial affairs in the European Union turns around a thorough focus on the underlying ways of territorialisation.

\section{Concluding to Understand Territorial Affairs Trough the Manners of Territorialisation}

\subsection{Making Thoroughly Understanding Complicated Territorial Affairs Easier by Disentangling Two Puzzles}

Many social researchers find the territorial affairs of the European Union difficult to grasp and debates about its territoriality can give a puzzling impression indeed. Compared to those of the modern state, where most of us are used to, they indeed do not appear alike, but to be much more complicated. The addition of the supranational European level namely came with fundamental reconfigurations of territorial affairs, also for lower levels, making them complex and uncertain. This essay then argues that these complicated affairs are easier to understand by not trying to pin them down in one clear picture, but by first distinguishing two territorial "puzzles": one based upon precepts for dealing with territories and one based upon, paradoxically, precepts for dealing with markets. While Jacobs' (1992) systems of survival have been used (in political geography) before, territorial affairs have never been thoroughly disentangled with reconsidered guardian and commercial syndromes, that is, as bases for different manners of territorialisation. Now that we through conceptual reflection did do so, the complicatedness of the territorial affairs in the European Union can be seen to rest on simple fundaments. The argument for how we got there is then in brief shown below.

\subsection{Turning from Territory via Simplest Forms to Territoriality}

We first tried to envision the territorial affairs of the European Union with simplest forms as the cleaner ideational basics signalling the fundaments of the messy real. This to easier grasp how such union challenges the comprehensive territoriality of modern states, with their supreme rule, centralising sovereignty, exclusive dominion, multipurpose administrations, and fixed borders, by adding a supranational level and another territorial logic. For that, we outlined the territorial basics of territory, elementary as a marked cone, scale, as a cone incorporating smaller cones, and territoriality, as an encircling behaviour with which circles are made through cones.

Yet, "having inside" does not automatically mean "having control over", and control in this supranational entity, to which its member states transferred se- 
lected powers, is dispersed over interlocking institutions, while it has no territory itself and even aims to overcome borders. No wonder this makes territorial affairs fluid through dynamic unbundling of territoriality, with voluntary choice in systems of rule that depend on the task at hand (i.e. variable geometry). More surprising, because paradoxical, is the dynamic re-bundling of territoriality, which only occurs indirectly via member state's territories for own (territorial) concerns. We pictured these three aspects respectively as: 1) fundamentally a "cone" on top of smaller cones that encircles them without any incorporation, but 2) dynamically controls affairs with an encircling with overlapping ovals that do not cover all the circles these smaller cones keep, and 3) with cones "through" the circle it marks on them, also with an encircling to control them through their own circles.

Hence, although the territorial affairs of the European Union were in sight, their underlying essentials were difficult to see beyond this endless change and complexity, especially when one considers the said three aspects together. Discussions on this union's territorial cohesion policy exemplify this, because it is neither clear what this policy is about (e.g. balanced development, services of general interest, coordination of policies), nor with what territories it is concerned. We could thus merely infer that the territorial logic involved revolves less around territory and scale, as framed by and frames for contesting social forces, than around territoriality, as just one though common and indispensable means to exercise power therein.

\subsection{Following the Ascendency of the Commercial Syndrome to Understand Territorial Affairs}

Our alternative way of looking to understand the fundaments of the territorial affairs of the European Union is the usage of Jacobs' (1992) systems of survival as heuristic tool. These systems namely prescribe two totally unalike ways of behaving, since they resolve contradictory moral precepts (e.g. be loyal or honest) as clusters, each with its own integrity, that is, the guardian syndrome for ruling territories and the commercial syndrome for exchanging in markets. Guardians therefore typically play a role in territorial affairs, as reflected in the contrasting behaviour of guardians and traders, who respectively cultivate exclusive authority or mutuality, respect hierarchy or contracts, adhere to tradition or invent, shun trading or trade, handle zero-sum or win-win games, simplify or complexify, control social and concrete space through encircling or networking, limit or open, and set up borders or cross them. With a clear division of labour, guardian-commercial symbioses can then reasonably work, when guardians provide order, also for the market, and traders create wealth, also for the state, for example, because then the integrity of each is maintained. Guardian/commercial hybrids in which these integrities are corrupted, however, can be disastrous, such as a state directing economic change or a mafia controlling territory for profit.

Throughout history guardians and traders then played different roles when 
they as political and economic elites tried to control affairs and each other, what resulted in ever more control of social practices since Medieval Europe. And while this also holds for modifications of the territorial logics that set up the territorial affairs of the European Union, the role of the commercial syndrome manifestly ascended ever higher herein as well. Where previously feudal guardians simply set up local circles and Medieval traders dealt within and between them, modern and Christian guardians for instance already encircled royally for commerce in centralising and mercantilist ways too. Furthermore, the nation-state's downwards swirling encircling and intertwined encirclement of social relations, through unified subordination and totalisation within fixed circles, was even clouded by its philosophical base of an inventively imagined social contract that never mentions territorial affairs. While territorial affairs therefore became increasingly puzzling for guardians, we could thus at least with the addition of the commercial syndrome peek at their fundaments in the European Union.

\subsection{Linking the Territorial and No-Territorial Gestalts with Commercial Rule}

The commercial syndrome starts to enlighten the territorial affairs in the European Union by highlighting that concrete spatial reality is not territorial in nature and social space is socially constructed with encircling and networking logics, what enables us to recognise how commerce also rules territories today. To be precise, besides that in the European Union the nation-state's rule obviously does not hold exclusively anymore, regionalisation and European integration territorially challenge the nation-state with new territorial units and identities, a territorial rule of negotiated networking between regions, also sponsored by the European Union, challenges hierarchy in general, and functional networks of public and private actors (e.g. that provide services) challenge the encircling involved in territorial rule.

Together these networking logics thus open up a passage between the territorial and non-territorial Gestalts, and by linking them commercial rule challenges territorial rule too. This in general to secure structural coherence between capitalist accumulation regimes and modes of regulation in particular contexts by using the borders and scales of guardian rule for a spatial fix, and specifically when territorial cohesion policy is made for the equal provision of services (e.g. health care, social services) by functional networks, but politically relies on guardian encircling. Commercial rule therefore clearly complicates the territorial affairs in the European Union.

\subsection{Portraying the Market of Territories Formed with Commercial Territoriality}

The intricate territorial affairs of the European Union itself particularly suit modern commercial societies where traders thrive in the complexity innate to market exchanges. They become simpler through the traders' eye though, as, since no guardian oversight appears, this union's territoriality seems to follow 
commercial precepts. That is to say, to be innovative for efficient task-led enterprise it is flexible with changing territorial constructs, to voluntary collaborate across borders it is multiple with overlapping territorial constructs, to level with contracts it fluctuates over multiple levels for profitable options with different scales per level, and to enable force-shunning competition it is mediated by setting up a supranational market of territories with territorially framed policies that politically depend on (sub)national territories. The European Union therefore shows a flexible, multiple, fluctuating, and mediated, in short, commercial territoriality.

The discussions on territorial cohesion policy exemplify this territoriality. Its specific trade-jurisdictions would namely take a geographical space and the people living in it into account depending on the task at hand (e.g. equally providing a service) and it would thus for many functional networks demarcate multiple spaces. Plus, this policy comes with an inconsistent technocratic levelling of subnational, national and supranational scales due to a constant squabbling over specifically who does what precisely, as the Member States and the European Union share the competence for it in accordance with the principle of subsidiarity. It also vaguely and without (own) territory deals with territorial affairs, thus double indirectly. With commercial territoriality territories are thus constructed as "semi-finished products" to be commodified to market. What therefore for the reason of commerce makes the European Union's territorial affairs chaotic, with many, overlapping, and changing territorial constructs on multiple levels, and ambivalent, by setting moving limits and porous boundaries, separating to unite, levelling to fluctuate, organising without order, and territorialising without territory. Then again, what is thus essential to understand the territorial affairs of the European Union is that we see them together with the other territorial affairs in it.

\subsection{Landscaping the Guardian and Commercial Building Blocks Structured Together}

That both the guardian and commercial syndrome are abided by in the territorial affairs in the European Union made the territorial basics involved even more difficult to recognise. Territory is in discussions on territorial cohesion policy for instance not adequately defined, if at all. This then shrouds whether this policy aims to harmonise activity within limits or to increase efficiency and agreement in the relational complexity of networks that cross borders. Nevertheless, we could for starters distinguish the territorial building blocks that either follow to federalism related guardian rule or to specialized jurisdictions related commercial rule.

European integration namely first added a supranational economic space to national political spaces, while on this supranational level guardians then also politically represented economic interests by (sub)nationally territorialising them. Later on, subnational territorial constructs with inclusive governance formations were innovated in line with the commercial syndrome. Thereafter 
the shift from common to single market completed these territorial modifications by also organising the building blocks with-not a single-point perspective, but-one and the same, because commercial, logic, an economisation of territorial interests that is.

These building blocks are with juridical intricacies structured through fragmegration. The fragmentation of stiff governmental hierarchies of nested authorities into loose parts that metamorph into intersectional governance assemblages with shared responsibilities for their partial integration into the market of territories, to be exact. Discussions on territorial cohesion policy display such fragmegration in two ways with its combination of shared competency and subsidiarity. That is to say, it opens the door for a variable technocratic sharing of different scales of guardian territoriality per level across each level, what shows that fragmentation. And the constant technocratic squabbling that this vague policy gives room for thereby also shapes the inconsistent metamorphosis of (sub)national guardian territories for their partial integration within the level playing field of the market of territories. When we overviewed these structured buildings blocks thus, we discerned two territorial "puzzles" in the European Union.

That is, with a easy guardian logic political and bureaucratic elites on the one hand function in a clear-cut amount of centralised encirclings of nested cones marking stiff national and subnational spaces that are simultaneously jurisdictional and judicial. But with a sophisticated commercial logic technical and economic besides political elites on the other hand appear to function in a landscape of a potentially huge number of networked encirclings of flexible task specific subnational and supranational trade-jurisdictions that complexly develop and entangle over varying scales and criss-cross judicial boundaries. The guardian and commercial technical elites (e.g. lawyers, technocrats, accountants) are able to intricately puzzle both territorial logics together by furthering their investigative business, because, just as how networking facilitates commercial rule to link territorial and non-territorial Gestalts, they all operate through networking. Networking in principle de-territorialises though, because it crosses encircling behaviour. We therefore pondered over how in the European Union networking, and the commercial syndrome more in general, thus paradoxically also appears to rule in territorial affairs.

\subsection{Reflecting Upon Commercial Parasitism Engendering Corruption in Guardian Corpora}

The parasitical dynamic between traders and guardians of today enabled us to understand how the de-territorialising logic of networking rules in territorial affairs in the European Union as well. This dynamic namely shows in more depth how the ascendency of the role of the commercial syndrome in territorial affairs in European history came with a commercial taming of the state. Modern traders are then substantially insulated from, while for their market transactions being parasitic on, state authority with the order it secures (e.g. via its military, po- 
lice, judiciary). To be precise, guardians host traders in their territory, but have increasingly less control over them, while traders prey upon political units, the guardian corpora, but have their own commercial (social) space shielded from guardian interference too. Such a symbiosis obviously favours the reproduction of the commercial syndrome over, and to the detriment of, the guardian syndrome.

This comes with an image wherein the virulence of traders increases by their footloose competition, what doubly speeds up the deterioration of the guardian corpora they facultatively prey, through their entrepreneurial selection of specific laws and taxes for instance. What is more, traders relatively weaken a guardian corpus insofar they become stronger than it (e.g. qua financial weight) and absolutely so by receiving more from it than it can give (e.g. by being bailed out with national debt). Still, traders do not take part in territorial affairs so far. Moreover, even when traders form their patchwork of private jurisdictions with own areal-trade constructs, they do not need the stability of (specific) guardian territorial affairs as long as they stay within their economic margins.

Yet, while traders most often reside outside guardian corpora, they also fluidly do so within them. This with lobby groups and inclusive governance structures for instance, what the many governmental and non-governmental centres and fuzzy limits between in- and outside of the European Union polity seem to portray and advance. Traders as a consequence selectively take part in a guardian's encircling as well, due to which they in cooperation and coordination can employ their host's corpus for governmental objectives that benefit traders more than they do guardians (e.g. bail out too big to fail banks). This generates guardian/commercial hybrids of course.

In such hybrids the guardians' encircling namely typically functions for commercial purposes. Parasitic traders inside or taping-in on their guardian host then modify its behaviour with commercial logic in many ways, as shown in discourses circulating in the political body (e.g. on securing open borders). And it is with such hybrids that through territorial affairs a spatial fix comes to embody the institutionalised compromises which for capitalism try to coordinate accumulation, state activities, and social formations strategically. Thus the corruption of the integrities of the syndromes ensues, that is, parasitic traders engender corruption in the guardians' corpora. Still, although networking hereby paradoxically does not de-territorialise as it manoeuvres encircling, it then does not rule in territorial affairs in the European Union either.

\subsection{Pointing out Commercial Parasitism Generating Corruption in Territorial Affairs}

It is with territorial hybrids that networking also rules in territorial affairs in the European Union, what consequentially leads to corruption in them themselves. The addition of this new supranational trade-jurisdiction namely set the stage for a market of territories by incorporating the national guardian encircling into commercial territoriality as if parasitic traders perfectly trapped their hosts 
through their own encircling. Initially it advanced commerce without challenges from other functional issues (e.g. the environment, labour safety), later on it also transformed such guardian matters into economic ones. This by eliminating their restraints on trade and even their distortions of competition (i.e. negative integration) and by including them in the common policies made for how markets operate (i.e. positive integration). Without the need to control territorial affairs directly, commercial territoriality thereby parasitically uses the strict national guardian encircling selectively, this to boundly mediate in the fluid direction of supranational policies, of which most are functional, thus often economised, but territorially framed as well.

Commercial territoriality parasitically uses directing guardian encircling selectively on transnational and regional levels too. Task-led enterprise hereby invents territorial constructs by restructuring fixed (sub)national territories into trade-jurisdictions (e.g. trading best practices) through the dynamic un- and re-bundling of their guardian territoriality. This for instance metamorphs regions on national borders to Alpine regions and cities in various regions to a flexible international city system. Such a fluid (com)modification of hierarchical guardian behaviour thus corrupts all-encompassing, bound, fixed, exclusive, and direct territorial affairs by reshaping them into task-led, voluntary, changeable, overlapping, and/or mediated areal-trade constructs too, what further weakens guardian corpora of course.

On the supranational level meanwhile, the associated sub- and transnational economic interests are also politically represented, in the Committee of the Regions and with lobby groups for certain cities for instance. They are also coordinated, such as with the European Regional Development Funds and funded programs for interregional cooperation. A hierarchy of guardian levels in scales then comes forward as one extreme, and a market of territories where levels are commodified, through the fluctuating scales per level (e.g. an urban region on a par with a Bundesland) and levelling with contracts (e.g. a contrat de plan Etat-Région), to loosely organise them commercially as the other extreme. Traders can therefore cherry pick from bound guardian territories in hierarchies, loosely levelled voluntary areal-trade constructs, and hybrid territorial constructs to do business (with).

For territorial cohesion policy it is for example discussed whether the policy is about harmonising the activities of what is inside fixed and layered jurisdictions or about ameliorating inefficiencies and conflict in relations within a complex network of probably ad hoc and overlapping task-led trade-jurisdictions. It hereby comes to the fore that issues relevant for the policy escape all-encompassing guardian territories, and that its implementation therefore demands to be controlled in tandem. This with on the one hand hard state spaces, which are traditional through guardian encircling with legally fixed limits and a nested hierarchy. And this with on the other hand soft cross-border and transnational spaces, which are contractually flexible through commercial networked encircling with new policy scales and fuzzy internal and external boundaries, to be 
precise. This strong because double grip for reaching territorial cohesion with either a territorialising hard hand, spacing soft hand, or both, enables this policy to grasp what escapes either of them. Territorial cohesion policy thus in and of itself is a territorial hybrid puzzled together by chiefly technocrats moving inside and outside guardian corpora.

Moreover, discussions on territorial cohesion policy also represent a more specific territorial hybrid with its appropriation of the service-provision operation from states. This would namely part the equal provision of services from guardian territories, directly bring them back in for mediation with their political citizenry and governments, but this for them to assess policy made with flexible territoriality in an institutional void for multiple functional aspects. Furthermore, their networked task specific trade-jurisdictions can through overlap then together even form new territorial constructs. Also with territorial cohesion policy the parasitism of the commercial syndrome thus appears to corrupt the integrities of the guardian and commercial syndrome in territorial affairs in the European Union. The policy's supranational, transnational, interregional, and cross-border spaces are hereby supported by the states' order of (sub)national territories. Yet, it weakens guardian corpora (e.g. their exclusivity, hierarchy) through the selective territorial usage of them for its own (vague) ends while constructing a new territorial order.

Hence, commercial parasitism does not only engender corruption in guardian corpora, but commercial parasitism of guardian corpora basically generates corruption in the territorial affairs in the European Union too. And even though networking hereby paradoxically does not de-territorialise as it rules in territorial affairs, the for contradiction between commercial crossing and guardian encircling, so essential for dealing with space, implies that hybrids combining both signal the corruption at work in these territorial affairs.

\subsection{Overviewing the Cognitive Dissonance of Systemic Corruption in Territorial Affairs}

Although our exposé of commercial territoriality certainly made the fundaments of the territorial affairs in the European Union clearer, we also recognise that these fundaments made them more complex and systemicly uncertain too. To wit, ruling thus, through their encircling crossing networking, simply entails exercising control in cognitive dissonance. These affairs are namely beyond merely chaotic and ambivalent, as they are also always guardian, commercial, or hybrid. That is to say, they always respectively are either clear-cut or limitless, all-encompassing or task specific, centralised or networked, stiffly (sub)national or flexibly sub-, trans-, and supranational, directing or mediating, and hierarchically nested or plainly entangled, or, most essential, each time both as well. Commercial territoriality therefore generates systemic corruption in territorial affairs. For the encircling involved the question namely always is when which of the systems of survival is engaged while each guardian precept is contradicted by a commercial one. 
When contesting social forces work themselves out thus, the symbiosis between hosting guardians and parasitic traders developing in these territorial affairs remains on course. But this is impossible without the detailed diverging expertise of specialised technical elites (e.g. on law, technology, finances) that enables the political and economic elites to have the two territorial puzzles puzzled together piecemeal. To be exact, with such expertise, the cognitive dissonance can be complexified away (e.g. choose between precepts with each contradicting pair, but not between the two opposing underlying syndromes that bring both into coherent being) or made uncertain (e.g. swing between precepts bit by bit per contradicting pair to have no definite choice) on an ad hoc basis. Else, chaotic contradiction ensues, what risks this symbiosis.

Do note that in this symbiosis traders appropriate guardian corpora for their own encircling uses. Just as two other vital guardian operations, both territorially based on the modern state, appear to be seized by the commercial syndrome in the European Union already, the judiciary and taxation that is. As hybrid supreme jurisdiction the Court of Justice of the European Union namely for commerce centrally directs and encircles, also against states (e.g. by ruling on monetary policy), and the public and/or private European Central Bank levies taxes indirectly on citizens and states (e.g. with inflation due to currency-issuing, by purchasing sovereign debt). The traders' appropriation of the guardian encircling operation goes beyond other such seizures though. Since territorial affairs are fundamental for distinguishing the guardian and commercial systems of survival, the territorial affairs in the European Union show how the integrities of the syndromes have become fundamentally corrupted here. That is, with their corruption as the system, they have become systemicly corrupt.

Discussions on territorial cohesion policy show this systemic corruption exemplarily due to its hybridity. This policy namely revolves around both functional issues within territories and/or territorial constructs and these entities as policy issue in themselves. Territorial cohesion expertise then cannot puzzle the two territorial puzzles together in piecemeal fashion though, as the territorial is too general for that. Technocrats therefore cannot converge with spatial visions without engendering chaotic contradiction between many diverging convergences of territorial and functional issues that follow different combinations of particular guardian and commercial precepts for encircling. Instead, for economic and political elites to rule territorial affairs side by side through many territorially and functionally contrasting variations of encircling, networking, and networked encirclings, chiefly technocrats may again and again divergently connect the guardian and commercial territorialities in new and even contradictory ways. Territorial cohesion policy then plays its showcasing part in the systemic corruption of the integrities of the guardian and commercial systems of survival in Europe.

We thus never know when the guardian rules commerce by encircling, the trader the guardian corpora by networking, or who of them us by which. There- 
fore, just as the authorities are in the European Union as Kafkaesque Schlo $\beta$ hard to find, so is the accountable "someone" who plays the encircling puppet, nay even the logic of what to encircingly play, puzzling in territorial affairs. And this makes our understanding of the complicated territoriality in the European Union much simpler, because it seems that it is essential that the involved territorial puzzles are not solved.

\subsection{Opening up a Wide Field of Inquiry Uncovering Manners of Territorialisation}

While we easier understood the territorial affairs in the European Union by turning from territory towards territoriality, to grasp their underlying essentials we arrive at the manners of territorialisation, how activities are made territorial that is, and the ways they link. To be precise, we realise how encirclements influence manoeuvring behaviour as a marked cone and we beyond that see how encircling behaviour makes such cones that influence thus, but we focus on how behaviour becomes to work as such an encircling and how these encirclings interlink. Opening up a wide field of research beyond merely guardian and commercial territoriality thus enables inquiries that uncover this modern predicament of ours. Else, we might unknowingly parade into disaster. This to find ourselves flexibly besieged, inside our own homes and/or in public, and variably locked out, from the specific precincts for your and/or other's enterprise, through combinations of complexifying micromanaged (digital) networking, hybrid organisations from the global to local with diverging expertise (e.g. on health, finances) that lacks overview, and vague contradictory policies inconsistently swirling through more and less levelled governmental hierarchies, and each backed up by simplifying sovereign decree. Hence, after digesting this four-course meal of Gordian knots, welcome to the Faustian ball of wild order and neat chaos.

\section{Conflicts of Interest}

The author declares no conflicts of interest regarding the publication of this paper.

\section{References}

Agnew, J. (1994). The Territorial Trap: The Geographical Assumptions of International Relations Theory. Review of International Political Economy, 1, 53-80. https://doi.org/10.1080/09692299408434268

Allen, J., Massey, D., \& Cochrane, A. (1998). Rethinking the Region. London: Routledge.

Allmendinger, P., \& Haughton, G. (2009). Soft Space, Fuzzy Boundaries, and Metagovernance: The New Spatial Planning in the Thames Gateway. Environment and Planning A, 41, 617-633. https://doi.org/10.1068/a40208

Allmendinger, P., \& Haughton, G. (2010). Spatial Planning, Devolution, and New Planning Practices. Environment and Planning C: Government and Policy, 28, 803-818. https://doi.org/10.1068/c09163 
Amin, A. (2004). Regions Unbound: Towards a New Politics of Place. Geogrfiska Annaler, Series B, 86, 33-44. https://doi.org/10.1111/j.0435-3684.2004.00152.x

Andersson, J. (1996). The Shifting Stage of Politics New Medieval and Postmodern Territorialities? Environment and Planning D, Society and Space, 14, 133-153. https://doi.org/10.1068/d140133

Ansell, C. K. (2004). Restructuring Authority and Territoriality. In C. K. Ansell, \& G. Di Palma (Eds.), Restructuring Territoriality, Europe and the United States Compared (pp. 3-18). New York: Cambridge University Press. https://doi.org/10.1017/CBO9780511617072

Ansell, C. K., \& Di Palma, G. (2004). Restructuring Territoriality, Europe and the United States Compared. New York: Cambridge University Press. https://doi.org/10.1017/CBO9780511617072

Arnold, M. (2006). The Vikings, Culture and Conquest. London: Hambledon Continuum.

Arrighi, G. (1994). The Long Twentieth Century. London: Verso.

Axtmann, R. (2004). State Formation and Supranationalism in Europe, the Case of the Holy Roman Empire of the German Nation. In M. Berezin, \& M. Schain (Eds.), Europe without Borders: Remapping Territory, Citizenship, and Identity in a Transnational Age (pp. 118-137). Baltimore, MD: Johns Hopkins University Press.

Bartlett, R. (1994). The Making of Europe, Conquest, Colonization, and Cultural Change, 950-1350. London: Penguin Books.

Bartolini, S. (2004). Old and New Peripheries in the Processes of European Territorial Integration. In C. K. Ansell, \& G. Di Palma (Eds.), Restructuring Territoriality, Europe and the United States Compared (pp. 19-44). New York: Cambridge University Press. https://doi.org/10.1017/CBO9780511617072.003

Baudelle, G., Guy, C., \& Mérenne-Schoumaker, B. (2011). Le développement territorail en Europe: Concepts, enjeux et débats. Rennes: Presses Universitaires de Rennes.

Berezin, M. (2004). Introduction: Territory, Emotion, and Identity, Spatial Recalibration in a New Europe. In M. Berezin, \& M. Schain, (Eds.), Europe without Borders: Remapping Territory, Citizenship, and Identity in a Transnational Age (pp. 1-30). Baltimore, MD: Johns Hopkins University Press.

Berezin, M., \& Schain, M. (2004). Europe without Borders: Remapping Territory, Citizenship, and Identity in a Transnational Age. Baltimore, MD: Johns Hopkins University Press.

Borneman, J., \& Fowler, N. (1997). Europeanization. Annual Review of Anthropology, 26, 487-514. https://doi.org/10.1146/annurev.anthro.26.1.487

Brenner, N. (1998). Between Fixity and Motion: Accumulation, Territorial Organization and the Historical Geography of Spatial Scales. Environment and planning D: Society and Space, 16, 459-481. https://doi.org/10.1068/d160459

Brenner, N. (1999). Globalisation as Reterritorialisation: The Re-Scaling or Urban Governance in the European Union. Urban Studies, 36, 431-451. https://doi.org/10.1080/0042098993466

Brenner, N. (2001). The Limits to Scale? Methodological Reflections on Scalar Structuration. Progress in Human Geography, 25, 591-614. https://doi.org/10.1191/030913201682688959

Brenner, N. (2004). Rescaling State Space in Western Europe, Urban Governance and the Rise of Glocalizing Competition State Regimes (GCSRs). In M. Berezin, \& M. Schain (Eds.), Europe without Borders: Remapping Territory, Citizenship, and Identity in a Transnational Age (pp. 140-169). Baltimore, MD: Johns Hopkins University Press. 
Burchell, G., Gordon, C., \& Miller, P. (Eds.) (1991). The Foucault Effect, Studies in Governmentality, with Two Lectures by and an Interview with Michel Foucault. Chicago: The University of Chicago Press.

Burgess, M., \& Vollaard, H. (2006). Introduction: Analyzing Westphalian States in an Integrating Europe and a Globalizing World. In M. Burgess, \& H. Vollaard (Eds.), State Territoriality and European Integration (pp. 1-14). London: Routledge. https://doi.org/10.4324/9780203969601

Campbell, H. (2005). Editorial. Planning Theory \& Practice, 6, 277-280. https://doi.org/10.1080/14649350500219073

Caporaso, J. A., \& Jupille, J. (2004). Sovereignty and Territory in the European Union, Transforming the UK Institutional Order. In C. K. Ansell, \& G. Di Palma (Eds.), Restructuring Territoriality, Europe and the United States Compared (pp. 67-89). New York: Cambridge University Press. https://doi.org/10.1017/CBO9780511617072.005

Cartledge, P. (2001). Spartan Reflections. Berkeley and Los Angeles, CA: University of California Press.

CEC, Commission of the European Communities (1999). European Spatial Development Perspective: Towards Balanced and Sustainable Development of the Territory of the $E U$. Luxembourg: Office for Official Publications of the European Communities.

CEC, Commission of the European Communities (2008). Communication from the Commission to the Council, the European Parliament, the Committee of the Regions and the European Social and Economic Committee: Green Paper on Territorial Cohesion-Turning Territorial Diversity into Strength. Brussels: Commission of the European Communities.

https://eur-lex.europa.eu/legal-content/EN/ALL/?uri=CELEX\%3A52008DC0616

CEC, Commission of the European Communities (2017). Seventh Report on Economic, Social and Territorial Cohesion, My Region, My Europe, My Future. Luxembourg: Publications Office of the European Union.

Collinge, C. (1999). Spatial Articulation of the State: Reworking Social Relations and Social Regulation Theory. Unpublished Manuscript, Birmingham: Centre for Urban and Regional Studies, University of Birmingham.

CoR, Committee of the Regions (2010). A New Treaty: A New Role for Regions and Local Authorities. Brussels: Committee of the Regions.

Court of Justice of the European Union (2019). Judgment in Joined Cases C-202/18, Ilmārs Rimšèvičs v Latvia and C-238/18 European Central Bank v Latvia, Press Release No 18/19. Luxembourg.

Cowell, A. (2007). The Medieval Warrior Aristocracy, Gifts, Violence, Performance and the Sacred. Cambridge: D. S. Brewer.

Cox, K. (1998). Spaces of Engagement, Space of Dependence and the Politics of Scale, or: Looking for Local Politics. Environment and Planning A, 23, 197-214. https://doi.org/10.1016/S0962-6298(97)00048-6

Dangschat, J. S. (2006). Raumplanung unter Unsicherheit-Beherrschbarer Widerspruch? In K. Selle (Ed.), Zur räumlichen Entwicklung beitragen: Konzepte, Theorien, Impulse (Planung neu denken, Bd1), Edition Stadt/Entwicklung (pp. 378-388). Dortmund: Dorothea Rohn.

Davies, S. J. (1612/1988). A Discovery of the True Causes Why Ireland Was Never Entirely Subdued. Washington DC.

Davoudi, S. (2007). Territorial Cohesion, European Social Model and Spatial Policy Research. In A. Faludi (Eds.), Territorial Cohesion and the European Model of Society 
(pp. 81-104). Cambridge, MA: The Lincoln Institute for Land Policy.

Davoudi, S., \& Strange, I. (2009). Conceptions of Space and Place in Strategic Spatial Planning. London: Routledge. https://doi.org/10.4324/9780203886502

Delanty, G., \& Rumford, C. (2005). Rethinking Europe: Social Theory and the Implications of Europeanization. London: Routledge. https://doi.org/10.4324/9780203640050

Deleuze, G., \& Guatarri, F. (1980/1987). A Thousand Plateaus, Capitalism and Schizophrenia. Translation and Foreword by Brian Massumi, Minneapolis, MN/London: University of Minnesota Press.

Dühr, S., Colomb, C., \& Nadin, V. (2010). European Spatial Planning and Territorial Cooperation. London: Routledge. https://doi.org/10.4324/9780203895290

Elden, S. (2010). Land, Terrain, Territory. Progress in Human Geography, 34, 799-817. https://doi.org/10.1177/0309132510362603

Elliot, A., \& Devine, P. (1994). On the Motivational Nature of Cognitive Dissonance: Dissonance as Psychological Discomfort. Journal of Personality and Social Psychology, 67, 382-394. https://doi.org/10.1037/0022-3514.67.3.382

ESPON, European Spatial Planning Observation Network (2019). ESPON Seminar: State of the European Territory, Digital Innovation Paving the Way for Territorial Cohesion. 27-28 November 2019, Helsinki. http://www.espon.eu/helsinki-2019

ESPON, European Spatial Planning Observatory Network (2006). Territory Matters for Competitiveness and Cohesion, ESPON Synthesis Report III. Luxemburg: ESPON.

Fabbrini, S. (2004). The European Union in American Perspective, the Transformation of Territorial Sovereignty in Europe and the United States. In C. K. Ansell, \& G. Di Palma (Eds.), Restructuring Territoriality, Europe and the United States Compared (pp. 163-187). New York: Cambridge University Press.

Faludi, A. (2002). Positioning European Spatial Planning. European Planning Studies, 10, 897-909. https://doi.org/10.1080/0965431022000013284

Faludi, A. (2003). Unfinished Business: European Spatial Planning in the 2000s. Town Planning Review, 74, 121-140. https://doi.org/10.3828/tpr.74.1.1

Faludi, A. (2004a). Territorial Cohesion: Old (French). Wine in New Bottles? The Third Joint ACSP-AESOP Congress, Leuven, 9-12 July 2003.

Faludi, A. (2004b). Territorial Cohesion: Old (French). Wine in New Bottles? Urban Studies, 41, 1349-1367. https://doi.org/10.1080/0042098042000214833

Faludi, A. (2005a). Territorial Cohesion. Special Issue of Town Planning Review, 76, $1-118$.

Faludi, A. (2005b). Territorial Cohesion: An Unidentified Political Objective, Introduction to the Special Issue. Special issue of Town Planning Review, 76, 1-13. https://doi.org/10.3828/tpr.76.1.1

Faludi, A. (2005c). Polycentric Territorial Cohesion Policy. Special Issue of Town Planning Review, 76, 107-118. https://doi.org/10.3828/tpr.76.1.9

Faludi, A. (2005d). From European Spatial Development to Territorial Cohesion Policy. Regional Studies, 40, 667-678. https://doi.org/10.1080/00343400600868937

Faludi, A. (2007). Territorial Cohesion and the European Model of Society. Cambridge, MA: The Lincoln Institute for Land Policy.

Faludi, A. (2009). Territorial Cohesion under the Looking Glass, Synthesis Paper about the History of the Concept and Policy Background to Territorial Cohesion (p. 2). European Commission Regional Policy-Inforegio. 
https://www.google.com/url? sa=t\&rct=j\&q=\&esrc=s\&source=web\&cd=\&cad=rja\&uact $=8 \&$ ved=2ahUKEwib1sWs1LfwAhWOPewKHcf1Dy4QFjAAegQIBBAD\&url=https\%3 A\%2F\%2Fec.europa.eu\%2Fregional_policy\%2Farchive\%2Fconsultation\%2Fterco\%2Fp df\%2Flookingglass.pdf\&usg=AOvVaw0FOsoUBc8AHyviejupv6HQ

Faludi, A. (2010). Cohesion, Coherence, Cooperation: European Spatial Planning Coming of Age? London: Routledge. https://doi.org/10.4324/9780203842324

Faludi, A. (2012). Multi-Level (Territorial). Governance: Three Criticisms. Planning Theory \& Practice, 13, 197-211. https://doi.org/10.1080/14649357.2012.677578

Faludi, A. (2013a). Territorial Cohesion and Subsidiarity under the European Union Treaties: A Critique of the "Territorialism” Underlying. Regional Studies, 47, 1594-1606. https://doi.org/10.1080/00343404.2012.657170

Faludi, A. (2013b). Territorial Cohesion, Territorialism, Territoriality, and Soft Planning: A Critical Review. Environment and Planning A, 45, 1302-1317. https://doi.org/10.1068/a45299

Faludi, A. (2013c). Territory: An Unknown Quantity in Debates on Territorial Cohesion. European Journal of Spatial Development, 51, 1-16.

Faludi, A. (2014). Territorial Cohesion beyond State Territoriality. GIS College international des sciences du territoire, Paris, 179-183. http://www.gis-cist.fr/wp-content/uploads/2014/02/faludi.pdf

Faludi, A., \& Waterhout, B. (2002). The Making of the European Spatial Development Perspective-No Master Plan. London/New York: Routledge.

Foucault, M. (1968). Politics and the Study of Discourse. In G. Burchell, C. Gordon, \& P. Miller (Eds.), The Foucault Effect, Studies in Governmentality, with Two Lectures by and an Interview with Michel Foucault (pp. 53-72). Chicago, IL: The University of Chicago Press, 1991.

Foucault, M. (1977). Discipline and Punish: The Birth of the Prison. London: Routledge.

Foucault, M. (1981). The History of Sexuality: Volume I: An Introduction (Trans. R Hurley). Harmondsworth: Penguin Books.

Foucault, M. (2003). Society Must Be Defended. Lectures at the Collège de France, 1975-76 (Translated by David Macey). New York: Picador.

Foucault, M. (2006). History of Madness (Translated by J. Murphy, \& J. Khalfa, Edited by J. Khalfa).

Gordon, C. (Ed.) (1980). M. Foucault, Power/Knowledge. Brighton: Harvester.

Gottman, J. (1975). The Evolution of the Concept of Territory. Social Science Information, 14, 29-47. https://doi.org/10.1177/053901847501400302

Gualini, E. (2001). Multi-Level Governance: Interdisciplinary Perspectives. Sheffield: The Political Economy Research Centre, University of Sheffield.

Hacker, J. S., \& Pierson, P. (2002). Business Power and Social Policy: Employers and the Formation of the American Welfare State. Politics \& Society, 30, 277-325. https://doi.org/10.1177/0032329202030002004

Hampsher-Monk, I. (1992). A History of Modern Political Thought, Major Political Thinkers from Hobbes to Marx. Oxford: Blackwell Publishers Ltd.

Harrison, J. (2013). Configuring the New "Regional World": On Being Caught between Territory and Networks. Regional Studies, 42, 55-74.

https://doi.org/10.1080/00343404.2011.644239

Harvey, D. (1982). The Limits to Capital. Oxford: Blackwell.

Harvey, D. (1985). The Geopolitics of Capitalism. In D. Harvey (Ed.), Social Relations 
and Spatial Structures (pp. 128-129). Edinburgh: Edinburgh University Press. https://doi.org/10.1007/978-1-349-27935-7_7

Haughton, G., Allmendinger, P., Counsell, D., \& Vigar, G. (2010). The New Spatial Planning: Territorial Management with Soft Spaces and Fuzzy Boundaries. London: Routledge. https://doi.org/10.4324/9780203864425

Healey, P. (2010). Making Better Place-The Planning Project in the Twenty-First Century. London: Palgrave Macmillan. https://doi.org/10.1007/978-1-137-01379-8_1

Héritier, A. (1999). Policy-Making and Diversity in Europe, Escape from Deadlock. Cambridge: Cambridge University Press. https://doi.org/10.1017/CBO9780511491948

Hissink Muller, B. M. (2013). The Place Where Streams Seek Ground, Towards a New Territorial Governmentality: The Meaning and Usage of the Concept of Territorial Cohesion in the European Union. PhD Thesis, Amsterdam: Universiteit van Amsterdam.

Hissink Muller, B. M. (2016). Opening up das Schloß: Creating Room for Thinking by Combining the Territorial Cohesion Discourse and the Debate on the European Union Polity. Art and Design Review, 4, 83-112. https://doi.org/10.4236/adr.2016.43011

Hooghe, L., \& Marks, G. (2010). Types of Multilevel Governance. In H. Enderlein, S. Wälti, \& M. Zürn (Eds.), Handbook on Multi-Level Governance (pp. 17-31). Cheltenham: Edward Elgar.

Husson, C. (2002). L'Europe sans territoire: Essai sur le concept de cohesion territoriale. Paris: Datar/éditions de l'aube.

Jacobs, J. (1969). The Economy of Cities. New York: Random House.

Jacobs, J. (1984). Cities and the Wealth of Nations. New York: Random House.

Jacobs, J. (1992). Systems of Survival. New York: Random House.

Janssen-Jansen, L., \& Waterhout, B. (2006). Grenzeloze ruimte: Regionale gebiedsgerichte ontwikkelingsplanologie in Europees perspectief. Den Haag: Sdu Uitgevers.

Jastrow, J. (1899). The Mind's Eye. Popular Science Monthly, 54, 299-312.

Jensen, O. B., \& Richardson, T. (2003). Making European Space, Mobility, Power and Territorial Identity. London and New York: Routledge.

Jessop, B. (2002). The Future of the Capitalist State. Oxford: Blackwell Publishing Ltd.

Jones, M., \& Paasi, A. (2013). Guest Editorial: Regional World(s): Advancing the Geography of Regions. Regional Studies, 47, 1-15. https://doi.org/10.1080/00343404.2013.746437

Knight, R. V., \& Gabbert, G. (1989). Cities in a Global Society. London: Sage.

Kohler-Kock, B., \& Eising, R. (1999). The Transformation of Governance in the European Union. London: Routledge.

Laffan, B., O’Donnell, R., \& Smith, M. (2000). Europe's Experimental Union: Rethinking Integration. London: Routledge.

LeBlanc, S. A. (2003). Constant Battles, Why We Fight. New York: St. Martin's Griffin.

Lefebvre, H. (1976). De l'État: De Hegel à Marx par Staline, Volume 2. Paris: Union Générale d'Éditions.

Lefebvre, H. (1991). The Production of Space. Oxford: Blackwell.

London and New York: Routledge.

Loriaux, M. (2008). European Union and the Deconstruction of the Rhineland Frontier. Cambridge: Cambridge University Press. https://doi.org/10.1017/CBO9780511720550

Low, M. (1997). Representation Unbound: Globalization and Democracy. In K. Cox 
(Ed.), Spaces of Globalization (pp. 240-280). New York: Guilford Press.

Mamadouh, V. (2001). The Territoriality of European Integration and the Territorial Features of the European Union: The First 50 Years. Tijdschrift voor Economische en Sociale Geografie, 92, 420-436. https://doi.org/10.1111/1467-9663.00169

Marks, G. (1992). Structural Policy in the European Community. In A. M. Sbragia (Ed.), Euro-Politics: Institutions and Policymaking in the "New" European Community (pp. 191-224). Washington DC: The Brookings Institution.

Marques, T. S., Saraiva, M., Santinha, G., \& Guerra, P. (2018). Re-Thinking Territorial Cohesion in the European Planning Context. International Journal of Urban and Regional Research, 42, 547-572. https://doi.org/10.1111/1468-2427.12608

Martin, A., \& Ross, G. (2004). Introduction: EMU and the European Social Model. In A. Martin, \& G. Ross (Eds.), Euros and Europeans: Monetary Integration and the European Model of Society (pp. 1-19). Cambridge: Cambridge University Press. https://doi.org/10.1017/CBO9780511492020.002

Martin, M. (2018). Why We Fight. London: C. Hurst \& Co Ltd.

McCloskey, D. N. (2006). The Bourgeois Virtues, Ethics for an Age of Commerce. Chicago, IL and London: The University of Chicago Press. https://doi.org/10.7208/chicago/9780226556673.001.0001

Murphy, A. B. (2008). Rethinking Multi-Level Governance in a Changing European Union: Why Metageography and Territoriality Matter. GeoJournal, 72, 7-18. https://doi.org/10.1007/s10708-008-9161-9

Neocleous, M. (2003). Off the Map, on Violence and Cartography. European Journal of Social Theory, 6, 409-425. https://doi.org/10.1177/13684310030064003

OJEC, Official Journal of the European Communities (2008). Consolidated Versions of the Treaty of the European Union and the Treaty of the Functioning of the European Union (2008/C 115/01).

Olsen, J. P. (2002). The Many Faces of Europeanization. JMCS, 40, 921-952. https://doi.org/10.1111/1468-5965.00403

Perkmann, M. (2007). Construction of New Territorial Scales: A Framework and Case Study of the EUREGIO Cross-Border Region. Regional Studies, 41, 253-266. https://doi.org/10.1080/00343400600990517

Peyrony, J. (2007). Territorial Cohesion and the European Model of Society: French Perspectives. In A. Faludi (Ed.), Territorial Cohesion and the European the Model of Society (pp. 61-79). Cambridge, MA: The Lincoln Institute for Land Policy.

Polverari, L., \& Bachtler, J. (2005). The Contribution of European Structural Funds to Territorial Cohesion. Town Planning Review, 76, 29-42. https://doi.org/10.3828/tpr.76.1.3

Richardson, T., \& Jensen, O. B. (2003). Linking Discourse and Space: Towards a Cultural Sociology of Space in Analysing Spatial Policy Discourses. Urban Studies, 40, 7-22. https://doi.org/10.1080/00420980220080131

Rosenau, J. N. (1999). Toward an Ontology for Global Governance. In M. Hewson, \& T. Sinclair (Eds.), Approaches to Global Governance Theory (pp. 287-301). Oxford: Oxford University Press.

Rosenau, J. N. (2004). Strong Demand, Huge Supply: Governance in an Emerging Epoch. In I. Bache, \& M. Flinders (Eds.), Multi-Level Governance (pp. 31-48). Oxford: Oxford University Press. https://doi.org/10.1093/0199259259.003.0003

Ruggie, J. G. (1993). Territoriality and Beyond: Problematizing Modernity in International Relations. International Organisation, 47, 139-174. 
https://doi.org/10.1017/S0020818300004732

Sabel, C. F., \& Zeitlin, J. (2010). Experimentalist Governance in the European Union: Towards a New Architecture. Oxford: Oxford University Press.

Sack, R. D. (1986). Human Territoriality: Its Theory and History. Cambridge: Cambridge University Press.

Sassen, S. (2006). Territory, Authority, Rights: From Medieval to Global Assemblages. Princeton, NJ: Princeton University Press.

Scharpf, F. W. (1999). Governing in Europe, Effective and Democratic? Oxford: Oxford University Press. https://doi.org/10.1093/acprof:oso/9780198295457.001.0001

Schill, S. W. (2017). Authority, Legitimacy, and Fragmentation in the (Envisaged). Dispute Settlement Disciplines in Mega-Regionals. In S. Griller, W. Obwexer, \& E. Vranes (Eds.), Mega-Regional Agreements: TTIP, CETA, TiSA, New Orientations for EU EXternal Economic Relations (pp. 111-150). Oxford: Oxford University Press. https://doi.org/10.1093/oso/9780198808893.003.0005

Scholte, J. A. (2000). Globalization: A Critical Introduction. London: Macmillan.

Schön, P. (2005). Territorial Cohesion in Europe? Planning Theory \&Practice, 6, 389-400. https://doi.org/10.1080/14649350500209397

Scott, J. C. (1998). Seeing like a State. New Haven, CT: Yale University Press.

Seabright, P. (2010). The Company of Strangers, a Natural History of Economic Life. Princeton, NJ and Oxford: Princeton University Press. https://doi.org/10.1515/9781400834785

Selgin, G. (1996). Bank Deregulation and Monetary Order. London/New York: Routledge.

Shuger, D. (1997). Irishmen, Aristocrats, and Other White Barbarians. Renaissance Quarterly, 50, 494-525. https://doi.org/10.2307/3039188

Sidaway, J. D. (2008). Globalizing the Geohistory of City/State Relations: On "Problematizing City/State Relations: Towards a Geohistorical Understanding of Contemporary Gloablization" by Peter J Taylor. Transactions of the Institute of British Geographers, 33, 149-151. https://doi.org/10.1111/j.1475-5661.2007.00276.x

Smith, N. (1993). Homeless/Global: Scaling Places. In J. Bird, B. Curtis, T. Putnam et al. (Eds.), Mapping the Futures: Local Cultures, Global Change (pp. 87-119). London: Routledge.

Soja, E. W. (1971). The Organization of Space. Resource Paper 8, Washington DC: Commission on College Geography, Association of American Geographers.

Stone Sweet, A. (2004). Islands of Transnational Governance. In C. K. Ansell, \& G. Di Palma (Eds.), Restructuring Territoriality, Europe and the United States Compared (pp. 122-144). New York: Cambridge University Press.

Stone Sweet, A., \& Sandholtz, W. (1998). Integration, Supranational Governance and the Institutionalization of the European Polity. In W. Sandholtz, \& A. Stone Sweet (Eds.), European Integration and Supranational Governance (pp. 1-26). Oxford: Oxford University Press.

Storey, D. (2001). Territory: The Claiming of Space. Harlow: Prentice Hall.

Taylor, P. J. (1994). The State as Container: Territoriality in the Modern World-System. Progress in Human Geography, 18, 151-162. https://doi.org/10.1177/030913259401800202

Taylor, P. J. (1999). Modernities: A Geohistorical Interpretation. Cambridge: Polity.

Taylor, P. J. (2006). Development as "Monstrous Hybrid": An Essay on the Primacy of 
Cities in the Expansion of Economic Life. Environment and Planning A, 38, 793-803. https://doi.org/10.1068/a38286

Taylor, P. J. (2007). Problematizing City/State Relations: Towards a Geohistorical Understanding of Contemporary Globalization. Transactions of the Institute of British Geographers, NS 32, 133-150. https://doi.org/10.1111/j.1475-5661.2007.00245.x

Taylor, P. J. (2008). City-States and Globalisation: A Reply to Sidaway. Transactions of the Institute of British Geographers, NS 33, 152-153. https://doi.org/10.1111/j.1475-5661.2007.00283.x

Turner, B. (2003). Warrior Charisma and the Spiritualization of Violence. Body Society, 9, 93-108. https://doi.org/10.1177/135703403773684676

Urry, J. (2000). Sociology beyond Societies: Mobilities for the Twenty-First Century. London: Routledge.

van Creveld, M. (2008). Culture of War. Spellmount.

Varrò, K., \& Lagendijk, A. (2013). Conceptualizing the Region: In What Sense Relational? Regional Studies, 47, 18-28. https://doi.org/10.1080/00343404.2011.602334

Vaughan-Williams, N. (2011). Off-Shore Biopolitical Border Security: The EU's Global Response to Migration, Piracy, and "Risk" Subjects. In L. Bialasiewicz (Ed.), Europe in the World: EU Geopolitics and the Making of European Space (pp. 185-200). Farnham: Ashgate.

Vogelij, J. (2006). Grenzeloze Ruimte gelezen: Debat, conclusie, synthese. In L. Janssen-Jansen, \& B. Waterhout (Eds.), Grenzeloze ruimte: Regionale gebiedsgerichte ontwikkelingsplanologie in Europees perspectief (pp. 217-231). Den Haag: Sdu Uitgevers.

Wallerstein, I. (1979). The Capitalized World-Economy. Cambridge: Cambridge University Press.

Waterhout, B. (2007). Territorial Cohesion: Discourses Underlying. In A. Faludi (Ed.), Territorial Cohesion and European the Model of Society (pp. 37-60). Cambridge, MA: The Lincoln Institute for Land Policy.

Weber, M. (1978). Economy and Society: An Outline of Interpretive Sociology. Berkeley, CA: University of California Press.

Wellens, A. (2017). Het Euro Evangelie, Deel II. Tweede druk, Gopher B.V.

Whatmore, S. J., \& Thorne, L. B. (1997). Nourishing Networks: Alternative Geographies of Food. In D. Goodman, \& M. Watts (Eds.), Globalising Food. Agrarian Questions and Global Restructuring (pp. 287-304). London: Routledge.

Whitby, M. (2001). Sparta. Edinburgh: Edinburgh University Press Ltd.

Wiehler, F., \& Stumm, T. (1995). The Powers of Regional and Local Authorities and Their Role in the European Union. European Planning Studies, 3, 227-250. https://doi.org/10.1080/09654319508720302

Williams, R. H. (1996). European Union Spatial Policy and Planning. London: Paul Chapman Publishing Ltd.

Zaman, A. (2019). Lecture 13 "History of Central Banking". https://www.youtube.com/watch?v=HugE171zNj8 